\title{
THINKING OTHERWISE: SPECULATIVE IMAGINING IN PFC
}

By

Amalia Louisson

\begin{abstract}
A thesis
submitted to the Victoria University of Wellington in fulfilment of the requirements for the degree of Master of Arts in Political Science
\end{abstract}

Victoria University of Wellington 





\begin{abstract}
In the face of looming ecological catastrophe, ever-expanding neoliberalism and the ongoing integration of our lives into virtual spaces, there is an urgent need to expand people's political imagination and responsiveness to these challenges. Engaging with philosophy outside the academic sphere - for example, in school and community contexts - can contribute to addressing this political need. Using the example of Philosophy for Children (PfC), an international educational movement, this thesis explores the potential for cross-paradigmatic approaches to philosophical inquiry. It observes that adherence to particular philosophical paradigms, as has largely been the case in PfC, binds the imagination to particular epistemic and political parameters and precludes ideas that contradict paradigmatic assumptions. Invoking the sensibility of Gillian Rose, I argue that we need a philosophy that permits people to imagine radically different political worlds in a manner that actively resists political 'bubble-think'. This thesis illustrates how Rose's cross-paradigmatic approach, speculative negotiation, can help to address some of the limits of paradigm thinking by inspiring a more transformative philosophy in contexts such as PfC. In doing so, this thesis contributes both to an expansion of the PfC programme and to questions surrounding the concrete practise of Rose's rich theoretical oeuvre.
\end{abstract}





\section{Acknowledgements}

First and foremost, a special thanks to my supervisors Andrea Milligan, Greta Snyder, Kate Schick and Xavier Marquez for their thoughtful and challenging feedback. I was lucky to have each of you on board. And thanks to Andrea for her pragmatic reassurances throughout the writing process. I am grateful to the Rosemary Barrington Trust for awarding me a scholarship to embark on this project.

Thanks to Ziva, Leah and Tristan for cooking me dinner and the endless phone calls. I would have had a hard year if it weren't for your distraction and love. A final thanks to my loving parents Tami and Simon for their ongoing support. 



\section{Contents}

Introduction

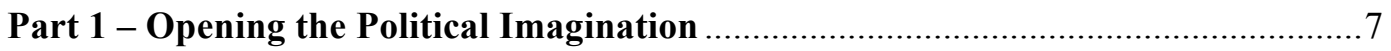

Chapter 1 - The Political Potential of Philosophy ……............................................

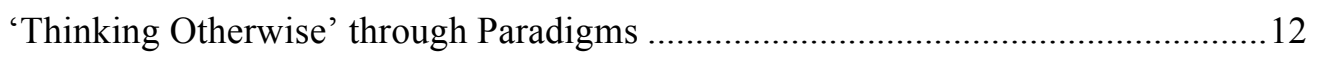

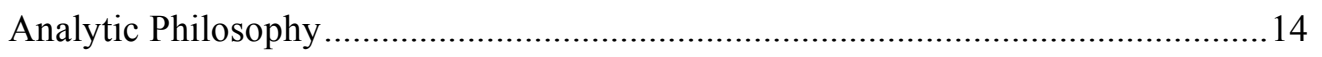

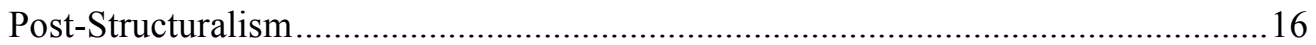

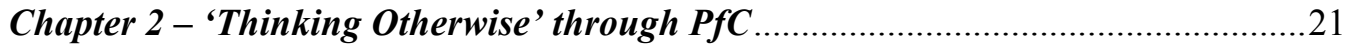

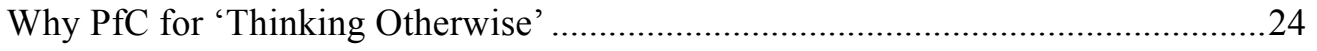

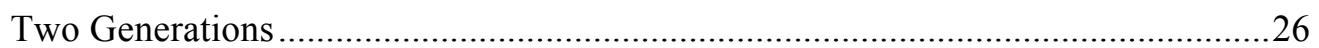

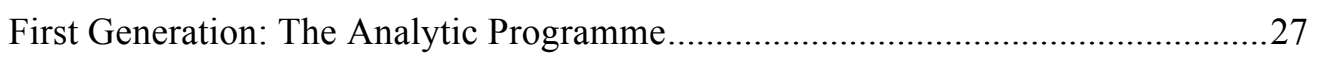

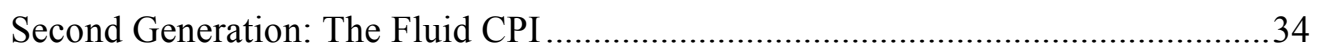

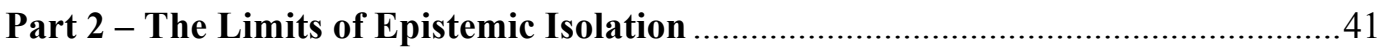

Chapter 3 - The Tendency Towards Epistemic Isolation .........................................42

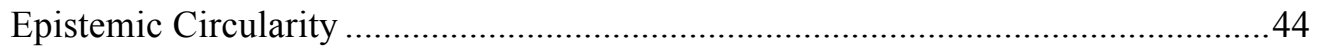

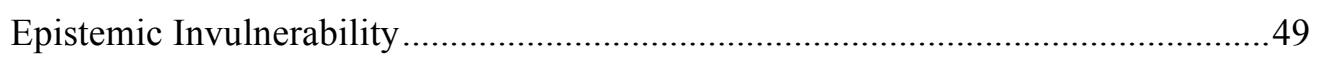

The Limiting Effects of Epistemic Isolation..................................................................53

Chapter 4 - The Presence of Epistemic Isolation in PfC .........................................57

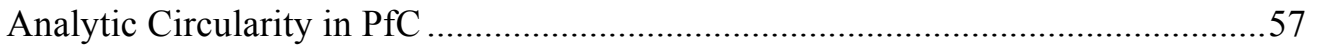

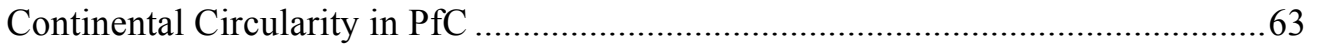

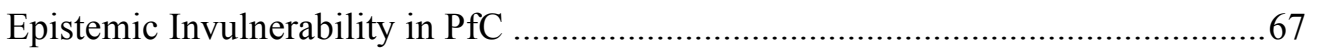

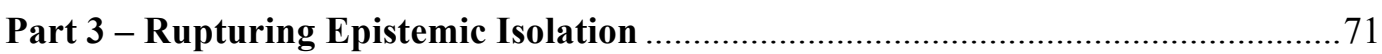

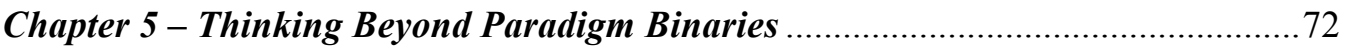

Speculative Negotiation: in the Space of the Broken Middle ....................................76

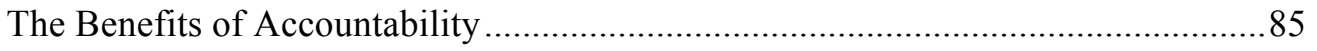

The Contribution of Speculative Negotiation to Everyday Life ................................. 88

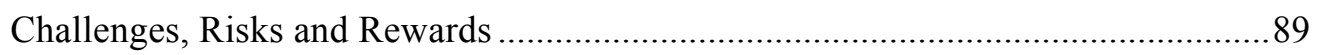

Chapter 6 - Speculative Negotiation in the Classroom ….............................................

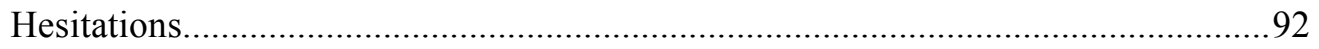

A Colourful CPI: a Pedagogical Example …….....................................................95

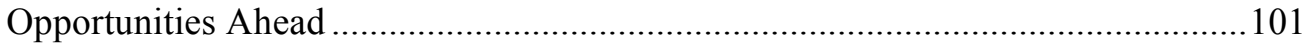

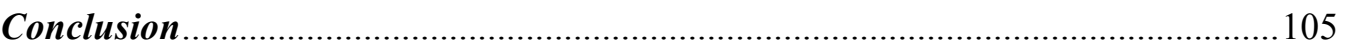




\section{Tables}

Table 1: Lipman's recommended steps for a CPI........................... 22

Table 2: Describes the recommended steps for a negotiating CPI............... 96

Table 3: Possible characteristics for each approach/coloured ball.............. 97

Table 4: Examples of introspective questions.............................. 99

Table 5: Examples of evaluative questions to guide negotiation................. 100

Table 6: Examples of how identified limitations can be negotiated............. 101 


\section{Introduction}

Contemporary societies face a host of challenges that require radical and systemic political response, for which existing political systems are unsuited. These include looming ecological catastrophe, unimpeded free-market expansion, increasingly blurred boundaries between physical and virtual spaces, among others. ${ }^{1}$ The scale and pace of these challenges have dampened political dreaming and promote resignation. ${ }^{2}$ Consequently, some political scientists call for a revitalised societal practice of imagining beyond existing political norms, institutions and systems - the practice of 'thinking otherwise'. ${ }^{3}$ Political imagining is useful when significant change seems daunting because it allows people to move beyond resignation towards a pragmatic mindset. ${ }^{4}$ The central problem this thesis attempts to answer is how to meet this political need for 'thinking otherwise'.

One possible route to strengthen 'thinking otherwise' in society is through widespread engagement with philosophy outside academic contexts - of equipping citizens with philosophical resources to imagine different political worlds. Philosophy is an undervalued resource in political theory, yet can aid radical imagining because it questions the ordinary state of affairs and has many resources for envisioning alternative societal arrangements. However, I argue that philosophy's two dominant but mutually isolated paradigms - analytic and continental philosophy - are currently unsuited for the political project of 'thinking otherwise' because they promote political bubbles. This is because each paradigm only supports visions that coincide smoothly with its epistemic assumptions. Although each paradigm supports an expansive range of approaches for political change, their limited epistemic boundaries nonetheless encourage the circulation of thought and the exclusion of views that contradict their basic methodological principles, in a manner that is difficult for philosophers to become aware of and challenge.

\footnotetext{
${ }^{1}$ Morton, "Ecology without the Present"; Berardi, Futurability; Srnicek and Williams, Inventing the Future; Wilson, "Neoliberal Gothic"; Moore, Anthropocene or Capitalocene?

${ }^{2}$ Nissen, “'We Don't Do Protest””; Springer, "Fuck Neoliberalism”; Peters, "Education, Neoliberalism, and Human Capital"; Berlant, Cruel Optimism.

${ }^{3}$ Springer, "Fuck Neoliberalism"; Berardi, Futurability; Srnicek and Williams, Inventing the Future; Mouffe, Agonistics; Weber, "Embarking into the Future."

${ }^{4}$ Weber, "Embarking into the Future."
} 
While widespread citizen engagement with philosophy can meet the much-needed societal practice of 'thinking otherwise', philosophy should be engaged with in a way that actively resist political bubble-think. ${ }^{5}$ Political bubbles are increasingly prevalent in our era, where citizens are exposed primarily to a circulation of ideas that match the norms of their political party, and we can witness their detrimental political effects. Political theorists argue that the recent rise in political bubbles has promoted deeply undemocratic attitudes and "sharp divisions of trust and mistrust" the political bubble and those who go against the bubble's accepted status. It has been recorded to produce extreme ideas, sharp political polarizations and a context ripe for the introduction of authoritarian strategies. ${ }^{7}$

I became interested in this thesis topic because I found a striking resemblance between the topical discussions on the rise of political bubbles, and the broader political bubble present in the way my peers and I approach politics, derived from being intellectually raised within dominant theoretical paradigms in universities. ${ }^{8}$ I noticed that not only do paradigms actively shape the way we approach politics (leading us to think about politics rationally in the case of analytic paradigms, or through disruption in continental paradigms), but there is a distinct mistrust of thinking about politics in a way that contradicts the paradigm's assumptions, and a genuine inability to see the influence paradigm-thinking has over the way we approach politics. While it is unlikely that widespread engagement with philosophical paradigms will result in the circulation of specific political positions or ideologies, I argue that they threaten to form bubbles around the manner in which people approach politics.

Accordingly I argue for strengthening public engagement with an 'accountable' kind of philosophising. Accountable imagining is imagining in a way that is aware of, and responsible for, who and what one affects and excludes. Imagining accountably through philosophy requires attending to the unspoken and often-unnoticed ways philosophy shapes our thought and political practices. I particularly advocate Gillian

\footnotetext{
${ }^{5}$ Anderson defines bubble-think as a self-segregated sphere that promotes the circulation of a similar set of political ideas, through having no access to ideas that contradict the bubble. Anderson, "Epistemic Bubbles and Authoritarian Politics."

${ }^{6}$ Ibid.

${ }^{7}$ For these debates see Ibid.

${ }^{8}$ Also see Kolozova, Cut of the Real, 18.
} 
Rose's notion of speculative negotiation for this. ${ }^{9}$ Her speculative approach challenges philosophy to engage deeply with its limitations, and works persistently to reshape philosophy in a way that resists certain and circular thinking. Speculative negotiation is actively introspective - it asks the philosopher to engage across different paradigms so she can look inwards at who and what her ideas exclude, and at how the process of philosophising impacts political visions. ${ }^{10}$ By continuously reworking philosophy in light of its exclusions, speculative negotiation would encourage citizens to envision politics in a manner that actively surpasses existing political lenses while simultaneously circumventing political bubble-think.

This thesis explores these ideas within the Philosophy for Children (PfC) movement. Developed in the 1970s by Matthew Lipman, PfC is a global movement that, in a pragmatic and utopian manner, strives to engage children with philosophy in schools to better equip them to reshape their society. ${ }^{11}$ I advocate PfC as a promising path for engaging with philosophy to 'think otherwise' because it takes future generations seriously as political actors and bridges the gap between philosophical imagining and political action. Yet PfC illustrates how philosophy can be at risk of promoting circular philosophical thinking and could benefit from cross-paradigmatic engagement. While the PfC movement offers a range of different approaches for helping students 'think otherwise', most can be divided into two generations that draw on either of the two dominant philosophical paradigms. ${ }^{12}$ The first generation developed the original PfC curriculum from analytic philosophy, while later in the 1990s a second generation changed the programme in line with developments in continental philosophy, ${ }^{13}$ each offering a different kind of engagement with philosophy for political imagining.

Although these paradigms present many opportunities for expanding the political imagination in PfC, basing pedagogical methods too strictly on either paradigm may

\footnotetext{
${ }^{9}$ Rose, Mourning Becomes the Law; Rose, The Broken Middle; Rose, Judaism and Modernity.

${ }^{10}$ Rose, Judaism and Modernity, 3-9.

${ }^{11}$ Lipman, “(USA) Philosophy for Children”; Lipman, Sharp, and Oscanyan, Philosophy in the Classroom; Vansieleghem and Kennedy, "What Is Philosophy with Children-After Matthew Lipman?"; Gregory, Haynes, and Murris, The Routledge International Handbook of Philosophy for Children; Gregory, "Philosophy for Children and Its Critics."

${ }^{12}$ Vansieleghem and Kennedy, "What Is Philosophy with Children-After Matthew Lipman?," 172. Also see Reed and Johnson, Friendship and Moral Education.

${ }^{13}$ Vansieleghem and Kennedy, "What Is Philosophy with Children-After Matthew Lipman?"
} 
limit children's imagination and promote political bubble-think. It is imperative to address these limitations when philosophy is being mobilised to summon new political systems. Therefore I argue that approaches such as speculative negotiation warrant further attention in contexts like PfC. Through continuously changing the conditions of philosophising, speculative negotiation could provide children with the resources to radically change the face of philosophy, providing autonomy over the conditions of envisioning different worlds. Speculative negotiation can help expand our collective political imagination in a way that better equips us, as a society, to radically transform politics in a dynamic, accountable and self-aware way.

This thesis is divided into three parts, each containing two chapters. Part 1 discusses the political prospect of philosophy for 'thinking otherwise', drawing out the opportunities presented by paradigm-oriented thinking. I then present an overview of contemporary philosophy to draw out the benefits and limitations of analytic and continental philosophy for thinking about politics. More specifically, Part 1 assesses the influence of paradigm thinking in the PfC movement, showing how the inquiry methods of each paradigm influence the way students think about politics.

Part 2 outlines the central problem: that overly paradigmatic thinking in PfC encourages political tunnel vision. I first argue that the isolated methods of each paradigm confine one's imagination to its parameters. I do so by looking at how two features of isolated philosophical thinking - 'epistemic circularity' and 'epistemic invulnerability' - makes it difficult to identify and combat each paradigm's methodological biases and limits. I then argue that this is a particular problem when only one paradigm is integrated into non-academic contexts like PfC for the purpose of political imagining.

Part 3 outlines why I advocate using speculative negotiation to expand our political imagination in everyday settings. Speculative negotiation encourages methodological pluralism by allowing people to draw on both analytic and continental philosophy, ensuring that 'thinking otherwise' can move past existing ways of envisioning politics. Part 3 then presents an example of how speculative negotiation can be practised in the PfC classroom, arguing that engagement with speculative negotiation enables children to reshape existing philosophical practices to expand 'thinking otherwise', in a way that lets them burst philosophy's political bubbles. 
This thesis draws from, and adds to, two rich literatures - the PfC literature and the Rosean literature. Although there is a small but rich literature surrounding Rose's oeuvre, ${ }^{14}$ little attention has been paid to the question of how to put her theoretical insights into practise. ${ }^{15}$ My thesis presents one way to do so. Rose's deeply pragmatic approach advocates placing philosophy close to the political, so avenues for its everyday practise should be explored. In addition, this thesis contributes to the PfC literature by offering a cross-paradigm approach where one is lacking. ${ }^{16}$ Such approaches have much to offer the PfC literature because they provide a wider array of resources for children to 'think otherwise' and to reconstruct both philosophy and politics. ${ }^{17}$ I argue that speculative negotiation's trait of providing children with better opportunities to transform philosophy enables them to gain ownership over their ability to envision different futures. This thesis therefore contributes to ongoing debates about how to expand children's political voices through philosophy. While this thesis is situated in political science, and attempts to answer a distinctly political question, it has interdisciplinary links to philosophy and education, and aims contribute to discussions in all three disciplines.

\footnotetext{
${ }^{14}$ Lloyd, The Problem with Grace; Lloyd, "Gillian Rose, Race, and Identity"; Schick, Gillian Rose; Milbank, "On the Paraethical"; Osborne, "Gillian Rose and Marxism"; Latz, "Gillian Rose and Social Theory"; Rowlands, "Angry Angels." It is important to note that I intentionally do not engage this literature because Rose's work is filled with ambiguity and I did not want to be overly influenced in my reading.

${ }^{15}$ Only one person has turned to pragmatic questions. See Ombler, "Emancipating Space from the Conditions of Violence."

${ }^{16}$ See Karin Murris and Barbara Weber's cross-paradigmatic approaches in PfC. Murris, The Posthuman Child; Weber, "Embarking into the Future."

${ }^{17}$ It is important to note upfront that I have no classroom expertise, and therefore offer a conceptual contribution to the PfC literature.
} 


\section{Part 1 - Opening the Political Imagination}

Chapter 1 begins this thesis by outlining the need to think past current political arrangements and presents a case for deepening public engagement with philosophy to address this need. Through an analysis of philosophy's two dominant paradigms, analytic and continental philosophy, Chapter 1 then exhibits how thinking through philosophy within the bounds of one or the other of these paradigms influences people's political imagination. This discussion lays the groundwork for my subsequent argument in Part 2 that, although thinking through paradigms cultivates innovative political imagining, a lack of cross-paradigmatic engagement creates the possibility for political tunnel vision. Chapter 2 presents a case for widespread philosophical engagement through the PfC movement. It illustrates how PfC's analytic and continental pedagogical approaches offer distinct ways of thinking past existing politics, each presenting differing opportunities for 'thinking otherwise'.

\section{Chapter 1 - The Political Potential of Philosophy}

The practise of imagining beyond existing political arrangements needs to be actively encouraged in our era. 'Thinking otherwise ${ }^{, 18}$ refers to the act of trying to think outside what is imaginable within an established political conceptual order, an undertaking crucial for responding to unfavourable political realities and emerging societal opportunities. Chantal Mouffe argues that every socio-political structure contains a system of concepts that acts as a more or less "closed system"19 that sets the boundaries of what we consider possible, what is at any "given moment accepted as the "natural' order, jointly with the common sense that accompanies it." ${ }^{20}$ According to Mouffe, every conceptual order necessarily forms a "constitutive outside,"21 that can be invoked in times of political change. Because "every order is predicated on the exclusion of other possibilities" 22 Mouffe argues that "[e]very order is therefore

\footnotetext{
${ }^{18}$ Judith Butler introduced me to this term. See Butler, "What Is Critique?," 214.

${ }^{19}$ Laclau and Mouffe, Hegemony and Socialist Strategy, 113.

${ }^{20}$ Mouffe, Agonistics, 2.

${ }^{21}$ Ibid., 4.

${ }^{22}$ Ibid., 2.
} 
susceptible to being challenged," and so "[t]hings could always be otherwise."23 The process of 'thinking otherwise' actively works to challenge and restructure existing configurations of societal thought, and therefore holds the potential to replace the dominant conceptual order with the presently unimaginable.

'Thinking otherwise' is firstly important for politics because it expands the realm of feasible political possibility. Barbara Weber proposes that political dreaming cultivates political possibilities because it gives us something material to hope for in the political sphere: it provides something tangible to stand behind, and compresses the daunting task of political renewal to more concrete questions of actualisation, "to transcend the threshold from mere vision to reality." 24 She writes, "[t]he dream can be the hope that something might change to the better, a vague idea or a very concrete vision," 25 that can "overcome subjective idiosyncrasy... in public space.",26

Second, 'thinking otherwise' is important to politics because it enables radical/revolutionary political renewal. Levi Bryant advances this idea. He begins by making the distinction between 'marked space', which denotes "what can be indicated" (socially, politically and otherwise), and 'unmarked space,' which denotes the unimaginable. ${ }^{27}$ Bryant argues that 'normal' politics does not involve 'thinking otherwise' because it operates within an existing political structure: it assumes that "the game's rules are defined and set, and that the best one can hope for is to make strategically effective moves within that structural field" 28 (for example, campaigning for a particular party to win within a democratic party system). Within the realm of normal politics we often forget that "very different sorts of indications are possible." 29 By comparison, 'thinking otherwise' is central to revolutionary politics - "the politics of rupture" ${ }^{30}$ - because it aims to alter a given political structure. Revolutionary politics

\footnotetext{
23 Ibid.

${ }^{24}$ Weber, "Embarking into the Future," 15

${ }^{25}$ Ibid., 16.

${ }^{26}$ Ibid., 15.

${ }^{27}$ Bryant, The Democracy of Objects, 20.

${ }^{28}$ Bryant, "Rupture/Events."

${ }^{29}$ Bryant, The Democracy of Objects, 21.

${ }^{30}$ Bryant, "Rupture/Events."
} 
aims to "mutate the deep grammar of the game itself" 31 and is successful when the nature of politics is shifted so that "an entirely different set of rules and identities"32 are established. Although revolutionary change does not necessarily have to include 'thinking otherwise' (for example, it can occur spontaneously or accidentally ${ }^{33}$ ), conscious revolutionary efforts often try to imagine a political structure that does not yet exist. Therefore 'thinking otherwise' is important for politics because it enables revolutionary change. ${ }^{34}$

However, enabling a society to 'think otherwise', is not always considered intrinsically good, since radical change does not necessarily strengthen justice or equity. Conservatives, for instance, would not consider 'thinking otherwise' a positive societal attribute. ${ }^{35}$ Nonetheless, a case can be made for its importance through looking at its need in contemporary society. Broadly speaking, some non-political changes economic, cultural, technological or environmental - require radical, systemic political change when existing political norms and institutions are unsuited for response. ${ }^{36} \mathrm{We}$ can see how some current societal challenges require this sort of radical political responsiveness. The fast-evolving threats of looming ecological catastrophe, the forward march of neoliberalism, the seeping of technology and virtual spaces into our everyday existence, and the rise of 'post-truth' (among others) need political address to forestall disasters (ecological, political and otherwise) and market-encroachment on the political sphere. ${ }^{37}$ Yet some political theorists argue that existing political norms and institutions are unsuited for responding to these challenges because, for example, the scope of these challenges are global, and existing political norms primarily remain

\footnotetext{
${ }^{31}$ Ibid.

${ }^{32}$ Ibid.

${ }^{33}$ Arendt, On Revolution.

${ }^{34}$ Although there are criticisms that 'utopian thinking' does not always equate to feasible political action, which involves asking how ideas can be implemented in light of political realities, convincing others that one's vision is worth supporting, and makes sense, and so on, there are ways of 'thinking otherwise' that bridge the gap between utopian thinking and feasible action, as will be explained and advocated in Chapter 2.

${ }^{35}$ Burke, Reflections on the Revolution in France; Gray, The Silence of Animals: On Progress and Other Modern Myths.

${ }^{36}$ A point developed in conversation with Greta Snyder.

${ }^{37}$ Morton, Dark Ecology; Moore, Anthropocene or Capitalocene?; Wilson, "Neoliberal Gothic"; Roy, "New Zealand Housing Crisis"; Peters, "Education, Neoliberalism, and Human Capital"; Morton, "Ecology without the Present." Springer, "The Violence of Neoliberalism"; Virilio, Negative Horizon; Bryant, Srnicek, and Harman, The Speculative Turn.
} 
bound to nation-states. ${ }^{38}$ These challenges thus require a more actively imaginative politics. $^{39}$

Yet, a host of theorists argue that although the conditions of our era present many opportunities to expand political imagining (for example, the internet), the same conditions also inhibit radical political imagining. ${ }^{40}$ Some go so far as to say that we have arrived in an age of imaginative "impotence." contends that the neoliberal market is more responsive to changes in other parts of society than the political realm, encroaching even further on politics and our political imagination, and converting "distinctly political character[s] ... into economic ones." Brown considers it increasingly difficult to respond politically to societal changes in a manner that overcomes neoliberalism, in part because rapid expansion increasingly pervades our everyday common sense and our political imaginations. ${ }^{43}$ As she puts it, "neoliberal rationality disseminates the model of the market to all domains and activities - even where money is not at issue - and configures human beings... as homo oeconomicus.

Furthermore, it is important for citizens to respond politically to societal challenges because when political responses are inadequate, political norms, institutions and ideas further lose relevance, which then further inhibits the public's ability to meet societal challenges. Hannah Arendt's oeuvre illustrates that if a society loses its ability to think

\footnotetext{
${ }^{38}$ Morton, "Ecology without the Present."

${ }^{39}$ Berardi, Futurability; Springer, "Fuck Neoliberalism"; Weber, "Embarking into the Future"; Morton, "Ecology without the Present."

${ }^{40}$ See Springer, "Fuck Neoliberalism"; Nissen, “'We Don’t Do Protest”"; Berlant and Seitz, "On Citizenship and Optimism." Franco Berardi claims that our current context of pervasive neoliberalism has produced "mental cages" that threatens the "task of transformation." We remain inept due to the grip of neoliberalism's "epistemological dictatorship" (Berardi, "Reactivating the Social Body").

${ }^{41}$ Berardi, Futurability.

${ }^{42}$ Brown, Undoing the Demos, 17; Also see Peck, "Zombie Neoliberalism"; MacKinnon, Consent of the Networked; Sassen, Losing Control?; Peck, Constructions of Neoliberal Reason.

${ }^{43}$ Brown, Undoing the Demos, 35.

${ }^{44}$ Ibid., 31. Also see Jodi Dean for the limits that virtual space places on our ability to think beyond existing political arrangements - through encouraging the circulation of existing information rather than the development of political ideas - 'shares' and 'likes' on Facebook. Timothy Morton also asks us to observe how an embeddedness of anthropomorphic mentalities inhibits our ability to work towards a radically different relationship with ecologies that can halt environmental degradation. Dean, Democracy and Other Neoliberal Fantasies; Morton, "Ecology without the Present."
} 
and act innovatively, it loses connection to 'the political'. For Arendt, thinking and acting spontaneously keeps the political realm alive: it maintains the condition of acting in a manner that does not merely follow existing norms. Freedom, for Arendt, is the capacity to start something new, to do the unexpected: "[t]he fact that man is capable of action means that the unexpected can be expected from him, that he is able to perform what is infinitely improbable." 45 Doing the unexpected within politics keeps the political realm alive because it ensures the space for freedom to occur and re-occur, enabling further public action and renewal: it "keeps the public realm, the potential space of appearance between acting and speaking men, in existence."46 Arendt considers this vital because without maintaining the capacity for freedom, people are no longer conducting politics; they are following rules. Without changing our political ideas and institutions, we may further inhibit political responsiveness to societal challenges. ${ }^{47}$ Therefore 'thinking otherwise' should be actively promoted in our era.

Among those who stress the political importance of 'thinking otherwise', some have suggested philosophy as a rich resource. ${ }^{48}$ They argue that philosophy, by its nature, encourages people to ask questions that unsettle the ordinary state of affairs, ${ }^{49}$ and point out that the discipline is overflowing with resources to assist societal critique and utopian visions. As Lauren Berlant puts it, engaging with philosophy is "about creating better worlds, making it possible for us to think in more and different kinds of ways." ${ }^{\circ 0}$ Although I support other paths for 'thinking otherwise' in society (such as encouraging activism ${ }^{51}$ and political think-tanks ${ }^{52}$ ), I direct my attention to philosophy because it is a comparatively under-used and under-theorised resource in political theory. ${ }^{53}$ I agree with François Laruelle that "[p]hilosophy is indeed a revolutionary

\footnotetext{
${ }^{45}$ Arendt, The Human Condition, 177-178.

${ }^{46}$ Ibid., 200.

47 See d'Entreves, "Hannah Arendt."

${ }^{48}$ Butler, Undoing Gender; Laruelle, Philosophy and Non-Philosophy; Kolozova, Cut of the Real; Sharp, "And the Children Shall Lead Them."

${ }^{49}$ Dating back to Socrates, philosophising has paid attention to whether we are living in the correct way and imagining the ideal way to live. See Kohan, The Inventive Schoolmaster, 57.

${ }^{50}$ Berlant and Seitz, "On Citizenship and Optimism."

${ }^{51}$ Mouffe, Agonistics.

52 Srnicek and Williams, Inventing the Future.

${ }^{53}$ Arendt did not think that philosophy could prompt 'thinking otherwise' because she considered philosophy to be a solitary act and 'thinking otherwise' to require a plurality of others: it "corresponds to the condition of plurality to begin with" (Arendt, The Human Condition, 201). For Arendt, 'thinking otherwise' depends on unpredictability and she argues that the conditions of
} 
practice by its very essence" 54 and so follow Barbra Weber in her hope to engage with philosophy to "develop some criteria that will help us to envision and 'receive' the future more openly and help us dream more courageously.",55

However, contemporary philosophy is primarily an academic practice at universities. ${ }^{56}$ I argue that engagement with philosophy for 'thinking otherwise' should be explored beyond academic institutions. ${ }^{57}$ I use the term 'everyday' rather than 'non-academic' throughout this thesis because I advocate engaging with philosophy to 'think otherwise' as a part of citizens' ordinary lives. The distinction draws on what Lauren Berlant refers to as 'everyday practices' - spaces that citizens exercise everyday, mundane and ongoing processes of citizenship. ${ }^{58}$ My argument so far has illustrated that philosophy should be deepened in everyday life to enable much-needed inventive and radical responses to hegemony and to societal challenges.

\section{'Thinking Otherwise' through Paradigms}

Not all philosophical approaches, however, allow us to 'think otherwise' to the same extent. Gert Biesta emphasises that we must carefully attend to the way we define and approach philosophy when "philosophy is being mobilised to do something," especially when "philosophy is being mobilised to do something educational",59 because thinking through any philosophical approach will have unforeseen outcomes. Attention must be paid not only to defending philosophy's inventive character but also to the relationship between each philosophical approach and its political implications,

unpredictability can only arise with a group of others, because no one can predict how another will act and respond to action. Each communal action has boundless consequences that no one can control. Nonetheless the philosophical approach extended in this thesis is inherently communal, and so lends to Arendt's condition of plurality. Ibid.

${ }^{54}$ Laruelle, Philosophy and Non-Philosophy, 6.

${ }^{55}$ Weber, "Embarking into the Future," 15.

${ }^{56}$ Adam Briggle and Robert Frodeman tell us that "[b]efore its migration to the university, philosophy had never had a central home. Philosophers could be found anywhere" (Briggle and Frodeman, "When Philosophy Lost Its Way").

${ }^{57}$ However, I do not wish to accentuate this division but to unsettle it.

${ }^{58}$ Berlant, The Anatomy of National Fantasy; Also see 'folk politics' in Srnicek and Williams, Inventing the Future. 'Everyday settings' can also be distinguished from Socrates' philosophy as "a way of life" (Lipman, "Philosophical Practice and Educational Reform," 21) because I conceive of philosophy as a resource that can be, in a sense, picked up and put down.

${ }^{59}$ Biesta, "Philosophy, Exposure, and Children," 306. 
a consideration often overlooked. ${ }^{60}$ In the rest of this chapter I do two things. First, I trace the predominant paths for 'thinking otherwise' through philosophy - analytic and continental. ${ }^{61}$ As contemporary philosophy is predominantly approached through the two paradigms, its resources for 'thinking otherwise' have primarily evolved out of either. Consequently, engagement with philosophy to 'think otherwise' in everyday settings often draws on continental or analytic thinking. Each paradigm presents different opportunities for political change.

Secondly, I argue that 'thinking otherwise' through philosophy influences the way we think about politics and the way we approach politics. In 'The Ontic Principle,' Bryant highlights how contemporary philosophical paradigms are shaped according to how they answer epistemic questions, usually adhering to one epistemology, ${ }^{62}$ or several connecting epistemologies in the case of broad paradigms. As he writes, "it has been natural since Descartes and Locke to begin philosophical investigation with an inquiry into the nature, conditions, and limits of knowledge." ${ }^{\prime 63}$ Bryant asserts that paradigms' norms and methods are derived from several core epistemic assumptions because they were developed to help philosophers inquire into the world through that epistemology. ${ }^{64}$ Because a paradigm's inquiry methods reflect its epistemic assumptions, it is plausible that philosophical methods influence which kinds of political conclusions we can reach, even when 'thinking otherwise'. This is not to say that one's paradigm directly influences one's specific political position, such as whether one is socialist or conservative. Rather, 'thinking otherwise' through a philosophical paradigm sets a broad scope for how one envisions politics.

\footnotetext{
${ }^{60}$ Ibid.

${ }^{61}$ Braver, A Thing of This World; Campbell, "The Covert Metaphysics of the Clash Between 'Analytic' and 'Continental' Philosophy"; Buckle, "Analytic Philosophy and Continental Philosophy."

${ }^{62}$ Epistemology denotes the study of knowledge that aims to understand the nature of knowledge, including how we know things, the limits of knowledge and the appropriate requirements for knowledge (what it takes to know things in the right way). Different epistemologies answer these questions in different ways and have different methods for arriving at and holding knowledge in line with that epistemology. See Steup, "Epistemology."

${ }^{63}$ Bryant, "The Ontic Principle," 261.

${ }^{64}$ Ibid.
} 


\section{Analytic Philosophy}

Analytic philosophy, a dominant approach in the Anglophone world, is a philosophical approach that emphasises logical clarity and conceptual precision in formulating thoughts. ${ }^{65}$ Its conceptual resources for 'thinking otherwise' derive from several core assumptions that can influence the way philosophers envision politics: (i) that we can and should represent external reality as accurately as possible; (ii) that our claims can and should be objectively justified, using logical argument; and (iii) that we should aim to make our claims as clear and precise as possible. ${ }^{66}$ Hence, analytic philosophers seek to resolve ambiguity and resist the relativising effects of context and culture by focussing on the underlying logical structure of philosophical claims ${ }^{67}$ Consequently, they tend to draw on formal symbolic logic, linguistic conceptual analysis, ${ }^{68}$ and formal abstraction to reach conclusions about the world in an ordered, rational way. These methods allow the philosopher to think and act in a conscious, reasonable manner that can be measured against precise standards.

Many inquiry methods developed in analytic paradigms are engaged with to 'think otherwise'. For example, analytic philosophy's use of thought experiments enables one to look beyond current politics through a higher-order, stripped-back platform. ${ }^{69}$ The idea is that abstraction places one in a better position to think of alternative ways of doing politics because it is a societal analysis relieved of complications, so that philosophers can focus on fundamental questions about social change and redefine societal aspects in a more reasonable way. ${ }^{70}$ For another example, conceptual analysis

\footnotetext{
${ }^{65}$ Analytic philosophy was founded in the early $20^{\text {th }}$ century by G. E. Moore, Gottlob Frege, and Bertrand Russell. Other prominent analytic philosophers include Susan Stebbing, Alice Ambrose, Robert Nozick, Thomas Nagel, David Lewis, W.V.O. Quine, and Ludwig Wittgenstein.

${ }^{66}$ Braver, A Thing of This World, 15, 18.

${ }^{67}$ Glock, Rise of Analytic Philosophy; Bell and Cooper, The Analytic Tradition; Gutting, "Bridging the Analytic-Continental Divide."

${ }^{68}$ Conceptual analysis is a twofold method of using logics to work backwards to find a concept's fundamental components of meaning and of correspondingly synthesising what was discovered to establish a definitive and reworked meaning. See Vanderbeeken, "A Plea for Agonism Between Analytic and Continental Philosophy"; Haslanger, "A Social Construction Analysis of Race."

${ }^{69}$ A thought experiment is a hypothetical situation designed to illustrate only the essential features of something, such as knowledge, identity or moral obligations. See Rawls, A Theory of Justice; Wenar, Blood Oil; Nozick, Anarchy, State, and Utopia; Singer, Animal Liberation.

${ }^{70}$ Singer, Animal Liberation; Haslanger, "A Social Construction Analysis of Race"; Russell, Mysticism and Logic; Pogge, "World Poverty and Human Rights."
} 
enables philosophers to redefine fundamental social concepts in a way that enables a ripple-effect of social change. For instance, Sally Haslanger tackles the problematic treatment of racial issues in politics through redefining the concept of 'race' itself in a more reasonable, clear, and reflective manner. ${ }^{71}$ This provides a new perspective on how race should be treated in politics, and insight into how political institutions need to be adjusted. ${ }^{72}$

However, analytic philosophical methods are themselves premised on the idea that thinking in abstract terms, removed from the muddle of specific contexts, can reveal universal logical features of reality. I suggest that, consequently, the political conclusions we reach from 'thinking otherwise' through analytic methods will align with this assumption. For example, deriving conclusions through logical methods will encourage treating political change as if it were universally applicable because logic is a set of principles whose application aspires to be universal in scope. By measuring one's reasoning against a system of logic, one reaches conclusions that aspire to universality. Even defending relativism with logical argument will risk committing one to the view that relativism itself is universal in application. The use of 'objective' methods in political inquiry, therefore, favours the view that political claims can have a universal scope.

I also suggest that trying to rethink the world logically and clearly through abstract methods influences philosophers to approach political change against an abstract blueprint. If philosophers 'think otherwise' through abstract methods, for a clear, ideal and reasonable platform to think about politics, they will be more likely to approach political change in a way that measures existing politics against an abstract blueprint of what society should look like. In Kimberly Hutchings' words, abstract theorising leads to approaching politics against an ideal vision - a "kind of laboratory" to guide "the realm of application." ${ }^{, 73}$ Although this does not seem like an abnormal way to treat political change, it is completely different to their poststructuralist counterparts who avoid approaching politics against ideal visions.

\footnotetext{
${ }^{71}$ Haslanger, “A Social Construction Analysis of Race,” 384.

${ }^{72}$ Ibid.

${ }^{73}$ Hutchings, “A Place of Greater Safety? Securing Judgment in International Ethics,” 27-28.
} 


\section{Post-Structuralism}

Continental philosophy covers a wide and dissimilar range of paradigms, and is usually concerned with addressing wide-scale societal questions in an integrative and embodied manner. Contra analytical approaches, continental philosophers usually reject the assumption that it is desirable or possible to base knowledge in an external objective reality and instead position it within the cultural 'human' realm. ${ }^{74}$ While methods differ between continental philosophies, they tend to focus on broad societal analysis and on critically questioning prevailing norms, especially societal norms that keep political hierarchies in place. Continental philosophers aim to unearth and rethink a misleading (and false) trust in modernity's promise of 'objective knowledge' and are more focused on understanding the complexity of our social world. ${ }^{75}$ Throughout the thesis I will focus on post-structuralism, one branch of continental philosophy. Because the branches of continental philosophy are more wide-ranging, it is clearer to focus on one than to speak in general. ${ }^{76}$ Moreover, post-structuralism is the type of continental philosophy of most interest to other theorists discussed in this thesis (in particular, Katerina Kolozova, Gillian Rose and second-generation PfC theorists). ${ }^{77}$

Post-structuralism is typical of continental philosophy because it derives knowledge from the cultural realm and lived experience, focuses on broad societal analysis, and aims to undermine claims to truth. Post-structuralism is distinct in its fluid and disruptive treatment of knowledge, a treatment that reflects several core assumptions about the limitations of thought. Poststructuralists hold that societal norms stemming from a fixed treatment of knowledge govern our thought and behaviour in a way that solidifies social hierarchies and inhibits 'thinking otherwise'. First, they assume that humans are relational and that societal truth/knowledge is constructed through social interaction. ${ }^{78}$ Second, they hold that truth/knowledge is generally bound to power, in

\footnotetext{
${ }^{74}$ Braver, A Thing of This World, 15; Critchley, "What Is Continental Philosophy?"

${ }^{75}$ Vanderbeeken, “A Plea for Agonism Between Analytic and Continental Philosophy," 18.

${ }^{76}$ The branches of continental philosophy are wide-ranging, including phenomenology, existentialism, structuralism, Marxism, psychoanalysis, critical theory, among more. See Critchley, "What Is Continental Philosophy?"

${ }^{77}$ Nonetheless, if one were to replace post-structuralism with another continental paradigm, my argument about epistemic isolation still holds.

${ }^{78}$ Butler writes, "[t]his relational or contextual point of view suggests that what the person "is"... is always relative to the constructed relations in which it is determined" (Butler, Gender Trouble, 15).
} 
that meaning always empowers some and subjugates others, where those in power tend to have more influence over the assignment of meanings. Third, they claim that knowledge, as bound to power, governs our behaviour, as it establishes the norms we measure our actions against in order to be accepted in society. ${ }^{79}$ They assert that treating knowledge as 'fixed' inhibits our political imagining insofar as it ties our thoughts and actions to the power arrangements that govern our actions; knowledge is "subtle and politically enforced." ${ }^{\prime 00}$ Therefore, poststructuralists assume that 'thinking otherwise' requires actively breaking from the hierarchies that influence our thought. These views lead poststructuralists to conclude that knowledge and claims to truth should be continuously disrupted in order to disrupt the power structures attached to them. ${ }^{81}$

Post-structuralism, like analytic philosophy, has methods for thinking about the world in a way that aligns with their core assumptions. First, poststructuralists use various forms of textual analysis to unearth and disrupt the assumed truths that guide society, including genealogy, ${ }^{82}$ deconstruction, and intertextuality. ${ }^{83}$ These methods help one to 'open' what seems closed and fixed in society, including established political truths, and help people arrive at epistemically disruptive conclusions. For example, deconstruction aims to continuously unsettle the nature of meaning through revealing how the dominant side of conceptual opposites (for example, male over female) rely on repressing alternatives (the female) by placing the dominant concept in a context that reveals that its dominance makes no sense. ${ }^{84}$ These methods accentuate the inevitable gap between an intended meaning and its reception. By emphasising the

\footnotetext{
${ }^{79}$ Foucault writes that the soul "is produced permanently around, on, within, the body by the functioning of a power that is exercised on those that are punished" (Foucault, Discipline \& Punish, 29.). Also see Foucault and Lotringer, Foucault Live; Foucault, Power/Knowledge; Butler, Bodies That Matter.

${ }^{80}$ Butler, Gender Trouble, 146.

${ }^{81}$ Foucault, Power/Knowledge.

${ }^{82}$ A method that digs up the history of meaning to expose how meaning becomes attached to power, which in turn opens those aspects to contingency and disruption. See Foucault and Lotringer, Foucault Live, 57-59.

${ }^{83}$ Derrida, The Ear of the Other; Deleuze, Desert Islands; Lyotard, Driftworks; Kristeva, Revolution in Poetic Language; Foucault, Power/Knowledge.

${ }^{84}$ Derrida writes, to determine "what this history has been able to dissimulate or forbid, making itself into a history by means of this... motivated repression" (Derrida, Positions, 6).
} 
fluidity and slippage of meaning in this way, poststructuralists claim that we unsettle power and open spaces for reinterpretation, or 'thinking otherwise'. ${ }^{85}$

Second, poststructuralists have practices that reinterpret our relational existence in more fluid terms, such as performativity ${ }^{86}$ and projects of alterity. ${ }^{87}$ These practices work to unsettle the hierarchical way we are governed by norms, and help philosophers think in a way that aligns with assumptions about how relations, as bound to knowledge, should be treated to overcome hierarchy. For example, performativity, based on the idea that what is seemingly fixed in society depends on our relational repetition of its treatment ("the stylized repetition of acts" ${ }^{\prime 8}$ ), invites philosophers to dislodge a sign by treating it differently from its traditional understanding. ${ }^{89}$ Therefore, poststructuralist methods help the philosopher to "break the spell of its bewitchment by the world" ${ }^{90}$ and redefine our world in a way that aligns with assumptions about the value of disruption, epistemic fluidity and relationality. ${ }^{91}$

As with my reading of analytic philosophy, I argue that 'thinking otherwise' through post-structuralism influences us to treat politics and political change in a particular way. First, it makes it easier to engage in politics in a manner that is disruptive rather than constructive. The methods work to break, unsettle and cut the meaning we have prescribed to signs in society which leaves open space for new meaning to arise, yet they do not invite us to define what it will be. Although many post-structuralist theorists hope that when we disrupt and deconstruct parts of society, a new non-hierarchical ethics may arise, post-structuralism nonetheless leads to a politics largely free from set political visions, because its methods do not help people to reconstruct.

\footnotetext{
${ }^{85}$ Peters, "Education, Neoliberalism, and Human Capital"; Foucault, Power/Knowledge; Kristeva, Revolution in Poetic Language; Butler, Bodies That Matter.

${ }^{86}$ Butler, Undoing Gender.

${ }^{87}$ Levinas, Alterity and Transcendence.

${ }^{88}$ Butler, Gender Trouble, 179.

${ }^{89}$ For example, a homosexual responding to a taunting aggressor with pride rather than shame dislodges the shameful connotations that surround homosexuality. Butler writes, "appearance is achieved through a performative twist of language" (Ibid., 25).

${ }^{90}$ Laruelle, "What Can Non-Philosophy Do?," 179; Srnicek, "Capitalism and the NonPhilosophical Subject," 164.

${ }^{91}$ Kristeva, Revolution in Poetic Language; Guattari, Soft Subversions.
} 
The post-structuralist emphasis on fluidity and relationality also makes it easier, for example, to approach politics in a manner that is attentive to difference - its methods focus our attention on what differences are excluded from dominant norms and unities. These methods aim to disrupt what is unified as 'true' or 'normal' because of the way that unity excludes (as soon as you name what is normal, you exclude), and to unravel the 'One' so that what was excluded - difference - can arise. By using methods to think about politics in a way that actively resists the unification of truth or value, and drawing attention to the value of multiplicity, the conclusions we draw will favour extinguishing commonality to allow for difference to arise.

\section{The Benefits of Paradigm-think}

'Thinking otherwise' through analytic philosophy and post-structuralism has benefits for philosophers, especially since it enables specialised methods for thinking about the political. Primarily, thinking about politics through paradigms allows for continuity in conversation, meaning that philosophers can deepen their inquiries by building on advances made by other philosophers. This continuity allows philosophers to use longdeveloped and perfected methods for 'thinking otherwise'. Importantly for the project of this thesis, attending to philosophical paradigms also allows us to engage in crossparadigm discussion. With a plurality of philosophical perspectives come opportunity for creative disagreement, and the potential to highlight the biases and limitations of each perspective. ${ }^{92}$ As Robrecht Vanderbeeken puts it, “[a]s far as local cross-overs are concerned, the plurality of points of view renders several opportunities for fruitful encounters between both traditions... the creative power of disagreement and the (occasional) critical disclosure while facing odds." ${ }^{93}$ Without a plurality of philosophical perspectives there would be no opportunity for the benefits of a range of perspectives. Our philosophical imaginations have much to gain from thinking through philosophical paradigms.

'Thinking otherwise' through specific philosophical paradigms also present benefits for 'thinking otherwise' in everyday settings. Approaching philosophy through distinct paradigms allows people to draw on paths developed by philosophers for opening the

\footnotetext{
92 Schmid and Hatchuel, "On Generic Epistemology."

${ }^{93}$ Vanderbeekin, “A Plea for Agonism Between Analytic and Continental Philosophy,” 16, 18.
} 
political imagination. People can engage, for instance, with analytic philosophy to focus on changing the universal 'big picture' of politics and use methods like conceptual analysis or abstract thinking to avoid manipulations and misunderstandings of language. Similarly, engaging with post-structuralism can help people use the ambiguity of language to play with shifting relations and hierarchies. As Rick Dolphijn puts it, "revolutionary and radical ideas are actualized through an engagement with scholars and scholarly traditions of the canonized past." ${ }^{\text {"94 }}$ Although specialised philosophical methods help people to 'think otherwise', in Part 2 I argue that integrating philosophy into everyday life through a single paradigm establishes the potential for political tunnel vision. The following chapter deepens this exploration by analysing our opportunities for 'thinking otherwise' through paradigms in PfC. It outlines the PfC movement as a promising path for deepening engagement with philosophy in everyday life - PfC is a movement that already practises strengthening philosophical engagement for 'thinking otherwise' in everyday contexts.

${ }^{94}$ Dolphijn and Tuin, New Materialism, 13. 


\section{Chapter 2 - 'Thinking Otherwise' through PfC}

In the early 1970s, inspired by the work of Socrates and John Dewey, Matthew Lipman and members of the IAPC $^{95}$ developed a curriculum for introducing philosophy to schools. ${ }^{96}$ This curriculum was based on the idea that introducing philosophy to children would support their ability to think for themselves, deepen their understanding of society, and invite them to see how their ideas and actions can give shape to their world. Lipman sought to inspire the confidence, interest and skills in children to 'think otherwise' and to translate their ideas into political reality, promoting, in Nancy Vansieleghem's words, political "renewal and change by means of the child." ${ }^{\text {97 }}$ After almost 50 years, the PfC curriculum is now taught in schools in over 60 countries ${ }^{98}$ and although it began as a relatively uniform programme, ${ }^{99}$ it has diversified into a range of different methods. ${ }^{100}$ After briefly outlining the broad skeleton of a PfC session, this chapter describes my rationale for supporting the integration of philosophy to everyday life through PfC. I then outline the different ways in which analytic and continental PfC pedagogies recommend engaging with philosophy to 'think otherwise'.

Lipman developed a philosophical curriculum he considered more suited to children's philosophical exploration, transforming traditional academic philosophy into a dialogical pedagogy. He speculated that engaging children communally with foundational questions that have perplexed philosophers throughout the ages would prompt enthusiasm in children to seek meaning in their world. The structure that Lipman developed is a community of philosophical inquiry $(\mathrm{CPI})^{101}$ - a group that explores philosophical ideas dialogically and collectively, "with the expectation that

\footnotetext{
${ }^{95}$ Institute for the Advancement of Philosophy for Children

96 This curriculum remains to be the primary resource utilised by schools. See IAPC, "Institute for the Advancement of Philosophy for Children (IAPC)."

${ }^{97}$ Vansieleghem, “Listening to Dialogue,” 175.

${ }^{98}$ Gregory, Haynes, and Murris, The Routledge International Handbook of Philosophy for Children, xxi.

${ }^{99}$ Although the field of PfC was fully never uniform, with Ekhart Martens, Karel van der Leeuw and Oscar Brenifer offering alternative curriculums for introducing philosophy to schools in the 1970s. See Ibid., xxvi.

${ }^{100}$ Vansieleghem and Kennedy, "What Is Philosophy with Children-After Matthew Lipman?," 172.

${ }^{101}$ See Kennedy and Kennedy, "Community of Philosophical Inquiry as a Discursive Structure"; Sharp, "What Is a 'Community of Inquiry'?"
} 
new meaning or significance will arise."102 Table 1 pictured below identifies the five stages of Lipman's CPI process. The session usually begins with the teacher sharing a stimulus, such as a book, a poem, or an image intended to present a philosophical dilemma and provoke philosophical curiosity. ${ }^{103}$ The students generate initial questions, ideas and concerns about the prompt and then choose one or more of these questions to discuss. During the enquiry, the teacher or facilitator introduces different philosophical resources depending on the type of philosophy being taught at the school - usually guided by some variation of analytic or poststructuralist methods of inquiry. ${ }^{104}$

\begin{tabular}{|c|l|l|}
\hline & The steps & What happens \\
\hline 1 & The offering of the text & Students read or enact a philosophical story together \\
\hline 2 & The construction of the agenda & $\begin{array}{l}\text { Students raise questions prompted by the text and } \\
\text { organize them into a philosophical enquiry agenda }\end{array}$ \\
\hline 3 & Solidifying the community & $\begin{array}{l}\text { Students discuss their questions in a dialogue facilitated } \\
\text { by an adult }\end{array}$ \\
\hline 4 & Using exercises & $\begin{array}{l}\text { The facilitator introduces relevant activities to deepen } \\
\text { and expand the students' inquiry }\end{array}$ \\
\hline 5 & Encouraging further responses & $\begin{array}{l}\text { These include, e.g. students' self-assessment of } \\
\text { philosophy practice, art projects and action projects }\end{array}$ \\
\hline
\end{tabular}

Table 1: Lipman's recommended steps for a $C P I^{105}$

\footnotetext{
102 Kennedy and Kennedy, "Community of Philosophical Inquiry as a Discursive Structure,” 266.

${ }^{103}$ Each generation has a range of resources that they suggest for prompts. For example, Lipman and the IAPC created 8 carefully crafted philosophy books for this purpose - to prompt philosophical meaning - accompanied by manuals that help teachers with a source of games, exercises and tasks to help children learn how to think with one another. For example see Lipman, Pixie; Lipman, Elfie.

${ }^{104}$ There is no standard practise of PfC. Usually PfC is its own subject, practised roughly once a week. But some advocate that it be practised through other disciplines (for example, the philosophy of mathematics that takes place in maths classes. See Kennedy, "Lipman, Dewey, and Philosophical Inquiry in the Mathematics Classroom"). Ideally children participate in $\mathrm{PfC} /$ philosophical discourse throughout their education. However due to lack of integration into school curriculums, this is often not the case. This thesis envisions PfC as a weekly practice that endures throughout the school curriculum, and focuses on primary school PfC.

105 This is a summarised table of Lipman's description of the steps of a CPI from Gregory, Haynes, and Murris, The Routledge International Handbook of Philosophy for Children, xxvi. See Lipman, Thinking in Education, 101-3.
} 
Lipman's CPI developed as a natural progression from the pragmatic and educational work surrounding John Dewey's community of inquiry. ${ }^{106}$ Dewey, taking issue with traditional forms of education, considered it more educationally significant for children to construct knowledge through engagement with their surrounding environments than be spoon-fed existing knowledge - a "doing' or "mode of participation"107 in the world. Dewey maintained that the 'community' aspect of communal inquiry would provide reliability by allowing students to test their observations about the world against each other, a process which Dewey argued would continuously improve children's thought processes. ${ }^{108}$ Furthermore, Dewey understands there to be a process of mutual adjustment between the individual and their environment, where the environment is altered through the inquiry process, insofar as the changed individual may need to adapt their environment (society) to fit into it. ${ }^{109}$ Dewey thus sought to transform the world through transforming individual subjectivity. Furthermore, Dewey saw the community of inquiry as a mode of being and a mode of building society - an important mechanism for the practice of democratic values, shaping the ways children engage with each other and wider society, and supporting them as they reshape their social world. ${ }^{110}$

As Lipman writes: "[t]here is the familiar ripple effect outward, like the stone thrown in the pond: wider and wider, more and more encompassing communities are formed, each community consisting of individuals committed to self-corrective exploration and creativity."111 While Dewey's community of inquiry, that invites children to seek meaning through altering, and being altered by their environment, is drawn from the pragmatic tradition beginning with Charles Peirce, Lipman applied this method of inquiry to a distinctly philosophical search for meaning. Lipman therefore was first to develop a community of philosophical inquiry, grounded in Dewey's notion of mutual adjustment.

\footnotetext{
${ }^{106}$ Kennedy, "Lipman, Dewey, and Philosophical Inquiry in the Mathematics Classroom."

${ }^{107}$ Dewey, Democracy And Education, 196; Ellerton, "Pragmatist Epistemology."

${ }^{108}$ Charles Peirce first developed the community of inquiry in light of human's faulty reasoning capacities, leaving his understanding of truth to be only what a community of inquirers decide it to be: "The opinion which is fated to be ultimately agreed upon by all who investigate, is what we mean by truth." Peirce, Philosophical Writings of Peirce, 38; Also see Legg, "Charles Peirce's Limit Concept of Truth."

${ }^{109}$ Cam, "Dewey, Lipman \& the Tradition of Reflective Education"; Lipman, "Philosophical Practice and Educational Reform," 29.

${ }^{110}$ Dewey, Democracy and Education.

${ }^{111}$ Lipman, "Philosophical Practice and Educational Reform," 29.
} 


\section{Why PfC for 'Thinking Otherwise'}

There are several reasons I support deepening people's engagement with philosophy through the PfC movement. I firstly follow Megan Laverty in the assertion that " $\mathrm{t}] \mathrm{he}$ urgent need for humanity to... address global concerns is felt specifically in education, because as the next generation of adults, our children will be burdened with both the responsibility for resolving global concerns and the devastating consequences of our not doing so." 112 It is therefore vital to at least endow future generations with a wider array of resources to navigate these challenges as they choose, including a strengthened chance to dream beyond. ${ }^{113}$

Second, the PfC movement is suited to this undertaking because it takes children seriously as political actors. Across the PfC literature, children are recognised as undervalued thinkers with much to offer philosophy and politics. ${ }^{114}$ Being less familiar with societal norms that limit the imagination, children are often curious to ask questions about society that adults do not, and commonly have alternative outlooks to adults. ${ }^{115}$ As Haynes and Murris put it, children are inclined "to make the familiar appear strange; playful[1]; provoking questions that cannot easily be settled through empirical investigation." "116 If given appropriate resources, children arguably have the potential to radically shift the nature of philosophy and politics because their openmindedness can reveal the world from an unorthodox angle. ${ }^{117}$ As I will later argue, shaking up philosophical orthodoxy is crucial for 'thinking otherwise' through philosophy because it alters possibilities for 'thinking otherwise'.

\footnotetext{
${ }^{112}$ Laverty, "The Bonds of Learning: Dialogue and the Question of Human Solidarity," 120.

${ }^{113}$ I do not by any means suggest placing today's societal issues on future generations. Endowing future generations with a wider array of resources should be done as well as attempting to address some of these contemporary problems now.

${ }^{114}$ Haynes, "Listening as a Critical Practice," 50; Haynes and Murris, "The Realm of Meaning," 1086; Kohan, "What Can Philosophy and Children Offer Each Other?"; Sharp, "And the Children Shall Lead Them"; Lipman, "(USA) Philosophy for Children."

${ }^{115}$ Gareth Matthew argues that children are 'natural' philosophers because of their natural curiosity, an attitude common in PfC. See Matthews, Dialogues with Children; Wartenberg, Big Ideas for Little Kids, 3-8. In disagreement Michael Hand presents an argument that children are distinctly not natural philosophers, arguing this as a reason that philosophy should be taught in schools. See Hand, "Can Children Be Taught Philosophy?"

${ }^{116}$ Haynes and Murris, "The Realm of Meaning,” 1088; Also see Lipman, “(USA) Philosophy for Children," 27.

${ }^{117}$ Matthews in Vansieleghem, "Listening to Dialogue," 181.
} 
Third, the pragmatic side of PfC shrinks the space between 'thinking otherwise' and feasible political action, something vital yet often left out of utopian attempts to "think otherwise'. This is because PfC's distinct pragmatic core encourages every abstract vision or PfC session to be followed with questions of how to implement that provisional conclusion or lesson in one's life and in our unideal political reality, impressing the importance not only of 'thinking otherwise' but also of 'acting otherwise'. ${ }^{118}$ As Jen Glaser puts it, PfC encourages students to "evaluate criteria for constructive action."

However, not all theorists consider PfC suitable for integrating philosophy into everyday life. Critics have asserted, for instance, that teaching philosophy in schools is a form of indoctrination, ${ }^{120}$ that it takes time away from more important parts of education, ${ }^{121}$ and that philosophy cannot challenge the status quo because schools are an instrument of government control (for this, teachers have to operate "outside the official curriculum"122). Largely, critics claim that children are too immature to 'do' philosophy - thinking does not necessarily constitute philosophising, and if you shift philosophy to suit children's (underdeveloped) abilities, as Lipman did with the CPI, you may not end up doing philosophy at all, devaluing its political potential. John Wilson complains that "children may enjoy questioning and discussions" but "enthusiasm alone is [in] sufficient to warrant calling this activity 'philosophy'."123 In addition, Maughn Gregory points to disapproving appraisals that the 'real' philosophy of 'professional philosophers' is solitary, comprised of thinking and writing, a standard which PfC does not meet. ${ }^{124}$

\footnotetext{
${ }^{118}$ Glaser, "Educating for Citizenship and Social Justice." Yet conclusions arrived at within a CPI are encouraged to be held as provisional, warranted assertions that are continuously reassessed, rather than final. A CPI is part of an ongoing iterative process of inquiry.

119 "Ibid., 108. Also see Gregory, "Practicing Democracy."

${ }^{120}$ See Ann Sharp's complaint about this critique in Gregory, "Philosophy for Children and Its Critics," 202.

${ }^{121}$ Michael Hand (FAPSA conference).

${ }^{122}$ Fitzsimons, "School and the Limits of Philosophy," 1288.

${ }^{123}$ Fiachra Long talking about the attitude of John Wilson. Long, "Thomas Reid and Philosophy with Children," 600-601.

${ }^{124}$ Gregory, "Philosophy for Children and Its Critics," 202.
} 
Nonetheless, children's customary exclusion from philosophy is perceived by many in the PfC literature as having more to do with unsuitable ('adult') philosophical methods that privilege epistemic soundness than to do with children's ability itself. In response to these criticisms Fiachra Long writes:

The issue of whether children should do philosophy is fatally affected by grumpy philosophers worried about whether such philosophy will stand on solid enough foundations. Obviously one does not want amateurs to dig foundations... this same attitude transfers to a similar concern today: that if you let children loose in philosophy, they will end up not doing philosophy at all. ${ }^{125}$

Instead, PfC theorists recognise that children's invitation to philosophy produces an opening for "philosophy's boundaries [to] shift under the influence of childhood,"126 and with it, the political potential of philosophy. As will become clearer in Part 3, this movability of philosophy presented by childhood is crucial for robust and metamorphic processes of philosophically 'thinking otherwise'. As Long argues, "to allow a 'naive' entry point to philosophy opens the field to children and non-experts in a way that is... significant." $" 127$

\section{Two Generations}

The question we should then turn to is: what kind of philosophy should be taught to children to best encourage their inclination to 'think otherwise'? Many philosophical approaches have been suggested throughout PfC's lineage, which Nancy Vansieleghem and David Kennedy divide to two broad generations: ${ }^{128}$ a first generation that developed the original content of the programme through analytic philosophy ${ }^{129}$ and a second that developed in the 1990s in line with insights from continental

${ }^{125}$ Long, "Thomas Reid and Philosophy with Children," 603.

${ }^{126}$ Vansieleghem and Kennedy, "What Is Philosophy with Children—After Matthew Lipman?," 176.

${ }^{127}$ Long, "Thomas Reid and Philosophy with Children," 605. Murris asks us to be wary of pigeonholing children in PfC as 'naïve' thinkers, because it deepens and naturalises images of what adults expect children to be: it "perpetuate[s] many adults' assumptions about who and what children are" (Murris, "The Philosophy for Children Curriculum," 74).

${ }^{128}$ Vansieleghem and Kennedy, "What Is Philosophy with Children-After Matthew Lipman?," 172. Also see Reed and Johnson, Friendship and Moral Education.

${ }^{129}$ Here I am referring to Matthew Lipman, Gareth Matthews, Ann Sharp, Jen Glaser, Robert Fisher, Thomas Wartenberg, Laurence Splitter, Philip Cam, Maughn Gregory (who is not strictly analytic), Peter Ellerton, Clinton Golding, and Michael Hand. 
philosophy. ${ }^{130}$ Both generations agree that engagement with philosophy in schools provides a constructive environment for children to explore thinking and to redefine existing social and political realities. The generations differ significantly, however, in the kind of philosophy they believe will help children 'think otherwise'. ${ }^{131}$

Before delineating the difference between these traditions, I want to highlight how broad the literature is and how reductive it is to divide this multifaceted movement into two categories. The movement has undergone numerous distinctive splits ${ }^{132}$ and the philosophical content of each programme is so influenced by other theoretical trends that the division between analytic and continental philosophy within PfC is already blurred, such as the commitment to pragmatism that runs through both generations. My intention is not to deepen the already non-traditional division between analytic and continental pedagogies in PfC or to criticise particular methods as 'too analytic' or 'too continental', but rather to illustrate broad trends that run through the PfC movement.

\section{First Generation: The Analytic Programme}

The first-generation CPI is distinctly guided by analytic inquiry methods of formal and informal logic. ${ }^{133}$ From its origins in the early 1970s until today, analytic PfC theorists take seriously the idea that teaching children to think reasonably and reflectively is an essential part of a citizen's education: a means to help them not only think critically and imaginatively about our world but to determine their own future. This conviction is two-fold.

\footnotetext{
${ }^{130}$ Here I am referring to Gert Biesta, Walter Kohan, Nancy Vansieleghem, David Kennedy, Barbara Weber, Karin Murris, Joanna Haynes, Megan Laverty, Karel Van der Leeuw, and Sara Goering.

${ }^{131}$ As Nadia Kennedy and David Kennedy put it, "[o]ne aspires to order, control and clear boundaries... the other insists on unpredictable, emergent 'assemblages' and a 'non-hierarchical, a-centred field of knowledge'." (Kennedy and Kennedy, "Community of Philosophical Inquiry as a Discursive Structure," 275).

${ }^{132}$ For example, the shift in the role of the teacher from facilitator to co-enquirer formed the split from philosophy for children to philosophy with children. See Haynes and Murris, "The Realm of Meaning," 1084. Maughn Gregory, Jen Glaser and Philip Cam are some influential theorists that have drastically shifted the content of the PfC programme while remaining distinctly analytic, forming an 'analytic' second-generation almost as distinct from the first-generation as their continental counterparts.

${ }^{133}$ Lipman, Sharp, and Oscanyan, Philosophy in the Classroom.
} 
Firstly, first-generation theorists aim to engage children with philosophy in order to strengthen their autonomy over their thoughts and actions through reflective thinking (being conscious of the way one thinks). ${ }^{134}$ The rationale behind this is that teaching children to think reflectively makes them less susceptible to the will of others, and more capable of reflectively determining how they think their lives and society should look. For example, Ann Sharp claims that autonomy over thought is crucial to helping children reshape society because it empowers them to break from the constraints of societal habit - to "investigat[e] critically all the cultural habits, ideas, and values of one's culture that block liberation." 135 She writes, "[o]ne engages in philosophical deliberation with one's peers in order to learn to think for oneself about matters of importance.... [to] slowly but surely develo[p] capacities that will work towards their overcoming of their oppression." 136 This critical interrogation is considered crucial for 'thinking otherwise' because unravelling aspects of society makes way for something new to blossom, for "new ways of looking at and understanding the world." 137 Furthermore, reflective thinking is said to sharpen children's ability to choose which aspects of society they want to change and how they want to do so. ${ }^{138}$

Second, first-generation PfC theorists aim to improve students' democratic skills to better enable them to collectively reshape their world. ${ }^{139}$ For example, Lipman considers learning to think reflectively not just essential for individualised benefits, but essential for each member's free participation in democratic engagement, so that better worlds can be built through thinking freely and living out the principles of a democracy. Where first-generation emphasises the collective democratic forming of the way children perceive, understand and engage with the world (rather than merely sharing and debating opinions), the capacity to reason allows each individual to assess the

\footnotetext{
${ }^{134}$ Lipman, "(USA) Philosophy for Children," 30; Splitter and Sharp, Teaching for Better Thinking; Daniel, Schleifer, and Lebouis, "Philosophy for Children"; Fisher, Teaching Thinking; Cam, "Dewey, Lipman \& the Tradition of Reflective Education"; Lipman, Sharp, and Oscanyan, Philosophy in the Classroom.

${ }^{135}$ Sharp, “And the Children Shall Lead Them," 178.

${ }^{136}$ Ibid., 177.

${ }^{137}$ Ibid., 179.

${ }^{138}$ Lipman writes that to learn "reflective thinking... is to liberate ourselves... and to bestow upon ourselves that power of choosing among and acting upon alternatives" (Lipman, Thinking in Education, 35).

${ }^{139}$ Sharp, "What Is a 'Community of Inquiry’?”; Glaser, "Educating for Citizenship and Social Justice"; Splitter and Sharp, Teaching for Better Thinking; Lipman, Philosophy Goes To School.
} 
arguments of their peers and contribute to the social vision. ${ }^{140}$ Lipman writes, "[i]t is especially important to recognize that philosophy in the school curriculum can directly improve the quality of life in a democratic society. That is, philosophy produces higherorder thinking among students."

First-generation theorists argue that analytic philosophy provides vital intellectual tools that support self-conscious thinking and democratic engagement. ${ }^{142}$ Following the CPI steps outlined earlier, first generation classroom discussions are guided by analytic inquiry methods, including logic and reasoning skills:

[G]iving good reasons... making valid inferences, hypothesising, asking good questions, using and recognising criteria, calling for relevance, seeking clarification, offering alternative points of view, building logically on the contributions of others, posing counter-examples, asking for reasons. ${ }^{143}$

During CPI discussions, each philosophical point raised is expanded on, questioned, clarified and/or re-articulated by others in a "collaborative, non-competitive fashion." ${ }^{144}$ Furthermore, the CPI is guided by several analytic 'moves'/methods for children to clarify and guide the discussion. ${ }^{145}$ These include abstract methods (such as conceptual clarification and thought experiments) and logical methods (such as deduction and recognising fallacies). Teachers and students can strategically employ these moves when misunderstanding, confusion, or disagreement arises, and gain increasing confidence with repeated use of the analytic strategies over time. ${ }^{146}$ For Lipman, in learning how to reason, students will be able to "extend knowledge through logical inference, defend knowledge through reasons and argument; and coordinate

\footnotetext{
${ }^{140}$ The CPI is considered a democracy in action - the principles cultivated in an analytic CPI are the same ones that found democratic action - "principles include egalitarianism, respect for persons, fallibilism, pluralism, open-mindedness, tolerance, and the procedures of democracy" (Sharp, "And the Children Shall Lead Them," 179).

${ }^{141}$ Lipman, "Teaching Students to Think Reasonably," 277.

${ }^{142}$ Lipman, Sharp, and Oscanyan, Philosophy in the Classroom; Cam, "Dewey, Lipman \& the Tradition of Reflective Education."

${ }^{143}$ Vansieleghem, "Philosophy for Children as the Wind of Thinking," 21; Lipman, Sharp, and Oscanyan, Philosophy in the Classroom.

${ }^{144}$ Sharp, "Community of Inquiry as Ritual Participation," 301.

${ }^{145}$ Among many others, these are some of the resources used in first-generation PfC classes to teach children to reason Philip Cam's Twenty Thinking Tools, Hymer and Sutcliffe's P4C Pocketbook Clinton Golding's Connecting Concepts, Robert Fisher's Games for Thinking.

${ }^{146}$ See Cam, 20 Thinking Tools, 54-57.
} 
knowledge through critical analysis." ${ }^{, 147}$ Collaborative engagement with these inquiry tools is argued to enable students to become more reflective because they draw attention to the thinking process, especially when students have to continuously justify their reasoning and thought processes to peers. As Lipman, Sharp and Oscanyan write, "because the rules of formal logic govern sentences, they can be used to help develop a kind of self-awareness. They provide a means for grasping and examining one's thoughts in a structured, clear-headed way."148

The analytic methods that guide a first-generation CPI broadly match those used in academic settings and maintain the same set of assumptions: that we should aim to mirror the objective world, that reliability is desirable, that we can master thought through reason, that "the forward movement of inquiry is always in the direction of meaning, if not truth" ${ }^{\text {"149 }}$ and so on. The first-generation definition of 'good reasoning' is synonymous with the analytic classification of good judgment, with its emphasis on "logical and epistemological criteria — such as sensitivity to logical fallacies, and the systematic application of logical principles (for example, syllogisms).,"150

Importantly, the first-generation programme emphasises evaluating the inquiry process to help strengthen students' higher-order reflective skills. Throughout the inquiry, teachers are requested to pause the discussion and ask students to identify which thinking skills the group has used (for example, identify if they are evaluating, inferring, disagreeing, exemplifying and so on), in order to provide a higher-order awareness of the philosophical process and to identify areas for improvement, making the inquiry a "self-correcting investigation." ${ }^{151}$ During this process children are invited to question and alter the programme itself. Laurance Splitter and Ann Sharp, for example, explain that the programme cultivates fallibilism ${ }^{152}$ where "the process[es] of thinking become legitimate objects of scrutiny and evaluation, ${ }^{153}$ an evaluation that

\footnotetext{
${ }^{147}$ Lipman, Thinking in Education, 111; in Biesta, "Philosophy, Exposure, and Children," 309.

${ }^{148}$ Lipman, Sharp, and Oscanyan, Philosophy in the Classroom, 131.

${ }^{149}$ Lipman, “Teaching Students to Think Reasonably," 278.

${ }^{150}$ Weber, "Childhood, Philosophy and Play," 237.

${ }^{151}$ Lipman, "(USA) Philosophy for Children,” 29.

${ }^{152}$ Fallibilism is the idea that all knowledge should be held in doubt, including meta-epistemic doubt where one must doubt also those assumptions. See Ellerton, "Pragmatist Epistemology."

${ }^{153}$ Splitter and Sharp, Teaching for Better Thinking, 90.
} 
"assists us to make [more] reasonable judgments." 154 Lipman calls the critical evaluation of the programme itself 'complex thinking', which takes place on two levels: first, focusing on procedure and methods, and second, on the values behind the programme (its commitment to valuing democracy, equality and so forth). ${ }^{155}$

While scepticism has been raised about children's capacity to grasp reason and reflective thinking, developmental theorist Lev Vygotsky highlighted for Lipman and other first-generation theorists that children "work at a different-and higher-level when doing intellectual work cooperatively rather than competitively."156 A community of inquiry is considered a "collectively constructed zone of proximal development" ${ }^{" 157}$ where children can continuously improve their reasoning skills both through adjusting their abilities in line with progresses made in a CPI ("internalizing the processes of the group" ${ }^{\text {158 }}$ ) and by having irrational ideas challenged by peers. ${ }^{159}$ This allows students to become aware of the reasoning behind what they do and say; to pause and reflect before taking action through conscious and defendable choice, ${ }^{160}$ which become "habits of the individual."

Therefore this reasoning process, first-generation theorists claim, helps students to collectively construct their future. ${ }^{162}$ Like traditional analytic philosophy, the firstgeneration programme gives children a clear, abstract platform to envision different worlds through philosophical methods that provide clarity and reason - thought processes that provide a "simple yet profound change in perspective." 163 Engagement with these methods is argued to provide students with the reflective ability to take a

\footnotetext{
154 Ibid., 56.

${ }^{155}$ Murris, "The Philosophy for Children Curriculum," 68; Lipman, Thinking in Education.

${ }^{156}$ Lipman, Natasha, xiii. Also see Lipman, "Teaching Students to Think Reasonably,” 278.

${ }^{157}$ Kennedy and Kennedy, “Community of Philosophical Inquiry as a Discursive Structure,” 268.

${ }^{158}$ Lipman, Sharp, and Oscanyan, Philosophy in the Classroom, 23.

${ }^{159}$ Reflective thinking and democracy in action are seen to have a symbiotic educational relationship, where children can learn to think reflectively through engaging in a communal CPI and where learning to think reflectively enables them to properly partake in democratic engagement. See Lipman, "Teaching Students to Think Reasonably," 277.

${ }^{160}$ Splitter and Sharp, Teaching for Better Thinking, 16.

${ }^{161}$ Lipman, Sharp, and Oscanyan, Philosophy in the Classroom, 45.

${ }^{162}$ Glaser, "Educating for Citizenship and Social Justice"; Sharp, "And the Children Shall Lead Them”; Lipman, “(USA) Philosophy for Children."

${ }^{163}$ Lipman, Sharp, and Oscanyan, Philosophy in the Classroom, 131.
} 
step away from society, imagine how it should be reshaped, and enable them to pursue that path. Unlike traditional analytic philosophy, first-generation theorists also hold that the programme inspires 'thinking otherwise' through encouraging children to reshape their self to embody that vision. It is thought that if a student changes his/her own thinking process to become more reasonable, it will ripple out through the rest of society. As Lipman states, "applying philosophy and doing it are not identical."164

As mentioned in the previous chapter, philosophical methods influence the way we think about politics. I suggest that engaging in an analytic CPI invites students to think about political change in a 'universal' manner, and against an abstract blueprint. First, analytic CPIs create the possibility for universal visions by striving to reach a collective and rational consensus at the end of each CPI. Ideas developed in a first-generation CPI may be treated as universal in scope because they are measured against, and defended by, logic and reason (objective standards of measurement). Even though the programme's pragmatic drive asks students to focus on "possibilities for action in this time and this place and under these circumstances"165 their conclusions, based in objective standards of reason and logic, will at the same time be orientated towards visions that can be applied universally.

Second, the abstract methods used in a CPI also influence children to think about politics in a way that is measured against an idealised blueprint of what the world should look like. Abstract methods, such as thought experiments and abstract imagining, are used to help children develop "a new vision of the kind of life they want to live," "166 to flesh out what ought to be done about the world in order to "know how to move an agenda forward." 167 As Glaser explains, for example, "a community of inquiry considers 'what is justice' in the abstract and ends with an ideational view of what justice is" followed by a practical navigation "between ideational thinking and worldliness." 168 Having an abstract blueprint pushes the political forward: it "cultivate[s] the imagination of young persons in such a way that they gain practice in... envisioning possibilities of a better world - a world in which the oppressed can

\footnotetext{
${ }^{164}$ Lipman, "Philosophical Practice and Educational Reform," 21.

${ }^{165}$ Glaser, "Educating for Citizenship and Social Justice," 108.

${ }^{166}$ Sharp in Gregory, "Philosophy for Children and Its Critics," 210.

${ }^{167}$ Glaser, "Educating for Citizenship and Social Justice," 108.

${ }^{168}$ Ibid.
} 
taste of liberation." ${ }^{\prime 169}$ Because analytic methods focus on developing visions of what the world should look like, children will be orientated to think about politics in a way that measures against to the abstract visions they develop.

Let's look at how first-generation pedagogies may influence the way children approach politics through an example. Jen Glaser runs PfC as a reconciliation programme in Isawiya, a village in East Jerusalem, with Palestinian and Israeli students. The idea behind this being that through engagement in PfC students can imagine beyond the political division between the two nationalities, build a sustained dialogue, and create a different kind of civic sphere. In these PfC sessions, students have a chance to listen to each other's perspectives, to reasonably inquire into the validity of those perspectives, and to develop a fallibilist position that is prepared to re-think one's political assumptions. ${ }^{170}$

First, this PfC session illustrates how children may then be more inclined to approach politics in reference to an abstract blueprint - it aims to encourage rational dialogue so that students can collectively construct a vision that children can then actualise. This will likely make students inclined to approach politics/reconciliation in a way that refers to a collectively-built blueprint of the future of Palestine/Israel. Second, this kind of philosophising is universal insofar as the engagement between Arabs and Israelis is guided by universally applicable principles of reason. Based on reason and rational dialogue, it is expected that children will form a political vision that is objectively (via reason) ideal and universally applicable to both parties because of that objectivity. Students may then approach politics in a way that they consider their conclusions universally valid. ${ }^{171}$ Although the first-generation CPI is useful in many ways for 'thinking otherwise' I am, alongside many second-generation PfC theorists, concerned that without cross-paradigm engagement, it orientates political imagining in a solidified and undetectable manner (as Part 2 illustrates). In what follows, I consider secondgeneration CPI and argue that it also presents a pedagogy that influences the way children envision different worlds.

\footnotetext{
${ }^{169}$ Sharp, "And the Children Shall Lead Them," 183-84.

${ }^{170}$ Glaser, "Dialogue and Difference."

${ }^{171}$ Ibid.
} 


\section{Second Generation: The Fluid CPI}

During the 1990s there was significant critical pushback from the original content of the programme and a collection of alternative methods were developed. This new literature is what Vansieleghem and Kennedy refer to as the 'second generation'. ${ }^{172}$ Drawing insight from different philosophers that challenged notions of truth, reason, nature, and instrumentality over the past 40 years, second-generation PfC shifted away from a set curriculum towards a philosophically relational approach. ${ }^{173}$ Many saw this shift as necessary progression to keep pace with developments in wider philosophy. As Ann Reed and Tony Johnson put it, "[g]iven the rise of post-modernity, one simply does not do philosophy the way one did it forty years ago. The assumptions about truth, perspective, nature and so on have, at least, been challenged." ${ }^{174}$ The second-generation point out that analytical skills do not support all forms of 'thinking otherwise'. In all likelihood, they claim, the rational underpinnings of the first-generation programme de-radicalise children's political and philosophical potential because they shape their thinking in accordance with adult rational ideals. As Biesta argues, "philosophy as an instrument to 'produce' a particular kind of [rational] human subjectivity.",175 According to second-generation theorists, this inhibits thinking about democracy and other parts of society in a radically alternative way.

The second-generation aim to help children 'think otherwise' in a way that frees them from the confines of adult thinking and the "dominant cultural forces of our time.",176 To open space for children to discover an alternative world, the second-generation welcomes "difference as a principle of growth." ${ }^{\text {"177 }}$ Through emphasising difference, "new meanings, new forms of social expression, new forms of empowerment... [are] expected to emerge." ${ }^{178}$ Rather than imparting a specific image of what politics should

\footnotetext{
${ }^{172}$ Vansieleghem and Kennedy, "What Is Philosophy with Children—After Matthew Lipman?," 172.

${ }^{173}$ Murris, "The Philosophy for Children Curriculum," 68.

${ }^{174}$ Reed and Johnson, Friendship and Moral Education, 64-65; Vansieleghem and Kennedy, "What Is Philosophy with Children-After Matthew Lipman?," 177.

${ }^{175}$ Biesta, "Philosophy, Exposure, and Children," 311.

${ }^{176}$ Kohan, "Childhood, Education and Philosophy," 345.

${ }^{177}$ Vansieleghem and Kennedy, "What Is Philosophy with Children—After Matthew Lipman?," 172.

${ }^{178}$ Ibid., 180.
} 
look like, second-generation CPI aims to help children disrupt what has become settled, "rearranging, shifting, displacing and reframing ideas and beliefs"179 and inviting relationships to be established along different lines.

This picture of PfC is presented through several distinct but interlinked suggestions that, for the most part, have not yet been translated into teaching programmes or manuals. ${ }^{180}$ Not all second-generation methods are poststructuralist, ${ }^{181}$ but many can be broadly traced to post-structuralist attitudes and advances (made by theorists such as Michel Foucault, Emmanuel Levinas, Gilles Deleuze, and Felix Guattari, for example). ${ }^{182}$ Second-generation methods usually start from poststructuralist assumptions that humans are relationally composed and that knowledge should remain fluid, allowing a plethora of interpretations to continuously emerge. Vansieleghem and Kennedy explain that the influence of post-structuralism can be seen in the care to avoid instrumentalist philosophical engagement that shapes people into disciplined and idealised bodies. ${ }^{183}$ Megan Laverty also highlights how the second-generation emphasis on "the fragmented subject, the slipperiness of meaning, the inescapability of discourse, and the ubiquity of power" ${ }^{\prime 184}$ illustrates the influence of post-structuralism and post-modernism over this pedagogy.

In what follows, I introduce several distinct pedagogical examples of the secondgeneration, unified in the way they draw on methods that emphasise relationality and epistemic disruption to guide a CPI. One approach advocated by Gert Biesta and Nancy Vansieleghem bases PfC's CPI on an ethical and disruptive exposure to peers rather

\footnotetext{
${ }^{179}$ Haynes in Murris, "The Philosophy for Children Curriculum," 69.

${ }^{180}$ Which in itself is arguably problematic and matches broader critiques of the tendency of postmodern thought to leave ideas in the abstract realm in avoidance of creating exclusions. See Rose, Mourning Becomes the Law; Kolozova, Cut of the Real; Bryant, Srnicek, and Harman, The Speculative Turn.

${ }^{181}$ See for example Weber, "Childhood, Philosophy and Play"; Long, "Thomas Reid and Philosophy with Children"; Murris, The Posthuman Child; Chetty and Suissa, "Racism and Discomfort in the CPI"; Fletcher and Oyler, "Curating an Asthetic Space for Inquiry."

${ }^{182}$ See Kennedy, "Rhizomatic Curriculum Development in Community of Philosophical Inquiry"; Biesta, "Philosophy, Exposure, and Children"; Kohan, "Childhood, Education and Philosophy"; Vansieleghem, "Philosophy for Children as the Wind of Thinking"; Vansieleghem, "Listening to Dialogue"; Haynes and Murris, "The Realm of Meaning"; Kohan, The Inventive Schoolmaster.

${ }^{183}$ Vansieleghem and Kennedy, "What Is Philosophy with Children—After Matthew Lipman?," 179.

${ }^{184}$ Gregory, "Philosophy for Children and Its Critics,” 207-8.
} 
than on dialogue. ${ }^{185}$ Exposure encourages students to listen to what each CPI member has to say, in a way that exposes their sense of self to being disrupted by that listening. Biesta's pedagogical exposure aims not to produce a kind of political citizen by teaching children how to think in a particular way, but to establish relationships in a way that allows for uniqueness to emerge. Through disrupting ourselves in the face of the 'Other', Biesta holds that we make room for difference, without trying to fully grasp it. ${ }^{186}$ Biesta explains that the pedagogy of exposure does not hold anything quantifiable, claiming that "[e]xposure does not produce; exposure only interrupts." 187 The hesitation involved in the "orientation towards not-knowing"188 leaves the possibility of interpretation open to different relations within the CPI.

Vansieleghem's ethical exposure similarly stresses the importance of encouraging pedagogical disruption of the self for encouraging a philosophy that is genuinely open to new arrangements of thought, writing relationships along fluid and unknowable lines. ${ }^{189}$ Vansieleghem points to how every dialogue is necessarily marked by lack: between what someone says and its inevitable misinterpretation. Rather than reaching a conclusion, she asks children to listen and remain in the gap between what is said and interpretation. This in-between space "embodies the possibility to render another self ${ }^{\prime 190}$ because it opens each student to being profoundly changed by their peers. ${ }^{191}$ This pedagogy understands that arriving at an ethical understanding of one another in a CPI requires "the courage to give up the position I hold and to be engaged in an uncomfortable position that is not mine."192 Although exposure does not construct anything, its gaps and disruption is argued to leave space for each individual to rethink "who we are and how we are related,"193 and to 'think otherwise' through disrupting relations.

\footnotetext{
${ }^{185}$ Biesta, "Philosophy, Exposure, and Children"; Vansieleghem, "Philosophy for Children as the Wind of Thinking"; Vansieleghem, "Listening to Dialogue."

${ }^{186}$ Biesta, "Philosophy, Exposure, and Children," 317.

${ }^{187}$ Ibid., 317-18.

${ }^{188}$ Ibid., 318.

${ }^{189}$ Vansieleghem, "Philosophy for Children as the Wind of Thinking"; Vansieleghem, "Listening to Dialogue."

${ }^{190}$ Vansieleghem, “Listening to Dialogue,” 186.

191 Ibid.

${ }^{192}$ Vansieleghem, "Philosophy for Children as the Wind of Thinking," 32.

${ }^{193}$ Vansieleghem, “Listening to Dialogue," 186.
} 
David Kennedy presents another example of a non-analytic CPI. His philosophical approach encourages a 'rhizomatic' conceptual exploration drawn from Deleuze and Guattari. Kennedy's PfC suggestion invites children to look for non-hierarchical horizontal connections between societal concepts through "principles of multiplicity, rupture, deterritorialization and reterritorialization." ${ }^{194}$ Kennedy’s CPI does not follow traditional CPI steps, but instead asks students to choose and examine a term used in another discipline in the school curriculum, like 'organism' from science. Students trace the history of that concept's authority, assumptions, and web-like connections to other concepts; a process intended to unsettle its authority and fixed moorings. ${ }^{195}$ This deconstruction unsettles an array of connected concepts across different disciplines and opens the way to re-conceptualising a more egalitarian school curriculum. Through unsettling the authority of concepts that comprise their school curriculum, and through seeking the dynamic links between those concepts, children have a chance to radically reinterpret their schooling experience.

A final example is Kohan's CPI that is based on students' experiences rather than reason, built on Michel Foucault's notion of 'synthesis'. Basing a PfC session on experience is valuable, according to Kohan, because experience is a domain of "movement, displacement, and transformation" that puts dominant discourses into question. ${ }^{196}$ By basing discussions on experience, neither the teacher nor the child will be able to anticipate the outcome. This can be contrasted to an analytic session, where the teacher has selected a stimulus and resources that may influence the direction of the conversation. From such uncontrolled and unexpected dialogue, Kohan claims, new forms of thinking and ways of organising ourselves can emerge: he states, (quoting Foucault) "we detach ourselves from what is taken as true, and we look for other rules of the game." 197

Second-generation PfC hence reflects a shift in focus towards fluidity and the particular, rather than set conclusions and the universal, as a means to ensure inclusion and recognition for all children. The methods outlined share a preference with

\footnotetext{
${ }^{194}$ Deleuze and Guattari in Kennedy, "Rhizomatic Curriculum Development in Community of Philosophical Inquiry," 2.

${ }^{195}$ Ibid., 7.

${ }^{196}$ Kohan, The Inventive Schoolmaster, 62.

${ }^{197}$ Kohan, "Childhood, Education and Philosophy," 346.
} 
traditional poststructuralist approaches for multiple interpretations (rather than a collective interpretation), a desire to help children unsettle hierarchy and the norms that exclude them, and methods to help children navigate ambiguity. While first-generation CPI closes with a consensus, Vansieleghem thinks CPI discussions should be dislodged from conclusions that have dominated our rational world. Meaning should be suspended, left "situated between a possible meaning and an impossible one,"198 in a fluid form so children can interpret the discussion for themselves. ${ }^{199}$ An emphasis on fluid relationality is seen in Murris' claim ${ }^{200}$ that the "[p]osthuman child is relational. There is no prior existence of individuals with properties, competencies, a voice, agency, etc. Individuals materialise and come into being through relationships; and so does learning." 201 Yet unlike traditional post-structuralism, second-generation PfC theorists, focus more on relational experiences than on textual analysis and genealogy (aside from Kennedy).

As with analytic philosophy, we can see how the conclusions drawn from the methodological practice of the second-generation suggestions may incline children to think about politics in a particular way. First, we can witness an inclination towards approaching politics in a way that emphasises difference. For example, it is a core underlying assumption that when we expose ourselves to one another, we start to understand the complexity of difference and the value of uniqueness for understanding the world anew. As pointed out, Vansieleghem maintains that CPI discussions should be dislodged from conclusions that have dominated our rational world, for something new to emerge, located "outside the attempt to restore, the attempt to unify." ${ }^{202}$ Biesta asserts that while difference/uniqueness is "structurally beyond our control," you can create an educational programme that is attentive to difference and to otherness that "keeps the possibility for interruption and intervention open" ${ }^{\text {"203 }}$ where "individuals-intheir uniqueness might come into the world." ${ }^{204}$ This philosophical pedagogy "does not

\footnotetext{
${ }^{198}$ Vansieleghem, “Listening to Dialogue," 188.

${ }^{199}$ Ibid., 185.

${ }^{200}$ The Posthuman Child is not a poststructuralist pedagogy, but is derived from a philosophical approach that takes heed of poststructuralist findings.

${ }^{201}$ Murris, The Posthuman Child, xi.

${ }^{202}$ Vansieleghem, "Listening to Dialogue," 185.

${ }^{203}$ Biesta, "Philosophy, Exposure, and Children," 316.

${ }^{204}$ Ibid., 317.
} 
intend to grasp the difference, but... to emphasise its strengths," ${ }^{205}$ so there is no threat to exclude difference and those who may not 'fit' a communal conclusion. Although children need not always think about politics through a lens of difference, understanding its value to 'thinking otherwise' and why it exists may provoke them to think about politics in a way that is attentive to difference.

Second-generation suggestions may also guide children towards political change that is disruptive (as opposed to constructive/building). For example, exposure helps children to disrupt their sense of self and their beliefs through opening themselves to one another, because other's experiences may contradict what one thought one knew. They claim that disruption opens space for something new to emerge, that perhaps is guided by more ethical and understanding principles: "it 'empties' the interlocutors of unexamined ideas, dogmas, beliefs, questions and values." ${ }^{206}$ Kennedy's rhizome is also, for example, "in opposition to totality"207 - not assimilated by a unity. It disrupts totalizing understanding of concepts, holding them in an ever-shifting form. It is emergent - constantly shifting and disrupting our web of concepts. This unsettling and unravelling disruption opens space for new interpretations to arise. If children are encouraged to engage in the political primarily through the practice of unsettling, they may be more likely to pursue political change in a manner that is disruptive.

We can witness the potential philosophical influence that second-generation pedagogies have over the way students approach politics through Karin Murris' PfC sessions on 'race' in Johannesburg, South Africa. ${ }^{208}$ Through a semiotic method, Murris invites students to each make their own picture book in response to a story about race - David Mckee's Tusk Tusk, which tells a story about violent relations between black and white elephants - and to share and discuss their stories together. This method emphasises encouraging "creative, lateral and critical connections... across the various sign systems," such as images, text and discussion. ${ }^{209}$

\footnotetext{
${ }^{205}$ Vansieleghem, "Listening to Dialogue," 186.

${ }^{206}$ Kohan, "Childhood, Education and Philosophy," 349.

${ }^{207}$ Kennedy, "Rhizomatic Curriculum Development in Community of Philosophical Inquiry," 4.

${ }^{208}$ Although this is not strictly-speaking a poststructuralist approach, it is still orientated towards a similar set of assumptions.

${ }^{209}$ Haynes and Murris, “The Realm of Meaning,” 1095.
} 
First, we can see how this method gives preference to multiple interpretations and difference (over consensus-building) by inviting each student to present their own response to Tusk Tusk, attentive to the difference in the way children interpret 'race'. Without building one story together, interpretation is multiple. Second, this method is profoundly disruptive of societal understandings of race. Its lateral weaving between children's stories "provokes infinite readings 'beyond' the text," intended to provide an opening for children's ideas to "bring something new and profound into the world" ${ }^{210}$ through disrupting traditional interpretations of, and stigmas around race. ${ }^{211}$ It does not aim to develop a blueprint of where-to next, but unsettles children's experiences of 'race' by making connections between the stories that are based on their personal experiences. We can see here how engaging with the notion of race through such pedagogies may influence children to approach race/politics through difference and disruption.

\section{Summary}

In Part 1 I have outlined the opportunities for 'thinking otherwise' through existing paradigms, and have made some suggestions about the potential political influence of thinking through philosophy's two primary paradigms. While paradigm thinking allows children to draw on the benefits of specialised advances made by philosophers for 'thinking otherwise', in Part 2 I argue that the political influence of each pedagogy's philosophical methods sets the potential for confining children's imagination to epistemic parameters. The second-generation have made promising steps in response to the limits of a strictly analytic programme, however they did not completely avoid the limits formed by the first-generation programme. The next two chapters will argue that when people are invited to 'think otherwise' about politics through one paradigm only, it may limit them to remain stuck in these ways of thinking about politics through philosophy.

\footnotetext{
${ }^{210}$ Ibid.

${ }^{211}$ For a more experimental example, see Vansieleghem, "Philosophy with Children as an Exercise in Parrhesia."
} 


\section{Part 2 - The Limits of Epistemic Isolation}

Part 2 discusses the complex relationship between epistemology, philosophical (un)certainty and political change as a means of outlining the problem this thesis seeks to address: that hardened paradigm edges limit engaging with philosophy for political change. In Chapter 3 I argue that paradigm-oriented thinking in academia grounds philosophical inquiry in holistic epistemic narratives - 'epistemic isolation'. This limits philosophers' imagination to existing epistemic parameters by encouraging the circulation of ideas derived from those narratives, including political ideas that reflect its assumptions. Through trapping philosopher's imagination to epistemic parameters, epistemic isolation threatens an exclusive kind of imagining, and promotes conceptual stagnation that creates a kind of political 'tunnel vision'.

By analysing both generations of the PfC movement, Chapter 4 argues that the limits imposed by epistemic isolation problematically encourage stuck paradigm-oriented political thinking outside academia. While the epistemic limits of 'thinking otherwise' are a problem for academic theorists, their political tunnel vision should be seen as a willed ignorance, because they have the philosophical means to question their assumptions. ${ }^{212}$ These limitations are intensified in contexts like PfC, where single paradigms are treated as exemplifying all philosophy. ${ }^{213}$ Taught at a nation-wide scale, the political implications of teaching isolated paradigms in PfC could be significant, forming citizens who approach politics through either a single constructive and universal lens or a single disruptive and fluid one. Later in Part 3, I highlight the importance of enabling people to reshape philosophical methods for 'thinking otherwise' in ways that can transcend the epistemic assumptions of singular paradigms.

\footnotetext{
212 Tuana, "The Speculum of Ignorance."

${ }^{213}$ Biesta, "Philosophy, Exposure, and Children."
} 


\section{Chapter 3 - The Tendency Towards Epistemic Isolation}

Constructive dialogue between analytic and continental philosophers is not as common as it should be. ${ }^{214}$ Engagement between them "has rarely risen above mutual disinterest, uninformed dismissal, or plain insult." ${ }^{, 215}$ Although there are attempts to work across this "virtual Berlin wall" 216 (as Part 3 will illustrate), Lee Braver explains that the divide between analytic and continental philosophers is much more severe than past philosophical divides, such as between empiricists and rationalists who "read each other's works and engaged in informed debate."217 Debate between analytic and continental philosophers, more often than not, aims to disprove each other's foundations rather than to understand and offer constructive insight. ${ }^{218}$ As Jack Reynolds et al. put it, continental philosophers are too often preoccupied with trying to prove that analytic philosophy is a "faux-neutral and ahistorical game" and analytic philosophers laugh at continental philosophy for being "nonsense, mysticism or literature.",219

There are many explanations as to why so little dialogue exists between analytic and continental philosophers. Some philosophers attribute it to incompatible stylistic and methodological differences, ${ }^{220}$ some to fundamental and irreconcilable epistemic differences, ${ }^{221}$ some to a radical difference in subject matter. ${ }^{222}$ In Vanderbeeken's words,

If we take into account the difference between both traditions concerning the respective subject-matters, the pivotal goals, the modes of inquiry and scholarship,

\footnotetext{
${ }^{214}$ Braver, A Thing of This World, 3; Reynolds et al., Postanalytic and Metacontinental. Green, "A Plague on Both Your Houses"; Humphries, "Analytic and Continental”; Buckle, "Analytic Philosophy and Continental Philosophy: The Campbell Thesis Revised."

${ }^{215}$ Braver, A Thing of This World, 4.

${ }^{216}$ Vanderbeeken, “A Plea for Agonism Between Analytic and Continental Philosophy,” 16.

${ }^{217}$ Braver, A Thing of This World, 3 .

${ }^{218}$ As Barad explains, "[c]ritique is all too often... a destructive practice meant to dismiss, to turn aside, to put someone or something down" (Barad, "Interview with Karen Barad," 49).

${ }^{219}$ Reynolds et al., Postanalytic and Metacontinental, 2.

${ }^{220}$ See Reynolds et al., Postanalytic and Metacontinental; Vanderbeeken, "A Plea for Agonism Between Analytic and Continental Philosophy."

${ }^{221}$ Barad, "Interview with Karen Barad"; Bryant, "The Ontic Principle"; Kolozova, Cut of the Real.

${ }^{222}$ Campbell, "The Covert Metaphysics of the Clash Between 'Analytic' and 'Continental' Philosophy"; Critchley, "What Is Continental Philosophy?"; Reynolds, "Sadism and Masochism."
} 
the semantic idioms, the methodological approaches, the ongoing discussions, the conferences and publications etc., it is hardly an overstatement to say that both traditions evolve[d] insulated and have a conflicting relation. ${ }^{223}$

Vanderbeeken claims that each paradigm developed divergent concerns and methods because of a lack of input from the other paradigm. I extend this observation to hypothesise how 'epistemic isolation' developed in academia. Epistemic isolation both intensifies the lack of cross-paradigm engagement in academia and works to confine the imagination to each paradigm's parameters when 'thinking otherwise.'

An epistemology is isolated if it is a self-containing explanatory system of knowledge, in which philosophers need only refer to that epistemology in inquiry, requiring little external epistemic input. Isolated epistemologies are shaped to answer most, if not all, epistemic questions on a holistic and totalising basis, exempting the need for external sources. For example, analytic philosophers need only refer to one epistemic narrative to consider themselves in possession with all the assumptions and resources necessary for inquiry.

I claim that an epistemology becomes isolated when its fundamental assumptions are not habitually challenged. Lack of constructive cross-paradigm engagement encourages epistemic isolation without opposing viewpoints, each epistemology can more easily develop into a holistic story that seems to make complete sense internally. ${ }^{224}$ The process of isolation is hence self-reinforcing because holistic epistemic foundations forfeit the need to seek answers outside of the relevant paradigm. The isolation of analytic and continental philosophical paradigms has increased as dialogue has lessened over the late $20^{\text {th }}$ and $21^{\text {st }}$ century, and inversely, cross-paradigm engagement has decreased as epistemic isolation has strengthened. ${ }^{225}$

While philosophical paradigms allow philosophers to deepen inquiry, epistemic isolation leads to a stagnation of ideas. Isolation limits one's ability to 'think otherwise' because it creates the conditions for epistemic circularity and epistemic invulnerability,

\footnotetext{
${ }^{223}$ Vanderbeeken, “A Plea for Agonism Between Analytic and Continental Philosophy," 16.

${ }^{224}$ As Part 3 explains, cross-paradigm engagement usually highlights biases and unchecked epistemic assumptions privileged within each paradigm. See Lather, "Paradigm Proliferation as a Good Thing to Think With.”

${ }^{225}$ Braver states "[b] eginning from different assumptions and methods, the early modern schools grew farther apart as they developed" (Braver, A Thing of This World, 3).
} 
both of which confine methodological and imaginative changes to specific epistemic parameters. Consequently, those parameters confine the political imagination, and with it the possibility for political action. Transcending philosophical limits on 'thinking otherwise' is politically important, as people engage with philosophy specifically because they trust it will help them to 'think otherwise' - as the PfC movement claims. I will discuss the limits of epistemic isolation for 'thinking otherwise' through analysing two conditions it creates, of epistemic circularity and epistemic invulnerability. Yet isolation, circularity, and invulnerability should be understood to have a symbiotic relationship; circularity and invulnerability are a cause, as well as an effect of isolation.

\section{Epistemic Circularity}

This section mounts the first part of a two-fold argument against the limiting effects of epistemic isolation, using the concept of epistemic circularity. ${ }^{226}$ Epistemic circularity denotes the circulation of a similar set of ideas within a single paradigm - ideas that coincide smoothly with the paradigm's epistemic assumptions. Criticisms have been raised by other academics that biases stemming from paradigms' epistemic commitments lead to epistemic circularity. ${ }^{227}$ Kolozova, for instance, is concerned that "the circular movement of thought" leads a paradigm to "[think] itself as the only relevant subject about which to theorize." ${ }^{, 28}$ While existing criticisms specifically address either an analytic or a continental paradigm, I argue that circularity emerges from broader trends of epistemic isolation and can affect any uncommunicative paradigm. Epistemic isolation works to keep the same sorts of ideas circulating within each paradigm because without significant challenges to a paradigm's epistemic assumptions from outside the paradigm, a paradigm's epistemic assumptions remain in place, as well as ideas that stem seamlessly from those assumptions (as can be seen in the isolated state of contemporary philosophy). This is because first, in order to engage in a paradigm's inquiry methods, a philosopher has to accept the epistemic assumptions

\footnotetext{
${ }^{226}$ The work of Matt Macdonald first introduced me to the notion of 'epistemic circularity' in referring to self-justifying evidence sources, although I have taken the term in a different direction. Macdonald, "Epistemic Circularity."

${ }^{227}$ See Laruelle, Philosophy and Non-Philosophy; Kolozova, Cut of the Real; Hutchings, "A Place of Greater Safety? Securing Judgment in International Ethics."

${ }^{228}$ Kolozova, Cut of the Real, 5.
} 
behind the methods. This means that they will be arguably more inclined to think in line with the assumption's bias in inquiry.

For example, 'performativity' is based on the assumption that meaning can be redefined through disrupting the normal ways we treat a societal symbol when we interact with each other. To enact performativity, one must first accept the underlying idea that humans and knowledge are both defined through this kind of relational engagement. ${ }^{229}$ A pre-emptive acceptance of epistemic assumptions makes it more difficult for the philosopher to see the bias present in their philosophising, and the way philosophical methods themselves can only be used to explore ideas that coincide smoothly with their paradigmatic assumptions. Moreover, this effect is exacerbated by the 'holistic' nature of paradigms, which encourage the perception that cross-paradigm engagement is not needed. Circularity hence emerges when philosophical conversations are confined to ideas too easily derived from the assumptions of the relevant paradigm.

Epistemic circularity remains in place because, secondly, it is difficult to question and challenge a paradigm's assumptions from within it. This is because the evaluative standards and critical methods of each paradigm are derived from its core assumptions, asking the philosopher to (once again) pre-emptively accept them. This leaves those assumptions in a place in a manner that is difficult to question, even if philosophers have self-critical intentions. For example, although there is a long tradition of selfcritique in analytic philosophy, ${ }^{230}$ some analytic assumptions are more difficult to question because of 'second-order' circularity. Take the assumption that logic is valid and valuable to inquiry. It is difficult to question this using analytic philosophy's critical methods (for example, deduction, testing justification, conceptual analysis, and so on), because those methods already rely on that assumption. ${ }^{231}$ The attempt at selfcritique would hence undermine its own conclusion because it would destabilise the assumptions that ground the very methods used in self-critique.

\footnotetext{
${ }^{229}$ Butler, Gender Trouble, 179.

${ }^{230}$ Several analytic philosophers discuss the difficulty of justifying fundamental epistemic principles and evidence sources within analytic philosophy. See Chisholm, The Problem of the Criterion; Alston, "Epistemic Circularity."

${ }^{231}$ See Dummett, "The Justification of Deduction"; Haack, "The Justification of Deduction"; Boghossian, "Knowledge of Logic."
} 
Accordingly, inquiry into the validity of the paradigm's core assumptions is difficult for philosophers. Epistemic isolation encourages this kind of 'second-order' circularity by inhibiting methodological exchanges across paradigms. Although internal methodological improvement is possible, the changes made will ultimately remain within the limits set by the paradigm's core assumptions. One can change philosophical methods in a number of ways, but not in ways that sever the analytic reliance on logic or the post-structuralist reliance on the formative power of language. Epistemic circularity hence entrenches biases that influence the way philosophers form political visions by recirculating ideas in a way that is difficult to question.

Again, this is not to say that philosophers completely lack the capacity for self-critique. Philosophers themselves can change ideas, switch between paradigms, receive influences from other parts of life, and so on. Rather, effective self-critique is difficult when philosophers do not engage across paradigms, which is often the norm. Moreover, epistemic self-critique is markedly difficult when applied in contexts like $\mathrm{PfC}$, as I will illustrate in the following chapter, because the introduction of a single paradigm into everyday life forecloses opportunities for cross-paradigm engagement. Epistemic circularity reinforces epistemic isolation because it leaves a paradigm's holistic epistemic world intact.

Epistemic circularity inhibits 'thinking otherwise' in two ways. First, it constrains political imagining within set philosophical parameters, establishing a degree of political tunnel vision. Although each paradigm does support an expansive range of political views, the deep influence of one's philosophical thinking on one's political thinking will favour a particular style of imagining, such as the analytic aspiration towards constructive universality or the post-structuralist inclination towards disruptive fluidity outlined in Part 1. Second, epistemic circularity discourages exploring political ideas that stand in tension with a paradigm's prevailing methods, some of which may help alter how we perceive politics.

Kimberly Hutchings and Katerina Kolozova illustrate how philosophical methods are often ill-equipped to take seriously political ideas that clash with a paradigm's core assumptions, each exploring only one example from the host of conceptual exclusions 
that isolated paradigms sustain. ${ }^{232}$ Using the case of ethical theory to make her argument, Hutchings contends that analytic philosophy's abstract arguments and reliance on thought experiments make it difficult to engage meaningfully with the actual experiences of those suffering from real-world injustice. She argues that thought experiments need only refer to fictional characters to ethically convince the reader. For instance, she points to Peter Singer's argument for poverty relief that uses the abstract story of a drowning child to make a case for poverty relief, discouraging the reader from considering real experiences and wants of poverty-stricken people. ${ }^{233}$ Although a philosopher can use both thought experiments and real examples, an overreliance on the former suggests that the latter (actual emotional experience) is unnecessary. Hutchings shows how thought experiments leave analytic ethical theory in an inadequate position to learn from the valuable moral insights of those suffering from injustice. She upholds that opening philosophy to the input of the oppressed may challenge the use of abstraction, reasoning and an excessive focus on sterile reliability. Yet through methods like thought experiments, analytic philosophers can avoid engaging in embodied emotional experiences and ways of thinking about politics that may throw their reliance on reason into question, contributing to epistemic circularity. For her, this "smuggl[es] in contextual biases"234 when using philosophy to think about politics.

Similarly, Kolozova illustrates how the post-structuralist idea that objective reality is unknowable makes it difficult to engage in politics in a universal manner. Kolozova claims that the post-structuralist emphasis on linguistic thought ("discursive constructs that fully determine thinking and are methodologically accounted for all the way down," ${ }^{, 35}$ ) equates attempts at generalisation "with totality, totalitarianism, and imperialistic universalism," declaring such attempts to be "reactionary."236 For

\footnotetext{
${ }^{232}$ Kolozova, Cut of the Real; Hutchings, "A Place of Greater Safety? Securing Judgment in International Ethics." To broaden the scope of Hutchings and Kolozova's arguments, commitment to analytic methods makes it difficult to explore political ideas in a range of ways, such as emotional, unjustified, irrational, contingent, and context-variant and difficult to approach politics through a fluid and contingent lens; while commitment to poststructuralist methods makes it difficult to explore a range of political ideas, such as in a way that is fixed, unified, justified, rational and seeking truth, and difficult to approach politics through a universal, institutional or rational lens.

${ }^{233}$ Hutchings, “A Place of Greater Safety? Securing Judgment in International Ethics,” 30.

${ }^{234}$ Ibid., 31.

${ }^{235}$ Kolozova, Cut of the Real, 2.

${ }^{236}$ Ibid., 7.
} 
Kolozova, the drive to include marginalised voices through the endless chain of signification leads to a political orientation that "always already excludes the possibility of conceiving of new forms of universalism that do not have to be totalitarian." 237 If post-structuralist methods are "as always already multiple, as always already non-fixed and fluctuating" then there is no room for "the one (unity and continuity), and the stable." ${ }^{238}$ She writes:

[T] he deconstructive promise of a never-ending textual and discursive (inter)play and the optimism of an unrestrained transformability of identity and freedom implied by the Foucauldian legacy... gives rise to the... impossibility of producing discourse about certain instances, such as the one, the real, the stable, and so on. ${ }^{239}$

For Kolozova, this ongoing textual dance rules out the possibility of a universal, which requires at least some degree of fixity and stability. Yet, she claims that thinking about universal visions is important to 'thinking otherwise' because it is the precondition for radical political transformation against global challenges, such as neoliberalism. ${ }^{240}$

As with analytic philosophy, the post-structuralist ineptitude to engage in ideas that contradict paradigmatic assumptions limits its growth because it excludes ideas that may throw it into question. For example, Kolozova thinks that if the philosopher never tries to capture the objective, or strive for the universal, she loses the ability to be "deeply surprise[d]" by political realities that contradict linguistic ideals (in the same way reality surprises the scientist). ${ }^{241}$ This leaves philosophy paralysed in addressing reality, caught in a linguistic loop of "narcissistic self-sufficiency" 242 where what exists outside particular individual or communal interests (for example, the fight for a universal) cannot disrupt that loop. A fixation on the linguistic and an aversion towards the universal, Kolozova argues, has outstripped "the desire of philosophy and social theory of its core ambition - namely, the "reinvention of worlds." ${ }^{243}$ Similarly, if the epistemic assumptions of a paradigm's inquiry methods are in a difficult position to question, the marginalisation of parts of the political solidifies. Methodological

\footnotetext{
${ }^{237}$ Ibid., 8.

${ }^{238}$ Ibid., from the blurb.

${ }^{239}$ Kolozova, Cut of the Real, 16.

${ }^{240}$ Kolozova, Toward a Radical Metaphysics of Socialism.

${ }^{241}$ Kolozova, Cut of the Real, 3.

242 Ibid.

${ }^{243}$ Ibid., 1.
} 
aversion towards those parts further reinforces epistemic circularity, by discouraging exploration of political ideas that may challenge the assumptions of the relevant paradigm.

Therefore, by making it difficult to question a paradigm's core assumptions, epistemic isolation encourages the circular movement of thought: a self-reinforcing process that leaves biases within an impervious realm in a way that stagnates 'thinking otherwise'. Not only do philosophical methods circulate the same sorts of ideas within paradigms, many valuable political ideas are pre-emptively foreclosed to those paradigms. ${ }^{244}$ Using Karen Barad's words, "the epistemological gets bounced back and forth, but nothing more is seen." ${ }^{245}$ As will become clearer in Chapter 4, this may be problematic for children whose ideas do not fit smoothly into prevailing epistemologies. Because of epistemic circularity, I suggest we should be critical of introducing philosophy to everyday life through one paradigm alone.

\section{Epistemic Invulnerability}

Epistemic isolation limits 'thinking otherwise' in a second way because it contributes to 'epistemic invulnerability', further confining the imagination within set parameters. An epistemically invulnerable idea is one actively and intentionally held in such a way that its epistemic assumptions are sheltered from being transformed by the influence of others (unlike circularity that shelters ideas in a structural and passive way). ${ }^{246}$ Although we can never fully shelter our ideas from external influences, we can hold them in a way that discourages challenges to their foundations. For instance, if we present our philosophical ideas with certainty - static, closed, and complete (rather than dynamic and revisable) - we are less receptive to contributions that unsettle their foundational assumptions than if we consider them open and revisable. Seeking invulnerability is not about avoiding having one's ideas questioned and critiqued, but about protecting the deep foundations of one's epistemic assumptions from transformation that would disrupt one's sense of self and worldview.

\footnotetext{
${ }^{244}$ Hutchings, "A Place of Greater Safety? Securing Judgment in International Ethics."

${ }^{245}$ Barad, Meeting the Universe Halfway, 135.

${ }^{246}$ Gilson, "Vulnerability, Ignorance, and Oppression."
} 
Philosophers tend to hold their ideas 'invulnerably' because philosophical norms present invulnerable ideas as more trustworthy and worth listening to. Erinn Gilson argues that in Western capitalist societies, vulnerability is usually perceived as a sign of weakness - a susceptibility to hurt or manipulation - so portraying oneself as invulnerable is the only way to appear "strong and competent." ${ }^{\text {"247 }}$ Accordingly, philosophical norms present invulnerable subjectivity as desirable. "If I demonstrate that I am in control," she explains, "then I get taken seriously." 248 Hutchings confirms, similarly, that invulnerability is sought after in academia because invulnerable judgments are considered credible: "[w] ithin this tradition of thought, authority and invulnerability become bound together - the judgments you can trust are the judgments that are safe from the literal and metaphorical knives of the world. ${ }^{249}$ In order for their opinions to be heard and considered valuable, philosophers have to present their ideas in a manner that resists fundamental transformation.

It follows that the desire for invulnerability was not produced by epistemic isolation. In fact the desire for epistemic invulnerability likely encourages epistemic isolation. Holding one's ideas in a manner that discourages external contribution exacerbates the lack of constructive dialogue between paradigms because of the need to protect one's ideas from fundamental transformation. Yet inversely, epistemic isolation also deepens epistemic invulnerability by providing one's ideas with comfort and apparent certainty. While there are different techniques philosophers use to protect their ideas from being uncontrollably transformed, ${ }^{250}$ I suggest that one way is through adherence to single paradigms. Adherence to a paradigm lessens the vulnerability of philosophical ideas because one's ideas seem more correct when they fit into a paradigmatic framework. Although placing one's ideas against the backdrop of a paradigm does not shelter all philosophical ideas from critique, it is difficult to fundamentally undermine their epistemic foundations without challenging the entire paradigm. Because paradigms come with histories and arrays of supporting arguments, this is a highly burdensome task.

\footnotetext{
${ }^{247}$ Ibid., 314.

${ }^{248}$ Ibid.

${ }^{249}$ Hutchings, "A Place of Greater Safety? Securing Judgment in International Ethics,” 25.

${ }^{250}$ Ibid.
} 
Hence, the norms of invulnerability keep one's epistemic assumptions in place because those assumptions are so difficult to question within the protected sanctuary of a paradigm, both for members of, and outsiders to, the paradigm. François Laruelle calls this 'coherence.' Coherence dislodges the opportunity for rigorous theoretical confrontation and transformation because it makes ideas seem causally correct. Although ideas themselves may be open to critique, their epistemic foundations are not. For instance, the post-structuralist notion of 'resignification' (which allows philosophers to disrupt and shift societal meanings and signs) makes sense against the coherent conceptual backdrop of the post-structuralist paradigm. Resignification, however, loses stability when removed from that context, raising questions that disrupt its soundness (against another backdrop, does 'resignification' make sense?). Sheltering thoughts within a paradigm makes it difficult for people outside of the paradigm to question the fundamental assumptions of the paradigm because of the coherence that a paradigm provides. But also from within the paradigm, a philosopher sees her ideas as correct amongst a web of correlative ideas. Laruelle argues, "[n]o philosophy can suspend the validity of its rule, which appears 'natural' to the philosopher in the same way that harmony and tonality appear natural to the classical musician." ${ }^{251}$ Coherence "impregnate[s] philosophical decision in the last instance continue to guarantee its cohesion and its ultimate coherence, essentially leaving philosophy to be the master of itself." 252

The norms that favour epistemic invulnerability hence contribute to epistemic isolation by encouraging philosophers to place their ideas in paradigms that provide them with coherence (correlative security). And conversely, epistemic isolation furthers one's desire for invulnerability by discouraging philosophers from holding ideas in an open way. Epistemic invulnerability is therefore both a cause and an effect of epistemic isolation. Of course, this is not to say that all philosophers tend towards invulnerability. Rather, I am trying to capture the systemic means by which epistemic isolation encourages invulnerability - tendencies that limit 'thinking otherwise'.

By silently pressuring philosophers to ground their thinking in a particular narrative, epistemic invulnerability tends to hide the biases in one's assumptions, especially when

\footnotetext{
${ }^{251}$ Laruelle, Philosophy and Non-Philosophy, 7.

${ }^{252}$ Ibid., 6.
} 
grounding them in a paradigm makes them seem coherent. It discourages moving beyond core assumptions because it works to bury them, rather than opening them up to transformation. Therefore, trying to expand one's political imagination through an isolated philosophical paradigm limits the project of 'thinking otherwise' because it makes it difficult to even become aware of, and break from, the political influence the paradigm's assumptions have over one's imagining.

The norms of invulnerability also keep epistemic assumptions in place because privileging invulnerability excludes the philosophical 'non-expert' - those who do not ground their ideas in a particular epistemic narrative. We can contrast 'epistemically invulnerable' ideas to those held with an openness that invites profoundly unsettling transformation. Epistemic openness requires the philosopher to hold ideas more tentatively, in an ungrounded or uncertain manner that invites collaborative input and involves a willingness to shift one's sense of self in light of that input. Holding ideas openly requires more "ambivalent" characteristics such as "passivity, affectivity, openness to change, dispossession, and exposure"253 and involves partially relinquishing control of one's ideas. ${ }^{254}$ Because one's epistemic commitments are closely tied to one's sense of self, ${ }^{255}$ epistemic openness also encourages shifting one's sense of self through philosophical engagement that might fundamentally alter one's beliefs about the world. Holding ideas in this manner helps one 'think otherwise' philosophically because it allows the input of others to transform one's ideas in unpredictable ways.

Because invulnerability is favoured in philosophy, philosophers fail to take epistemically ungrounded, open, and incomplete ideas seriously, or to consider the input of people who explore philosophy without seeking secure grounds (common to many children). ${ }^{256}$ Long insists that norms of invulnerability therefore work to keep

\footnotetext{
${ }^{253}$ Gilson, "Vulnerability, Ignorance, and Oppression," 310.

${ }^{254}$ Hutchings, “A Place of Greater Safety? Securing Judgment in International Ethics,” 25.

${ }^{255}$ Gilson explains that especially in Western societies our sense of self is deeply bound to the way we epistemologically order and understand the world. She argues we are fixated on a mastery of our mind and knowing the world, so our sense of self becomes bound to the way we think we can know the world. Hence when our way of accessing and measuring the world (our accepted epistemic story) is thrown into question, so too is our sense of self. Gilson, "Vulnerability, Ignorance, and Oppression," 317.

${ }^{256}$ Hutchings, “A Place of Greater Safety? Securing Judgment in International Ethics,” 35; Long, "Thomas Reid and Philosophy with Children."
} 
conversations confined to the invulnerable philosopher. She claims that if we conceive of philosophy as "a regional inquiry par excellence" then we "effectively confine it to... a set of experts who then play some kind of gatekeeping role for philosophy, deciding who should be admitted and who should not." ${ }^{257}$ This maintains each paradigm's epistemic biases and dominant argument forms. ${ }^{258}$ The desire for invulnerability accordingly contributes to epistemic circularity: it works to exclude epistemically ungrounded ideas and it discourages constructive cross-paradigm engagement, discouraging ideas that disrupt epistemic privileging. Integrating habits of invulnerability to everyday settings translates philosophical standards of what ideas are considered worthwhile, and accordingly who is worthy of contribution (those who can ground their thinking in existing epistemic narratives). Again, this contributes to the possibility of political tunnel vision and is inopportune for 'thinking otherwise' because it mutes the philosophical potential of ungrounded, open and non-traditional ideas.

\section{The Limiting Effects of Epistemic Isolation}

Philosophising through isolated paradigms has politically limiting effects. One implication of epistemic isolation is that the political influence of a single philosophical approach becomes solidified. Many argue that stagnation and circulation of thought is unfavourable to philosophy's ability to help people respond innovatively to new societal challenges. For example, Levi Bryant, Nick Srnicek, and Graham Harman write that: "there is a growing sense that previous philosophies are incapable of confronting [current societal] events," 259 alleging that the stagnation of academic thought "actively limits the capacities of philosophy in our time" 260 by keeping a limited set of political responses in place. On the one hand, the political attitudes that derive from post-structuralist thought, emphasising "issues [such] as death and finitude, an aversion to science, a focus on language, culture, and subjectivity" is insufficient because it comes at "the detriment of material factors," 261 which need to be grappled with in response to current crises. Ecological disasters and new challenges

\footnotetext{
${ }^{257}$ Long, "Thomas Reid and Philosophy with Children," 600.

${ }^{258}$ Also see Hutchings, "A Place of Greater Safety? Securing Judgment in International Ethics."

${ }^{259}$ Bryant, Srnicek, and Harman, The Speculative Turn, 3.

${ }^{260}$ Ibid.

${ }^{261}$ Ibid., 4.
} 
arising from technological, virtual, and biotechnical innovations, they assert, require a radical rethinking of our objective, material world in a fashion post-structuralism is illequipped for. On the other hand, analytic philosophy's "dogmatic belief in the powers of reason" 262 has led to political visions that are too exclusive to build constructive platforms that make space for our interconnected global world. Both, they conclude, result in inept political responses through the circular entrapment of visions, which is problematic in a time when scientific and technological advances provide opportunities to live in radically different ways.

Furthermore, Gillian Rose (whose work will be discussed at length in Part 3) explains that focusing on only one part of the political realm, even if that focus is broad, creates a less politically responsive and transformative philosophical approach. This is because philosophical visions that focus on just one part of the political only have to answer to parts of the political that match that vision. For example, because poststructuralist visions render the search for the universal irrelevant, post-structuralist philosophising need not respond to the difficulties of seeking a universal. Rose argues that this separation of isolated ideas from aspects of the political results in a kind of passivity from both sides of philosophy - a "passivity beyond passivity"263 - where commitment to universal or particular ideals need not be sacrificed in the face of reality. Rose argues that both philosophical branches cherish "inflexible abstraction" 264 that holds steady a picture of how the political world should look, which lessens philosophy's transformative power.

The exclusions produced by 'thinking otherwise' in an epistemically isolated manner are also limiting. First, excluding people and ideas from political visions weakens our ability to picture and build a radically different worlds because it "narrows the repertoire of moral and empirical truths on which normative theories of world politics might be built." ${ }^{265}$ Second, constructing political visions through an epistemic world that cannot hear contradictory ideas (from a closed epistemic network of people like-

\footnotetext{
${ }^{262}$ Ibid., 3.

${ }^{263}$ Rose, Mourning Becomes the Law, 37.

${ }^{264}$ Rose, Judaism and Modernity, 9.

${ }^{265}$ Hutchings, “A Place of Greater Safety? Securing Judgment in International Ethics,” 36.
} 
minded in values) solidifies an "us/them relation," 266 which makes it difficult to see the effects one's philosophical vision has on those it renders 'Other.'

Without having to face those parts of the political that clash with their visions, philosophers excuse themselves all too easily from considering how their ideas may evade important parts of politics, or exclude people, placing philosophy "beyond the world of being and politics"267 where it is "held in a transcendence far off the ground." ${ }^{268}$ Failing to engage in actualities or understand how structural injustice occurs "ruins the possibility of political action" 269 for Rose because it "disallows itself any conceptuality or means of comprehension for investigating its own implications"270 in the maintenance of exclusive political structures, forfeiting the need to transform either politics or philosophy in light of those exclusions.

Elizabeth Anderson presents a case that such closed epistemic and political networks/bubbles makes the community vulnerable to extreme beliefs through the circulation of an unchallengeable consensus that increases confidence in beliefs within the network, and increases mistrust in political views that challenge their accepted beliefs. She describes how confidence in beliefs are egged on in closed communities, where they often become more extreme and more solidified, opening the possibility for more extreme political action and polarization between the in-group and an out-group that disagrees. If philosophy is engaged in everyday life through one or the other of the dominant paradigms, the consequent bubbled way of approaching politics threatens to create a dualistic, polarised and uncommunicative way of approaching politics.

While the limits of epistemic isolation affect academic philosophers who adhere to single paradigms, academic philosophers can unsettle those limits, especially by constructively engaging with other philosophical perspectives. Although it partly derives from norms of epistemic invulnerability, strict paradigm-adherence in academia should be seen as an act of 'willing ignorance' because academics have easy access to engagement with other paradigms (as Gilson puts it, "an ignorance that... is

\footnotetext{
${ }^{266}$ Mouffe, Agonistics, 5.

${ }^{267}$ Rose, Mourning Becomes the Law, 38.

${ }^{268}$ Ibid., 7.

${ }^{269}$ Ibid., 26.

${ }^{270}$ Rose, The Broken Middle, xii.
} 
maintained because it appears to be in one's interests to remain ignorant"271). However, as mentioned, the limits of epistemic isolation are more difficult to break from in nonacademic contexts. The following chapter shows how reproducing epistemic isolation in an everyday setting like PfC creates the conditions for political tunnel vision.

${ }^{271}$ Gilson, "Vulnerability, Ignorance, and Oppression," 313. Also see Tuana, "The Speculum of Ignorance." 


\section{Chapter 4 - The Presence of Epistemic Isolation in PfC}

I argue that analytic and post-structuralist pedagogies create the condition for epistemic circularity and epistemic invulnerability in PfC, and that this, in turn, limits children's ability to 'think otherwise' through philosophy. Without cross-paradigmatic engagement in the classroom it can be difficult for students to develop the epistemic self-awareness necessary for challenging the core paradigmatic assumptions that influence their imagining. Although either paradigm can help students envision a radically different politics, confining the imagination to either rational or disruptive methods reduces children's potential for imagining in unfamiliar ways. This not only limits the extent to which philosophy can help children radically envision different worlds, it encourages an exclusive way of thinking about politics and lends to a sense of political certainty.

Before beginning, I want to emphasise that this chapter does not argue for abandoning first- or second-generation PfC methods. Both help children to 'think otherwise'. Instead, it aims to sound out their limitations in order to present a case for the importance of giving children a chance to experience both - to invite children to transform philosophical methods beyond their epistemic assumptions.

\section{Analytic Circularity in PfC}

I first maintain that assuming the validity of either analytic or post-structuralist epistemic ideas in order to participate in PfC makes it difficult for students to question each pedagogy's values and methods beyond its initial assumptions, forming circular thinking in the classroom. I begin this chapter by examining 'circularity' within the analytic CPI. I propose that by guiding the CPI with analytic methods (for example, deduction, seeking justified reasoning, thought experiments, conceptual clarification, counter-examples), the first-generation contributes to epistemic circularity in the classroom. As a prerequisite for using those methods, students need to assume the validity of logic, seek an accurate and reliable view of the world, agree that knowledge aims at truth, and so on. This will incline them towards ideas that smoothly derive from these assumptions. This pre-emptive acceptance for participation in a CPI both works to confine a student's imagination to rational parameters and closes non-rational realms of thought as significant places of meaning-making. 
Let's take one method that helps guide students to reasonable thinking in a CPI to show how analytic methods ask students to accept analytic assumptions. Deduction is a type of logical reasoning that allows one to derive a conclusion from premises in a way that guarantees that the conclusion is true if the premises are. According to the laws of logic, it is impossible for the conclusion of a valid argument to be false if its premises are true. The basic patterns of valid reasoning are captured by syllogisms, such as modus ponens, which has the following structure: i) If $\mathrm{P}$ then $\mathrm{Q}$, ii) $\mathrm{P}$, iii) therefore, $\mathrm{Q} .{ }^{272}$ Yet in order to use deduction, one must assume that syllogisms accurately represent reality and that logic allows ones to reliably describe it. Because deduction is a system of logic, it cannot work without these assumptions - rejecting them would lead to deriving either false answers or no answers at all. In this manner, when children use deduction to guide their discussions, they have to accept those assumptions. The same verdict applies to other analytic methods (for example, justification, thought experiment, conceptual clarification, and so on). Hence, students must endorse the rules of logic and similar assumptions in order to participate properly in an analytic CPI.

This is problematic because analytic methods subtly guide each CPI discussion to broadly align with those assumptions, directing the conversation in advance. This is because, as argued in Chapter 3, philosophical methods work to reach conclusions that can be derived from the assumptions of their own paradigm (conclusions that are reliable, that accurately mirror the world, that are clear, that are rational, that are justified and so on). In short, the first-generation programme sets the acceptance of analytic assumptions as a precondition for 'thinking otherwise'.

Yet the first-generation programme overall is based on a slightly different set of assumptions than that of analytic philosophy: its pragmatic assumptions also encourage unsettling circularity. Recall that the first-generation encourages constant critical evaluation and revision of the inquiry process, intended to allow students to critique and revise the programme. Critical self-evaluation is often emphasised by firstgeneration PfC theorists in response to criticisms about 'indoctrinating' children through reason. In response to these criticisms, for instance, Maughn Gregory emphasises the first-generation's chief commitment to fallibilism and the search for

\footnotetext{
${ }^{272}$ Steup, "Epistemology." Phil Cam provides a PfC example of a deductive argument: "No furry creatures are things that can fly. If all rabbits are furry creatures then they can't fly. They are, in fact, furry creatures and so cannot fly" (Cam, 20 Thinking Tools, 95).
} 
meaning, with only a looser commitment to the programme's value-content and analytic methods: a "secondary commitment... to the methods we've evolved for [seeking meaning] including analytic thinking." ${ }^{273}$ Gregory points to the critical "hammers" 274 provided in the first-generation programme to help children reshape its philosophical content and methods, as well as its ceaseless encouragement to deconstruct and re-construct the programme. Like other first-generation theorists, he considers it difficult to politically indoctrinate students when they are given the ability to transform what they are afforded. ${ }^{275}$

However, basing standards of good judgement and criticism on analytic philosophy sits in tension with the programme's fallibilist underpinnings, because it makes it difficult for students to question analytic assumptions. The standards of evaluation maintained in PfC encourage measuring it against analytic standards of 'good judgement' that favour reliability, logical consistency and objectivity. Splitter and Sharp, for example, claim that PfC's evaluative components "protect the community from lapsing into dogmatism or intellectual complacency. ${ }^{, 276}$ At the same time, however, they claim that this evaluative process should be driven by a desire to improve the CPI, where improvement "involves a search for more and more reliable criteria so that one's judgements can rest upon a firm and solid foundation." ${ }^{277}$ Here adjustment of the programme's methods and ideas are considered worthwhile only if they enable students to think more reasonably. ${ }^{278}$ This raises the question of how open the evaluative process is if it is intended by its makers to further sharpen processes of reasoning. In short, can it really be used to question its own foundations? It is more likely that this evaluation process reinforces the programme's (and children's) alliance to reason and consistency.

While first-generation PfC theorists claim that the programme provides "hammers" to transform its inquiry methods, the methods used in self-critique are the same methods that guide the CPI in general (deduction, counter-examples, and so on). Hence, it would be difficult for children to question analytic epistemic assumptions because, again,

\footnotetext{
${ }^{273}$ Gregory, "Philosophy for Children and Its Critics," 207.

${ }^{274}$ Ibid., 209.

${ }^{275}$ Splitter and Sharp, Teaching for Better Thinking.

${ }^{276}$ Ibid., 92.

${ }^{277}$ Ibid., 16.

278 Ibid., 56.
} 
students have to accept these in order to use the methods themselves. Although students are able to shift the classroom programme, change probably remains within the parameters of rational thought, reinforcing analytic assumptions rather than enabling children to question them. As these assumptions involve a bias that favours exploring some rational ideas over others, the first-generation programme confines children's imagination to particular epistemic parameters in a manner difficult to consciously question. It is unclear how this higher-order thinking allows students to "step out" of that epistemic world.

It is hence more problematic than first-generation theorists initially assume to claim that children can reconstruct the analytic programme with the programme's resources and break from epistemic circularity. The ability to look past epistemic assumptions is especially important for a movement that aims to encourage future generations to think past our existing worlds. If students primarily form political visions through the rational methods of PfC, biases towards 'universalised' thinking are likely to become ingrained over time, embedding circularity in their political imaginations without the resources to sufficiently question it. It also enshrines reason as an unassailable standard - which has been seen in the past to have negative political effects for those seen as 'unreasonable. ${ }^{280}$ I hold that in order for a programme to be effectively evaluable, its evaluative standards and methods for self-critique should arrive from a different paradigm.

At the same time, using analytic methods in a CPI limits 'thinking otherwise' by making it difficult for students to engage with ideas that clash with those assumptions (for instance, non-rational and unreliable ideas) in a manner that extends past scrutiny or investigation. Unreliable states (like feeling, dreaming, inventing, intuiting, magical thinking; thinking in "ambiguous, mysterious, macabre, gruesome or fantastical"281 terms) are excluded from consideration because they dislocate accurate reasoning.

\footnotetext{
${ }^{279}$ Murris asks a similar question in reference to the philosophical novels: "Can the particular selection of philosophers, philosophical themes, problems and answers to these problems, by the authors of these texts itself become the focus of enquiries?" (Murris, "The Philosophy for Children Curriculum," 72-73).

${ }^{280}$ Adorno and Horkheimer, Dialectic of Enlightenment.

${ }^{281}$ Murris, The Posthuman Child, 208.
} 
Take the process of justification, for example. Traditionally, analytic justification requires reliability, pre-emptively undermining unreliable ways of thinking. ${ }^{282}$ Not only must one's belief be reliable (one's belief must derive from facts through a reliable process, such as inference from evidence), one must use reliable sources in a reliable mindset. ${ }^{283}$ Unreliable states or sources are not considered because they lead to faulty reasoning. Many (non-PfC) analytic theorists have emphasised that intuition and emotion (so-called 'fast' cognitive processes) are not reliable enough to provide justification, pointing to the fact that inquirers frequently correct themselves when they reconsider intuitive or emotive beliefs in a more removed, objective and 'slow' manner. ${ }^{284}$ If using the concept of justification requires the inquirer to endorse the value of reliability, then a reliance on justification in a CPI rules out unreliable ways of thinking. Analytic methods accordingly distance philosophy from many unique and creative aspects of children's theorising - ideas that rarely fit smoothly with the analytic push to justify ideas reliably.

But sometimes those ideas are useful for imagining different worlds and are useful for helping students think beyond traditional rational parameters. Theorists in PfC have identified some ways non-rational ideas can be useful to children's philosophical exploration and political thinking. Haynes and Murris, for example, concerned with the way a focus on logic "tend[s] to close off the realm of magical thinking as a place of meaningful human exploration,"285 explain that non-rational, magical realms of thought are often helpful to children's political visions because they are more creative and unpredictable - irrational and magical ways of thinking are unconstrained by the need to make sense. This unexpected character holds the potential to counteract the rational status quo: "realms of fantasy, magical thinking and anthropomorphism"286 can raise questions for everyday authority, meaning that engaging in non-rational realms of thought may allow students to question rational thinking if they choose to. Barbara Weber claims that emotional thinking is also important in a CPI because it allows

\footnotetext{
${ }^{282}$ Steup, "Epistemology."

${ }^{283}$ Paxton, Ungar, and Greene, "Reflection and Reasoning in Moral Judgment"; Paxton, Bruni, and Greene, “Are 'Counter-Intuitive' Deontological Judgments Really Counter-Intuitive?”

${ }^{284}$ Ibid.

${ }^{285}$ Haynes and Murris, "The Realm of Meaning," 1085.

${ }^{286}$ Ibid.
} 
children to explore "a more complex and holistic understanding of being human.,"287 She writes that emotional thinking "reveals a horizon of existential questions that cannot be answered solely by reason."288 Politically speaking, Weber argues that attentiveness to the "cultivation of sensations, emotions"289 leads to a politics that is sensitive and sympathetic and can bestow a different nature upon reason. Weber argues that asking a child to alter their thinking pattern through a rational pedagogy alone encourages them to adopt a one-sided political mind: it will "reduce humanity to a 'disembodied head' that is able to speak and to apply reason, but is disconnected from any emotional or sensuous aspects." 290

Returning to Glaser's PfC sessions as a thought experiment, for example, if political answers are sought through reason/rational thinking tools, it might skip over important emotional processes needed for Arabs and Israelis to move forward. For example, there is much evidence to suggest that opening oneself emotionally to wounds of the past is essential to moving forward. ${ }^{291}$ Yet as illustrated, emotional ideas are pre-emptively considered, by analytic methods, too irrational and unreliable to build knowledge and political futures on. Therefore using rational philosophy in this way may confine political response to similar and sometimes unsuitable parameters. I must stress that I am not by any means claiming that Glaser's sessions omit emotions from exploration - I am merely presenting a hypothetical case to help the reader understand, in more concrete terms, the politically problematic impact of overreliance on reason in using analytic methods of inquiry. If philosophy is always engaged with in CPIs through analytic philosophy, in a manner that is difficult to question, political responses developed in a CPI will remain confined to answers that privilege reliability and forward-looking solutions - solutions that mirror current trends of political response.

Therefore, I argue that analytic CPI methods potentially exclude some non-rational political ideas, inhibiting the exploration of ideas that challenge analytic principles. This limits 'thinking otherwise' by preventing valuable ideas from being explored indepth (ideas that may be valuable to societal reimagining) and contributes to political

\footnotetext{
${ }^{287}$ Weber, "Childhood, Philosophy and Play," 239.

288 Ibid.

${ }^{289}$ Ibid., 245.

${ }^{290}$ Ibid., 238.

${ }^{291}$ Edkins, Trauma and the Memory of Politics.
} 
tunnel vision and conceptual exclusion in a manner that is difficult for children to be aware of.

\section{Continental Circularity in PfC}

I propose that basing second-generation suggestions on post-structuralism also encourages circularity in the classroom. There are several assumptions that students must endorse to participate in second-generation CPI: for instance, that humans are relationally composed, that hierarchies are formed through our interactions, that knowledge should be kept fluid, and so on. Let's look more carefully at the assumption that we are relationally composed. I argue that students would have difficulty engaging properly in a CPI that emphasises concepts like 'ethical exposure' or 'synthesis' unless they assume, in Vansieleghem's words, that “[w]e only exist in relation to the other and how we are positioned with regard to the other is always different and always more." 292 Through exposure, students come to understand our relationality - that we are always already 'Other': "a centre, a not centre and the relation between,"293 an understanding premised on the assumption that we are changed through our interaction with the 'Other'. Without assuming that we are relationally composed, it is difficult to fully open one's sense of self to transformation by another, because this very act involves opening oneself to being composed by another. Vansieleghem clarifies that there is a distinction between listening and exposure, where listening is the attempt to understand what someone says - "like to an audience"294 - while ethical exposure involves listening in a way that opens one's sense of self, "experiencing the other in me. ${ }^{295}$ If a student does not accept that we are relational, they will merely be listening rather than exposing. Although the listening student can at some level engage in a CPI of exposure, they will not properly be engaging in the philosophical practice of exposure (which involves assuming relationality).

\footnotetext{
${ }^{292}$ Vansieleghem, "Listening to Dialogue," 186.

${ }^{293}$ Ibid.

${ }^{294}$ Ibid., 188.

${ }^{295}$ Ibid.
} 
To provide another example, some second-generation suggestions also invite students to assume that knowledge should be kept in a fluid form. This is because secondgeneration methods usually involve a twofold process of disrupting what is settled ("a kind of radical affectivity, in that our truths and fixed points are disturbed, problematized, questioned"296) and actively averting fixed conclusions. For example, Kennedy's rhizomatic CPI actively resists totality and categorisation - it asks students to consciously unsettle the web of concepts that guide our world. He explains that "in opposition to totality" the rhizomatic CPI "calls infinity." ${ }^{297}$ By dissecting the fixed genealogies that define each concept, students are expected to continuously uproot closed definitions. While the rhizomatic CPI does redefine the web of concepts along different lines: students are invited to forever "[hold] those distinctions in loose and provisional 'assemblages'." 298 But without accepting the value of fluidity, one cannot properly partake in this kind of genealogical deconstruction because its very aim is to unsettle what has become settled. If one assumes that fixed knowledge is desirable and reconstruct concepts in a fixed form (as with conceptual clarification), one would be defeating the purpose of the rhizome by reattaching concepts to fixed definitions and hierarchies, and would therefore no longer be participating in the rhizomatic project. Although Kennedy's rhizomatic CPI invites children to reconstruct concepts along different lines, those lines remain fluid, floating on the edge of continuous renewal.

Ethical exposure also implies that knowledge should be held as loosely as possible. A CPI of exposure is left open to interpretation rather than ending in a consensus, "to symbolise its temporary and brief character." 299 Children may unconsciously accept a commitment to fluidity because knowledge held in this kind of CPI never tries to synthesise opinion or deliver a definitive answer - meaning is always multiple, shifting, and never graspable. Ethical exposure purposefully draws open the impossible gap between what is said and what is interpreted, asking students to float in this limbo. Without accepting fluidity, a student would be going against the aim of ethical exposure, where knowledge remains "alien.",300

\footnotetext{
${ }^{296}$ Kohan, Childhood, Education and Philosophy, 64.

${ }^{297}$ Kennedy, "Rhizomatic Curriculum Development in Community of Philosophical Inquiry," 4. 298 Ibid.

${ }^{299}$ Vansieleghem, “Listening to Dialogue,” 188.

${ }^{300}$ Vansieleghem, "Philosophy for Children as the Wind of Thinking," 31.
} 
These kinds of assumptions are difficult to question from within their own pedagogy. Returning to the example of ethical exposure, Biesta warns against developing collective ideas for fear that collective distinctions may exclude some students. ${ }^{301}$ The CPI is guided by some collective principles, primarily those of acknowledging difference and an ethics of love. Yet without the chance to develop their own collective principles in light of the aversion to fixity, children will have a hard time questioning and altering the programme beyond its core assumptions, because there is little else besides the overarching principles of fluidity and relationality to measure the programme against. The problem of leaving collective conclusions behind is that it "forecloses any perception or judgment that inclusive political promises may presuppose and... destroys the possibility of critique." ${ }^{302}$

Furthermore, as with the analytic programme, it would be difficult for students to move beyond a programme's core assumptions while needing to endorse them. For example, it is difficult for children to question the value of ethical listening from the position of an ethical listener. Ethical exposure asks the philosopher to pre-emptively accept the validity of relationality and disruption in a way that undermines the possibility of rational and autonomous thought/dialogue needed to question the validity of relationality, and therefore to question the authority of ethical listening. To do so, one would have to step outside the CPI of exposure. Again, this pedagogy fails to provide children with the resources to become aware of the influence of post-structuralism over their philosophising, and the ability to move beyond it.

I argue that the influence of post-structuralism is also limiting for children's capacity to radically reinventing our world, because its core assumptions clash with political ideas that may be useful to 'thinking otherwise.' These include ideas that have fixed definitions, ideas which make claims to objectivity or truth, ideas which are universal in scope, and ideas which assume a more expansive understanding of autonomy. Vansieleghem (among others) holds that the proliferation of possible interpretations is prevented if a conclusion is reached. Yet keeping the CPI open to reinterpretation comes at the expense of fixed knowledge. It is difficult to establish fixed collective

\footnotetext{
${ }^{301}$ Biesta, "Philosophy, Exposure, and Children."

${ }^{302}$ Rose, Judaism and Modernity, 73.
} 
conclusions in a pedagogy that prioritises disruption and fluidity that 'cuts', 'breaks', and 'exposes'. 303

Rossario del Collado, for example, argues that second-generation methods exclude possibilities for solidarity and universality because students are not given the chance to work together towards a conjoined political future. Yet he claims that solidarity and collective decision-making are important for political change because they are conditions for feasibly challenging the status quo, including fighting injustice and oppression. He proclaims that without seeking conclusions, children will learn to mistrust a crucial part of politics - building solidarity and making collective decisions. As he claims, "[t]he postmodernist emphasis on novelty, uniqueness, heterogeneity and radical otherness - the categorical mistrust of the collective and the normative- seems to me like a dangerous (and typically capitalist) distraction from political struggle and solidarity." ${ }^{304}$ Sharp also contends that the search for collective and stable (although fallibilistic) truth is important for politics because it gives children something to measure their actions and ideas against. She asserts that "scepticism alone does not give us a method for deciding what to believe or how to live. It just is not sufficient to the project of human flourishing." ${ }^{305}$ Sharp points out that once we give up the search for truth, we slip into a dangerous, directionless politics that can inhibit children's determination. By excluding these ideas from a CPI, children fail to experience the difficulties of building political solidarity and will be disinclined to pursue political changes that are universal in scope.

Therefore, both generations make it difficult for children to critique each programme beyond its given epistemic parameters. This limits the extent to which future generations can radically transform the political sphere and "define their own 'reality" ${ }^{306}$ using the philosophical lessons they take from PfC. This is not to say that children's imagination will always be confined to rational or disruptive parameters when 'thinking otherwise'. Children are exposed to a whole range of other life influences that bear on their political visions. Yet, in times when children engage with philosophy to 'think otherwise', their imagination will incline towards those

\footnotetext{
${ }^{303}$ Vansieleghem, "Listening to Dialogue," 187.

${ }^{304}$ Del Collado in Gregory, "Philosophy for Children and Its Critics," 210.

${ }^{305}$ Sharp talking in Ibid., 208.

${ }^{306}$ Sharp, "And the Children Shall Lead Them," 182.
} 
parameters. If we seek to equip future generations with the ability to think past politics as-is, we should equip them with the resources to draw on the political insight and concerns of more than one paradigm. Without cross-paradigm engagement, I am sceptical of the extent to which either analytic or post-structuralist CPIs empower children to deeply shake up the philosophical methods they are given for 'thinking otherwise' in a profound manner.

\section{Epistemic Invulnerability in PfC}

Unless taught, children are more likely to philosophise without strict epistemic foundations, in a manner open to epistemic transformation. ${ }^{307}$ According to Gilson, the desire for invulnerability is learnt; it is "a process that is... slow, subtle, and subconscious. ${ }^{~} 308$ If children learn that they are taken seriously in the classroom when they ground their ideas in an epistemic narrative and illustrate philosophical selfmastery over thought, they are more likely to shape their thinking accordingly. Because children's curiosity makes us anxious, we seek to reel them in - to fit more with our already mapped-out world. But this closes much potential to shift our collective imagination. I consider opening each pedagogy beyond its habits of invulnerability further opens philosophy to the groundless processes of children's thought. Following Murris, I consider it "crucial that... children do indeed know that they are allowed to think "the way they want and not in proper, true or right ways." "309 I suggest that the norms of invulnerability are transferred to the everyday simply through presenting philosophy as an isolated paradigm, because it provides a coherent and safe haven to refer back to in inquiry. By basing each programme on an isolated paradigm, both firstand second-generation PfC create the conditions for epistemic invulnerability.

There are different degrees to which epistemic invulnerability can be encouraged. On the one hand, the analytic programme encourages students to actively align their thinking with analytic philosophy. Within an analytic CPI, ideas are favoured if they rest on solid analytic grounds: strength of argument is equated with mastery over thought, which is illustrated by the revision sessions that help students better align with

\footnotetext{
${ }^{307}$ Long, "Thomas Reid and Philosophy with Children"; Matthews, Dialogues with Children.

${ }^{308}$ Gilson, "Vulnerability, Ignorance, and Oppression," 313.

${ }^{309}$ Murris, The Posthuman Child, 203.
} 
accurate reasoning. While the programme encourages collaborative peer input into how one thinks and who one is, collaboration is driven by an adjusting element that guides children to align one another's ideas with accurate reasoning in a Vygotskian sense in line with the improved reasoning processes of the collective CPI. Children are praised when they accurately ground their ideas in analytic philosophy, and taught to adjust ideas that remain epistemically open. This teaches students to ground their philosophising in line with a coherent paradigm, and to assume the habit of invulnerability. Students' sense of self is intended to shift so that each student has increased control over their ideas through reflective thinking: in other words, to become less vulnerable to the influence of others. As Cam states, "[w]e reason in order to control or reconstruct our world." 310 Yet Gilson argues that protecting one's sense of self and one's ideas from the will of others through grounding thought in an invulnerable story lends to the ideas of "a fantasy of mastery" 311 that keeps protected the ability to learn from opening the self to being deeply and uncontrollably transformed by the other.

If children have to focus too much on self-correction and resisting challenges by classmates, alternative ways of thinking can be pushed aside. Excessive focus on mastering rational skills and spending time considering "how to construct arguments",312 excludes students who are unsuited to grounding their thinking in rational stories: it "excludes those who do not live up to or are unable to live up to this norm." 313 This exclusion works against 'thinking otherwise' because it leaves behind many valuable ideas that children have to offer that do not fit with existing epistemic stories. As Kohan puts it, "showing [children] that they can think like adults... would be yet another way of silencing them." $" 314$

On the other hand, second-generation suggestions consciously acknowledge tentativeness and openness in a way that the first-generation does not. Exposure, for instance, helps children to transform each other in ways that cannot be controlled in advance. Yet by presenting philosophy through an isolated paradigm, second-

\footnotetext{
${ }^{310}$ Cam, 20 Thinking Tools, 92.

${ }^{311}$ Gilson, "Vulnerability, Ignorance, and Oppression," 308.

${ }^{312}$ Long, "Thomas Reid and Philosophy with Children," 604.

${ }^{313}$ Biesta, "Philosophy, Exposure, and Children," 312.

${ }^{314}$ Kohan, "What Can Philosophy and Children Offer Each Other?," 7.
} 
generation PfC encourages epistemic invulnerability through establishing reliance on the paradigm without questioning it - it presents a safe haven and a tendency to philosophise within that haven. I argue that there is a distinction between the openness of the self and epistemic openness. It is difficult to assume epistemic openness when the foundations that ground inquiry are not fundamentally open to transformation, despite a pedagogical commitment to vulnerability and opening the self. Without opening the epistemic foundations of thought to challenge, the practice of opening the self becomes fixed, quelling the need for children to question the ideological lineage of openness. In short, it again promotes the development of a particular mentality, and the habit of situating thought in a coherent body of ideas: "their newly achieved franchise imparts a fixity to them, even if, or precisely when, they are defined as fluid." 315

\section{Summary}

In this chapter I have argued that both generations of the PfC programme encourage a form of political thinking that sets the imagination within broad parameters. Transferring the habit of seeking invulnerability to PfC classes keeps epistemic worlds in place: it encourages children to situate their thinking in a closed and coherent paradigm. If it is difficult for students to evolve paradigms past their core assumptions, then the same sorts of political responses will derive from each paradigm. I assert that the limiting effects of epistemic isolation will be passed on to children, potentially resulting in a generation who think in the same recurrent way about politics - a political bubble-think. Although students will be able to 'think otherwise', their imagined alternatives will tend to be either overly rational or overly fluid. An isolated pedagogy solidifies exclusion, ruling out certain ways of thinking and awareness of the limits of one's thinking - of who and what they exclude. This creates the potential for a political dualism and political polarization. I am concerned that the feeling of political mistrust I see in my peers, of ideas that contradict their university-taught paradigm, will be accentuated if $\mathrm{PfC}$ is pushed as a more widespread practice for 'thinking otherwise'. It is therefore vital that students receive the resources to move philosophical methods beyond their initial epistemic assumptions, and to question the limits of their own thinking - of who and what they exclude.

${ }^{315}$ Rose, Judaism and Modernity, 4. 


\section{Part 3 - Rupturing Epistemic Isolation}

In Part 1 I outlined the necessity of 'thinking otherwise' in our current political climate, while in Part 2 I illustrated how the isolated methods of analytic and continental philosophy limit how far philosophical engagement can meet that need. I am not alone in the concern that thinking through uncommunicating paradigms limits people's imagination. For example, Lee Braver considers the divide between the two paradigms "wasteful to the point of absurdity" as "each deploys its own strengths to highlight and criticize the other's unnoticed presuppositions and biases." 316 In a similar vein, Vanderbeeken urges us to escape this "metaphysical deadlock",317 through opening paradigms to "fruitful" 318 dialogue. Frustrated with the lack of engagement, there have been attempts within philosophy to erode the paradigmatic borders of the two philosophical branches. These cross-paradigm ideas provide a valuable resource for introducing philosophy to contexts where isolation constricts the political imagination, such as when only one kind of philosophy is introduced for 'thinking otherwise'. Part 3 argues that one such cross-paradigm approach, speculative negotiation, provides a rich opportunity to overcome the limitations of epistemic isolation, especially in PfC.

Chapter 5 outlines two leading attempts to address epistemic isolation: cross-paradigm engagement and naïve/open thinking, highlighting their prospects for success. Chapter 5 then advocates speculative negotiation, as a hopeful, yet underutilised, alternative for addressing epistemic isolation, because it places responsibility on philosophers to become aware of the philosophical and political limits of their thinking - something necessary for addressing isolation, but guaranteed by neither cross-paradigm approaches nor naïve thinking. A sense of accountability unsettles circularity and invulnerability because it requests that the philosopher adjusts a paradigm's inquiry methods beyond its core assumptions. Chapter 6 presents an example of what speculative negotiation could look like in $\mathrm{PfC}$, arguing that it can help children overcome the restrictions of paradigm thinking.

\footnotetext{
${ }^{316}$ Braver, A Thing of This World, 4-5.

${ }^{317}$ Vanderbeeken, “A Plea for Agonism Between Analytic and Continental Philosophy,” 18.

${ }^{318}$ Ibid., 16.
} 


\section{Chapter 5 - Thinking Beyond Paradigm Binaries}

Academic attempts to expand the imagination across paradigms are infrequent yet wide-ranging, and include contributions from both analytic and continental philosophers. ${ }^{319}$ Cross-paradigmatic approaches intentionally combine the methods and ideas from more than one paradigm. Karen Barad explains that the general sensibility of these attempts "is not to reject things out of hand, to put the old out to pasture, but to renew ideas by turning them over and inside out." ${ }^{320}$ For example, one cross-paradigm approach developed by Barad, 'diffractive reading', asks philosophers to read aspects of one paradigm through aspects of another to gain a new understanding of both. ${ }^{321}$ She reads quantum physics through a post-structuralist lens to see what each can reveal about the other and to discover new conceptual meanings. ${ }^{322}$ For Barad, diffractive reading reveals that the 'hard edges' of separate entities and paradigms are not fixed, and that dynamic links already exist between separate paradigms and disciplines. ${ }^{323}$ She notes that unsettling borders opens an array of composite ideas and methods, creating new possibilities. Once a binary distinction (like analytic/continental) is unsettled, "there's no stopping the aftershocks and subterranean shifts, the build-up of energy and the creation of new fault lines that disrupt, unsettle, and undermine even the most seemingly solid grounds." 324

Vanderbeeken, drawing on the work of Mouffe, presents another example of a crossparadigm approach. Rather than trying to resolve deep paradigmatic disagreement, he suggests an agonistic relationship between analytic and continental philosophy, in which both approaches remain in a productive contradiction that generates fresh lenses for observing the world. Establishing this agonistic relationship involves providing

\footnotetext{
${ }^{319}$ See Reynolds et al., Postanalytic and Metacontinental; Lather, "Paradigm Proliferation as a Good Thing to Think with"; Spivak, A Critique of Postcolonial Reason; Vanderbeeken, "A Plea for Agonism Between Analytic and Continental Philosophy"; Barad, Meeting the Universe Halfway; Rorty, Contingency, Irony, and Solidarity; Rorty, Truth and Progress; Glendinning, The Idea of Continental Philosophy; Glendinning, On Being With Others.

${ }^{320}$ Barad and Kleinman, "Intra-Actions," 80.

${ }^{321}$ Barad, Meeting the Universe Halfway, 25. Barad's approach stretches across disciplines as well as paradigms.

322 Ibid.

${ }^{323}$ Barad and Kleinman, "Intra-Actions," 77.

${ }^{324}$ Ibid., 80. Karin Murris developed a PfC pedagogy from the work of Barad. Murris, The Posthuman Child.
} 
particular settings (like philosophy workshops) where conflicting perspectives can engage each other without being extinguished. ${ }^{325}$

Combining aspects of both paradigms can disrupt circularity because it can generate ideas that do not adhere to binary opposites, or in Kolozova's words, "create an opening for thought that escapes the binary clench." ${ }^{326}$ It unearths biases and throws new light on settled assumptions, prompting unexpected ideas to arise from combining a paradigm's ideas with foreign ones. Anne Schmid and Armand Hatchuel explain that juxtaposing various aspects of paradigms forms a "matrix of creation" 327 that draws "unexpected links" 328 between them: "relations between fragments of bodies of knowledge re-form., ${ }^{, 329}$ In doing so, a philosopher can reach conclusions that do not match either paradigm, unsettling their dichotomy. Barad's diffraction, for example, develops an idea of 'relationality' that does not remain in the traditional poststructuralist cultural/linguistic realm, but travels to the material 'objective' realm. Therefore, her conclusion does not adhere to binary opposites. Second, Rick Dolphijn contends that reading two traditions against each other better enables new paradigms to emerge, breaking traditional confines: "[it] is in the resonances between old and new readings and re-readings that a 'new metaphysics' might announce itself.",330

Advocates of 'naïve thinking' argue that cross-paradigm approaches do not go far enough because they do not unsettle the habit of basing ideas in a holistic epistemic world. ${ }^{331}$ A post-structuralist theorist, for example, might adopt some analytic ideas while mainly continuing to base their ideas in post-structuralism. Hence, some theorists call for a return to a 'naïve philosophy' to disrupt epistemic isolation, in the hope of undermining, unsettling, and confusing epistemic commitments in general. ${ }^{332}$ The idea behind naïve thinking is that philosophers should think without basing themselves in

\footnotetext{
${ }^{325}$ Vanderbeeken, "A Plea for Agonism Between Analytic and Continental Philosophy."

${ }^{326}$ Kolozova, Cut of the Real, 59.

${ }^{327}$ Schmid and Hatchuel, "On Generic Epistemology," 141.

${ }^{328}$ Ibid., 140

${ }^{329}$ Ibid., 141

${ }^{330}$ Dolphijn and Tuin, New Materialism, 13.

${ }^{331}$ Schmid and Hatchuel, "On Generic Epistemology."

${ }^{332}$ See Kolozova, Cut of the Real; Bryant, The Democracy of Objects; Long, "Thomas Reid and Philosophy with Children"; Schmid and Hatchuel, "On Generic Epistemology."
} 
paradigms, and abandon the desire for invulnerability in favour of epistemic openness. ${ }^{333}$ Bryant, for instance, calls us to experiment with a naïve thinking style that questions the world with wonder rather than adopting firm epistemic commitments. For him, this kind of messy, chaotic, and deeply open inquiry can surpass the secure epistemic foundations that shape philosophy today presents one promising way to proceed:

[W] hat if we were to 'bracket' the project of critique and questions of [epistemic] access and proceed in our speculations as the beginning student of philosophy might begin... [It] might give us the resources to pose different philosophical questions and open up new possibilities of thought. ${ }^{334}$

Kolozova similarly advocates toying with epistemic commitments by stepping out from the "scholastic enclosure that constrains the discourse of contemporary [philosophy]" in order to "re-create a naïve state of wonder." 335 The purpose of this project, she claims, is to awaken thought "from the rigidity of doctrine," "hinting at a radically new positioning of thought." ${ }^{336}$ Kolozova considers it vital (although perhaps philosophically irresponsible) to play with uncontained thought to re-radicalise philosophy through disrupting the security of coherence. This has the potential for "free and uncensored movement of thought. ${ }^{, 337}$

Naïve thinking challenges epistemic isolation because it removes the roots that provide inquiry with an invulnerable haven, opening each idea to deep transformation. Naïve thinking provides an epistemic openness that expands one's capacity to 'think otherwise', because it opens philosophical conversations to perspectives and people that have long been dismissed - those not grounded in an epistemic story ${ }^{338}$ - and illuminates different possibilities for approaching the world. Taking on an epistemically open position, even temporarily, encourages one to step into the unknown, removed from solid epistemic foundations. It is these risks and jumps that pivot the world in a different direction, rather than holding onto what is known: "Experimenting with different patterns of relationality... [is about] the material

\footnotetext{
${ }^{333}$ Epistemic openness, to recall, involves exploring philosophy in a way that the epistemic foundations of one's ideas are open to transformation/collaboration in a way one cannot control.

${ }^{334}$ Bryant, "The Ontic Principle," 262.

${ }^{335}$ Kolozova, Cut of the Real, 15.

336 Ibid.

${ }^{337}$ Ibid., 14.

${ }^{338}$ Hutchings, "A Place of Greater Safety? Securing Judgment in International Ethics.”
} 
intraimplication of putting 'oneself ' at risk, troubling 'oneself,' one's ideas, one's dreams." 339

Cross-paradigm engagement and naïve thinking can help overcome the limits of epistemic isolation, both in academia and in everyday life. There have been some attempts to introduce these cross- or non-binary philosophies to everyday settings, although there is still more to be done. ${ }^{340}$ We need to encourage these efforts because they address the political tunnel vision that occurs when only one paradigm enters everyday life. I turn to Gillian Rose's speculative negotiation for this task. Through a distinct engagement with Hegelian 'recognition', Rose recognises the importance of introspection to philosophy - an observational practice that demands considering the limitations of each philosophical perspective, and changing methods in light of those limitations. Neither traditional cross-paradigm approaches nor naïve thinking ask philosophers to directly address the way their philosophising is entangled in philosophy's limits, which leaves open the possibility of epistemic isolation, as we shall soon see.

Rose's work is underexplored in the cross-paradigm literature. This is perhaps because she is an especially challenging thinker, and because speculative negotiation is a demanding philosophical approach, both to comprehend and to participate in. Nonetheless, this engagement is worthwhile because it can lead to a more transformative philosophy that pragmatically works with its own limitations. I embark on a journey with Rose in light of Patti Lather's advice that we should always search for "a less comfortable social science full of stuck places and difficult philosophical issues of truth, interpretation and responsibility"341 if we are to find more worthwhile ways of coming to know and imagine. Before I begin, let me emphasise that because Rose's work is so arduous - her voice frequently weaving through lyrical metaphors this account of speculative negotiation slips between Rose's intent and my own interpretation, negotiated in my difficult path of understanding. Rose's oeuvre is broad, extending to concerns of theology, the law, phenomenology of love and mourning, and sociology, to which speculative negotiation is one part. Because Rose does not think

\footnotetext{
${ }^{339}$ Barad and Kleinman, "Intra-Actions," 77.

${ }^{340}$ For example see Bozalek and Zembylas, "Diffraction or Reflection?"; Murris, The Posthuman Child.

${ }^{341}$ Lather, "Paradigm Proliferation as a Good Thing to Think with," 52.
} 
we can pry these entwined aspects of life apart, splitting off her metaphysical thought risks doing her an injustice. Yet it is a necessity given the limited scope of this thesis. The following section outlines how speculative negotiation addresses the limits of epistemic isolation, drawing out how Rose's emphasis on philosophical accountability goes further than traditional cross-paradigm or naïve approaches.

\section{Speculative Negotiation: in the Space of the Broken Middle}

Rose's speculative sides takes shape through a radical re-reading of G.W.F. Hegel. This reading explains why Rose thinks each individual is involved in sustaining conceptual and paradigmatic binaries, and why she places the responsibility on each individual to continuously attend to philosophy's limits and to reshape existing philosophical paradigms. In line with traditional Hegelian interpretations, Rose understands each individual, as speculatively bound to the abstract, to play a role in shaping the nature of philosophy. Hegel sees our abstract world as a reflection of how society treats it and individuals, as part of society, as actively shaping philosophy. ${ }^{342}$

However, Rose disagrees with the traditional interpretation of Hegel as a static theorist. A static reading of Hegelian recognition interprets the struggle for political recognition as something that can be reached, understating that our collective structures (such as paradigms) are able to recognise all, and be wholly inclusive to all views. ${ }^{343}$ Rose claims that this misinterpretation leads to a conception of collective structures as overly idealised, which solidifies exclusion by de-emphasising the continuous need to work and rework our relationships and collective structures in the impossible struggle of recognition (as with the case of existing philosophical paradigms).

Rose instead sees the individual's role in philosophy as active and ongoing. ${ }^{344}$ She argues that we must realise the inevitability of misrecognition in collective structures and our role in facilitating misrecognition through participating in the use of those structures. She writes, the "'Spirit' in Hegel is, a fortiori, implicated in the drama of

\footnotetext{
${ }^{342}$ Kochi, "Being, Nothing, Becoming"

${ }^{343}$ Schick, "Re-Cognizing Recognition," 91. For Hegel, humans' desire for recognition is predicated on becoming validated as political beings through recognition from others, binding us, without choice, to seek recognition from others. See Butler, Frames of War, 23.

${ }^{344}$ Rose, Judaism and Modernity, 45-63.
} 
misrecognition." 345 For Rose, the inevitability of misrecognition illustrates how all our actions are closely tied to the exclusion and misrecognition of others, even, for example, solely by participating in an exclusive paradigm. Accordingly, she maintains that we need to be aware of our close involvement in the nature of philosophy and exclusion - to again hold ourselves accountable for the "misrecognitions attendant on abstract... and political life." ${ }^{346}$ Because misrecognition is ongoing, Rose argues that there are no quick fixes: she does not advocate abandoning paradigms in light of the exclusions they cause. Instead she places an ongoing responsibility on philosophers to work and rework the limitations of, and misrecognitions caused by, existing paradigms, and to learn from the inevitable exclusions that stem from our hopeful yet faltering attempts at recognition:

Learning in this sense mediates the social and the political: it works precisely by making mistakes, by taking risks of action, and then by reflecting on its unintended consequences, and then taking the risk, yet again, of further action. ${ }^{347}$

Rose's interpretation of Hegel provides us with a "more holistic comprehension of our human world" $" 348$ that acknowledges the intricate contribution of all individuals to the abstract and political structures that guide our lives, even just through our complacency. ${ }^{349}$

Following Hegel, Rose invites philosophers to embark on a speculative journey to engage across paradigms in order to continuously observe their own involvement in philosophical possibilities for, and limitations of, 'thinking otherwise'. In light of observed limitations, speculative negotiation invites people to continuously 'turn out' to rework the paradigm they engage with in philosophising ('turning out' denotes the work of adjusting the philosophical and political structures (and other people) in light of one's introspection - a give and take of outwards negotiation). Therefore in contrast to traditional cross-paradigm and naive approaches, speculative negotiation is a crossparadigm approach that works to continuously adjust the assumptions, values and methods of existing paradigms. The following describes this process of speculative negotiation in more detail.

\footnotetext{
${ }^{345}$ Rose, Judaism and Modernity, 68.

${ }^{346}$ Ibid., 67.

${ }^{347}$ Rose, Mourning Becomes the Law, 38.

${ }^{348}$ Schick, "Re-Cognizing Recognition," 96.

${ }^{349}$ Ibid., 99.
} 
For Rose, each side of the analytic/continental duality represents one side of a wider collection of conceptual dualities: the "unconditioned oppositions which have been formed by negotiation or lack of it." $" 350$ The accountability that speculative negotiation imparts for reshaping paradigms begins for Rose with an introspective turn inwards for each philosopher to observe how their commitment to only one side of this duality implicates them in habits of exclusion caused by dualistic and rigid thinking, "with its unwelcome and welcome surprises." ${ }^{351}$ To negotiate the hardened border between paradigms, defenders of each paradigm are asked to engage with the opposing paradigm to witness how their perspective excludes other ways of thinking: "it involves recognizing our mutual implication." ${ }^{352}$ For example, in engagement with poststructuralism, the analytic philosopher is asked to look inwards to realise how their pursuit of political objectivity may exclude other ways of thinking, such as attending to the political importance of embodied experiences.

Through introspection, philosophers can observe how their philosophising is implicated in philosophy's own structure, and in societal norms that exclude ideas and people from participating in philosophy, exclusions which have political consequences. Rosean introspection therefore asks us to face our own "(often unthinking and wellmeaning) complicity in the oppression of others." 353 Through introspection, Rose claims, we discover our speculative involvement in misrecognition:

[E]ach comes up against her own violence, her own abstractly universal selfidentity. This violence of each individual towards its 'Other' and towards itself is then discoverable, regardless of whether the original intention of each towards 'the other' was good, evil or indifference. ${ }^{354}$

When Rose attempts to understand why exclusion occurs, she explains that "[i]t is my own violence that I discover., ${ }^{355}$ She insists that refusing to look inwards to see how one's certainty excludes creates the condition for closed philosophical communities: it

\footnotetext{
${ }^{350}$ Rose, Judaism and Modernity, 56.

${ }^{351}$ Ibid., 4.

352 Ibid.

353 Schick, "Re-Cognizing Recognition," 101.

${ }^{354}$ Rose, Judaism and Modernity, 8.

${ }^{355}$ Rose, Mourning Becomes the Law, 48.
} 
"gives rise to the ill-fated twins of the devastation of reason and the phantasmagoric ethics of the community." 356

In light of introspection, and in realising the ways that each method, value or assumption excludes, speculative negotiation presents the philosopher with the responsibility to unsettle and redefine paradigmatic borders of that same paradigm they are thinking through. Introspection demands that we partake in a "thorough examination of those factors that have fostered misrecognition, ${ }^{357}$ including our own involvement, a realisation through which Rose maintains we will be "summoned into action and put in movement" ${ }^{\prime 358}$ - a personal responsibility to adjust each paradigm. Philosophers will be compelled to rework and redefine paradigmatic methods, values, and assumptions, a result which "emerges from the pain and lessons of experience[s]" of introspection. ${ }^{359}$ Through re-working a paradigm, we place it in a different "dynamic" $" 360$ relationship to other paradigms. This new relationship generates new exclusions and opportunities, again demanding both introspection and a turning out to redefine the content/methods of that paradigm. This gives speculative negotiation its ongoing character: it works continuously to unsettle the duality between the two dominant paradigms; an accountability to ceaselessly reshape each paradigm's methods and core values/concepts in light of their limits and exclusions: "[b]oundaries are transgressed and redrawn and ever-vulnerable." ${ }^{361}$ When the methods, claims and concepts of each paradigm shift beyond its initial assumptions, so too do the political possibilities it provides: "[a]fter the debilitations of the dance, the labour - which is equally repose - may refresh us." ${ }^{62}$ Therefore Rose re-engages with Hegelian spontaneity to interpret philosophy as a live entity that must continually be engaged. In her words, "I raise 'spirit' in Hegel ... in its changing configurations of misrecognition... of public and political life." $" 363$

\footnotetext{
${ }^{356}$ Ibid., 30.

${ }^{357}$ Schick, "Re-Cognizing Recognition," 88.

${ }^{358}$ Hegel in Rose, Mourning Becomes the Law, 64.

${ }^{359}$ Rose, Judaism and Modernity, 4.

${ }^{360}$ Ibid.

361 Ibid.

362 Ibid., 63.

${ }^{363}$ Ibid., 67. My italics
} 
Yet speculative negotiation does not merely entice people to actively critique and shape philosophy. It actively works to uproot methods from their set epistemic place, opening them to deep and uncontrollable transformation. Rose argues that enabling philosophers to negotiate and deeply unsettle paradigmatic foundations requires entering the conceptual middle between binaries - the 'broken middle' - because the middle, with its (mis)understanding and (mis)recognition, is where negotiation can unearth biases. The broken middle refers to the irreconcilable conceptual space between a whole muddle of opposing dualities that was born "from the tension" 364 between Modernity's political dreams and its contradictions with "systematic actualities of power and domination" ${ }^{\prime 365}$ in political reality. Rose describes the broken middle as the "breaks between universal, particular and singular, in individuals and in institutions... between inner morality and outer legality, individual autonomy and general heteronomy." 366 The broken middle is accordingly a conceptual space that resides close to actualities - filled with conceptual visions about the relationship between ideals and realities. This array of interwoven dualities still guides our political visions and our societal structures, which thinking through philosophical paradigms illustrates. Rose regards this proximity to difference as a means to start the process of introspection, because it illustrates how two sides of a dualism constitute and exclude each other. ${ }^{367}$

Analytic and continental philosophy, according to Rose, each represent one side of Modernity's dualism, so the space between them is a broken middle. ${ }^{368}$ When one enters this middle, one arrives in a space between one's philosophical position and its opposing commitments (or less demandingly, between the paradigm one is engaging and its opposite), a space that is "always pervaded with meanings neither party

\footnotetext{
364 Ibid., 78.

${ }^{365}$ Rose, Mourning Becomes the Law, 65.

${ }^{366}$ Rose, The Broken Middle, xii.

${ }^{367}$ Rose, Judaism and Modernity, 55.

${ }^{368}$ A speculative understanding of the world begins from an acknowledgement that a concept and its opposite are a contentious 'One' where one cannot exist without the other (immanent opposites): "the knowledge that the opposites are in truth one" (Hegel in Rose, Judaism and Modernity, 60). For example, darkness cannot exist without the notion of light - taken to its extreme darkness refers to the opposite of what it was initially supposed to reflect. Following Hegel, Rose argues that analytic and continental philosophy are each composed of immanent opposites. To properly introspect we must hold dualities that comprise analytic philosophy and post-structuralism together as 'One' to witness their mediation and mutual composition. Rose, The Broken Middle, 164.
} 
intends. ${ }^{369}$ In this space one can confront the way that engaging with a single paradigm creates dualistic philosophising, by coming face-to-face with excluded people and excluded ideas: "that idea comes up against the actuality of others and the unanticipated meanings between them." 370 In the broken middle, one can witness how these contradicting perspectives cannot be heard through dominant philosophical methods. Although Rose does not specify what the broken middle looks like in practice, we can imagine it as any sort of conceptual/actual space that presents one with the philosophical face of the 'Other'.

The broken middle refers not just to the space between "the now-sacralised opposition between demonic reason and new ethics;" "371 but also to the space between different philosophies, between one's embodied experiences and those of another, between the philosopher and societal structures (the particular and the abstract), between collective utopian dreams and political realities (the abstract and the law) and between one's experiences of misrecognition and the political (the particular and the law). Accordingly, Rose understands philosophy as something deeply entwined in other aspects of life:

Analysis of this kind... understands the plans as arising out of, and falling back into, the ambitions and the tensions, the utopianism and the violence, the reason and the muddle, which is the outcome of the struggle between the politics and the anti-politics of the city. ${ }^{372}$

The complex divisions between different philosophies cannot be understood separately from the political, from one's complicity in maintaining structures, from utopian hope or from ordinary embodied life. It is in the broken middle that Rose insists that people can confront their role in moulding our social world: "persons understand themselves to be confronting 'the world' in unstable attempts to maintain a stoical or sceptical relation to it, when 'the world' has itself been compacted and projected out of the misrecognition of work, desire and engaged otherness." 373 The broken middle allows philosophers to shift inquiry methods past core assumptions because deep introspection in light of the 'Other', from both sides in the broken middle, uproots epistemic

\footnotetext{
${ }^{369}$ Ibid., 4.

${ }^{370}$ Ibid., 10.

${ }^{371}$ Rose, Mourning Becomes the Law, 34.

372 Ibid.

${ }^{373}$ Ibid., 73.
} 
assumptions through working between the limitations and difference of each. Speculative philosophy thus places epistemic openness at the heart of cross-paradigm engagement, introspection also reveals the importance of surrendering strong commitments to particular epistemic narratives, by revealing how strict epistemic commitment to one side of a duality fixes binaries and stagnates conceptual progress. ${ }^{374}$

In cases where one philosopher negotiates their introspective lessons with philosophical methods, negotiation is the irreconcilable give-and-take between those lessons and the pragmatic necessities of the method. Rose describes the process of negotiation as "[n]egotiating the inference of meanings between idea and act, its isolation and implication, its self-identity and lack of self-identity and not hailing and sacralising the plurality or irreducible singularity of itself and of 'the Other'."375 But negotiating collective structures is also messy, complicated and difficult because one is required to simultaneously negotiate one's introspective lessons with others'. Taking these uprooted methods and negotiating them in light of both introspective processes requires holding those contradictions in an impossible unity, where "particular existence... recollects itself, whose existence is self-knowledge... [in] recollecting 'the whole." 376 Collective negotiation is hence the exchange of individual experiences, introspection, ideas and desires with each other and with collective structures, such as paradigms and political realities: "the relation of universality and particularity as it is actually and potentially negotiated by the singular."

Reworking collective structures often comes at the negation of another, such as another person or another philosophical perspective. One must continuously strive to negotiate and re-negotiate one's interests and needs with each other and with collective structures, but also forgo some of those interests. In Rose's words, "one must be able to give and take from others, to acknowledge difference and identity, togetherness and separation, understanding and misunderstanding." ${ }^{378}$ Despite negotiation's difficulty, Rose asks that we attend to our responsibility to partake in the chaotic reshaping of existing paradigms so that a more holistic and novel way of philosophising may arise.

\footnotetext{
${ }^{374}$ Ibid., 8.

${ }^{375}$ Rose, Judaism and Modernity, 9.

${ }^{376}$ Hegel in Ibid., 54.

${ }^{377}$ Ibid., 59.

${ }^{378}$ Ibid., 3.
} 
She states, "[i]f the Western tradition were to be approached aporetically and not deterministically or dogmatically, then the relation between metaphysics and ethics would acquire a different resonance and rationale."379

For Rose, paradigmatic components are blurred, relational, and responsive to each other and to how both sides of the dualism are treated. Philosophical negotiation plays on this responsiveness. For example, rather than "abandon" reason in light of the exclusions, as postmodernism did, ${ }^{380}$ Rose claims that one's understanding of reason can be negotiated in light of those experiences. Reason is "relational, responsive and reconstructive" 381 to experiences and the way that people use it, and "yields the actuality of the concept, not its alterity" which emerges from an "existential response to the crisis." 382 Speculative negotiation asks us to put in the effort to continuously and tentatively redefine relational paradigmatic borders with our personal and shared political experiences. And through the process of negotiating and adjusting one paradigm, the speculative process comes alive - one can see how shifts in one paradigm alters its relation to the 'Other', if both are held tentatively in the middle. ${ }^{383}$

While the broken middle is often considered a space to be mended, Rose thinks the disordered collection of paradigmatic dualities must be continuously negotiated decisive mending is ill-advised - yet we should always work towards an irreconcilable 'One'. She states, “[b]ecause the broken middle is broken... does not mean they should be eliminated or mended. The holy middle corrupts because... it draws away from the reconfiguration of singular, individual and universal at stake." ${ }^{384}$ As exclusions and limitations formed from philosophising are inevitable, the process of speculative negotiation should never restfully settle a border between the two paradigms. Rose

\footnotetext{
379 Rose, Mourning Becomes the Law, 9.

${ }^{380}$ Rose insists that poststructuralist thought "misrepresents the alterity of reason." Instead reason is "demonized" by this tradition for being "dualistic, dominant and imperialistic" (Ibid., 9. 3-4.).

${ }^{381}$ Rose, Judaism and Modernity, 4.

382 Ibid.

${ }^{383}$ Hegel's speculative process refers to the unsettling and resettling of the relationship between immanent opposites. While immanent opposites can sometime achieve a temporary stability, Hegel argues that contradictions continuously surface in response to social/material reality, which throws the relationship between immanent opposites into turmoil. Only by holding both together in tension does Rose think we can witness their relation, "as they come to light in a dynamic historical development" (Ibid., 61).

${ }^{384}$ Rose, The Broken Middle, 285.
} 
states, "instead of further defining and challenging these exclusive, polar oppositions" they should be "comprehended and not dogmatically contrasted." 385 Speculative negotiation remains comfortable with its inability to mend dualities, but sees that paradigms can gradually shift, "rediscovering its own movable boundaries." 386 A Rosean approach overcomes the "outmoded and dualistic contrast between the embrace of the contingency of language versus commitment to objective reality" 387 but "without generating any fantasy of mending." ${ }^{388}$ Speculative negotiation is hence a philosophical approach that asks one to, slowly but continuously, unsettle one's philosophical assumptions and hardened paradigm edges through negotiating all of a paradigm's components - an unfolding process of unsettling and resettling, drawing and redrawing, the area between binaries.

Speculative negotiation is thus distinct from traditional cross-paradigm approaches because it does not ask philosophers to juxtapose different paradigmatic aspects to develop innovative ideas. Instead, it asks one to engage across paradigms so that biases are exposed and that one can look inwards to see how one's paradigm can be reworked in light of its exclusions. Too often, cross-paradigm approaches turn outwards to develop new methods and ideas, without sufficiently looking inwards to examine how existing methods and ideas sustain exclusion and circularity, which is limiting for addressing the limits of epistemic isolation for two reasons. First, without consciously challenging the biases and exclusions within each paradigm, the limitations of exiting methods will remain unaddressed. Second, without looking inwards in introspection to continuously examine one's philosophical habits and how one's philosophising is bound to exclusion, the possibility of hardened new dualisms remains. This is because maintenance of epistemic certainty and the seeking of security is what contributes to uncommunicating paradigms in the first place: Rose argues it lends to thinking “deterministically or aporetically - as fixed closed conceptual structures, colonising being within the garrison of thought." 389

\footnotetext{
${ }^{385}$ Rose, Judaism and Modernity, 55.

${ }^{386}$ Rose, Mourning Becomes the Law, 11.

${ }^{387}$ Ibid., 6.

${ }^{388}$ Ibid., 9.

${ }^{389}$ Ibid., 8.
} 
Speculative negotiation, like naïve thinking, is therefore a philosophical approach that invites epistemic openness in the broken middle. Unlike naïve thinking, however, speculative negotiation does not abandon existing paradigms. It draws on crossparadigm engagement to expose the deep epistemic commitments of each paradigm to transformation. Naïve thinking, though removing paradigm thinking completely, removes the philosophical plurality that throws epistemic biases into question. Removing paradigms removes the opportunity to throw the assumptions of naïve thinking into question. While naïve thinking does challenge epistemic invulnerability by completely removing the safe havens of paradigms, it skips the difficult work of outward negotiation, work that is needed to question one's assumptions and expose one's biases. I agree with Rose that " $[t]$ he unsparing revulsion against the fallen idols and the rush to espouse their formerly degraded 'others' perpetuate dualisms." 390 Again, naïve thinking does not impart an indispensable accountability to continuously check the limitations of one's philosophical thinking, keeping open the possibility for epistemic circularity to form.

\section{The Benefits of Accountability}

I now turn to some of the ways speculative negotiation directly addresses epistemic isolation. It is not my intent to reify speculative negotiation over cross-paradigm or naïve approaches. I support both attempts to overcome the limits of isolation and maintain that both have much to offer unsettling the limits of isolation in PfC. Speculative negotiation is just one approach worthy of consideration when addressing epistemic isolation. However, it is worth paying attention to the striking way in which speculative negotiation connects cross-paradigm engagement to epistemic openness. Placing openness and accountability at the heart of cross-paradigm engagement, speculative negotiation addresses both epistemic circularity and epistemic invulnerability in addressing the limits of epistemic isolation. Holding philosophers accountable for continuously unsettling the methods, assumptions and core addresses the limits of isolation in a manner that traditional cross-paradigm engagement and naïve thinking do not: it alters the conditions of existing philosophic methods, pries open epistemic havens and positions philosophy to be unsettled by the political.

${ }^{390}$ Ibid., 3. 
First, inviting people to change philosophical methods past existing epistemic assumptions, in light of the philosophical 'Other', provides a potential break in epistemic circularity. Altering methods by interacting with opposing philosophical ideas in the broken middle offers new insights to existing methodological assumptions, permitting a paradigm to break from its fixed epistemic bias. Through enabling methods to shift in this way, ideas previously absent in exploration can be considered, along with an alternative set of opportunities for political dreaming. When people shift methods and paths for dreaming beyond existing assumptions, possibilities for 'thinking otherwise' expand beyond the parameters established by those assumptions. Moreover, the accountability imparted by speculative negotiation's introspective process urges people to continuously unsettle methods beyond existing assumptions, an ongoing and unfolding process of changing methods that constantly presents new opportunities for 'think otherwise'. Speculative negotiation therefore incessantly upsets philosophy's epistemic and political circularity.

Second, continually interrogating one's beliefs enables epistemic openness. It encourages philosophers to examine the epistemic foundations of their paradigm, and to open that space to transformation by the 'Other' in the space of the broken middle, challenging the habits of epistemic invulnerability. The broken middle invites collaboration and transforms the foundation of each philosopher's ideas. For Rose, relinquishing certainty enables us to start the process of understanding: "[o]nly the persistence of always fallible and contestable representation opens the possibility for our acknowledgement of mutual implication in the fascism of our cultural rites and rituals." ${ }^{391}$ Unearthing assumptions in the broken middle challenges habits of epistemic invulnerability because it transforms those assumptions in ways that neither party can control and removes the safety of coherence - in the broken middle both sides lose their epistemic haven. Therefore speculative negotiation challenges one's desire for epistemic invulnerability in a way that traditional cross-paradigm approaches do not, and allows the cross-paradigm engagement that naïve thinking removes. In this manner, speculative negotiation addresses the limits of epistemic isolation identified in Part 2.

${ }^{391}$ Ibid., 41. 
Third, unsettling paradigmatic borders through speculative negotiation "would permit us to rediscover politics ${ }^{\$ 392}$ because it would enable philosophy to respond to a wider range of political realities, resisting political bubble-think. As Rose explains, speculative philosophy sits "between the potentiality and actuality of the world and engag[es] at the point where the two come into a changed relation... [a] reconfiguration, oppositional yet vital - something understood." ${ }^{393}$ Negotiation places philosophy close to the political (a speculative trait) through historicising and personalising both analytic and continental concepts and methods. By drawing on both paradigms in a way that muddles their traditional political focus, one must answer to a wider array of political realities, challenging and altering philosophy in light of negotiation with actualities. Rose holds that negotiated philosophical visions can hence be disrupted by a more expansive range of realities that do not meet the intentions of the political visions: "It is this dynamic [between individual and societal structures] and predicament of modernity according to which social actuality tends to undermine and to invert overt moral and political intentions." 394 A continuously-negotiated philosophy is hence transformative, for it must respond to the incompatible realities of both the universal and the particular, the individual and the collective, morality and the law and so on.

Accordingly, Rose asks the philosopher to stop forgetting the actuality behind abstract concepts: "Let us continue to chase spirits back into their bodies, back into the history of their development, in order to comprehend their law and their anarchy." 395 In turn, she clarifies that this opens each side of the philosophical dualism to transform in relation to its opposite, which requires comprehending the relational nature of the abstract: "[t]his mode of exposition does not presuppose a subject-object dichotomy nor any utopian perspective: it comprehends legal dichotomies speculatively - as the illusory third term in a contradictory and changing relation." 396

Fourth, negotiation places philosophy in a better position to shift the political because it demands that we follow 'thinking otherwise' with political action. Speculative

\footnotetext{
392 Ibid., 76.

${ }^{393}$ Rose, The Broken Middle, xi.

${ }^{394}$ Rose, Judaism and Modernity, 68.

${ }^{395}$ Rose, Mourning Becomes the Law, 71.

${ }^{396}$ Rose, Judaism and Modernity, 58.
} 
negotiation places a continuous responsibility on philosophers to reshape political institutions and political realities, in light of introspection and the realisation of their complicity in sustaining political exclusions and norms of misrecognition (such as through framing political visions that are then actualised). This "opens up the irony of history." ${ }^{397}$

\section{The Contribution of Speculative Negotiation to Everyday Life}

Philosophical accountability is especially important in everyday settings, when philosophy is situated close to the political and is mobilised for political reasons. It is imperative that those forming political visions understand the influence philosophical methods have on them and how they might narrow those visions. Speculative negotiation renders people accountable by appealing to people to ask, 'how is philosophising through this lens impacting the way I think about politics?' This unsettles existing philosophical methods, and expands possibilities for 'thinking otherwise'. Although it may seem that speculative negotiation is unsuited to everyday life, being primarily directed at committed philosophers, it works without a deep epistemic commitment, asking that we look inwards even when we noncommittally engage a paradigm to 'think otherwise'.

Speculative negotiation is therefore valuable in everyday settings because it allows citizens to engage in both analytic and continental paradigms through an accountable lens. Inviting people into the broken middle allows them to confront their biases and to face who and what their thinking excludes, combatting ignorance and self-certainty that obstruct questioning. This introspective component not only allows to improve philosophical methods, but imparts an awareness of philosophy's political implications, inviting people to transform methods in light of exclusions.

${ }^{397}$ Ibid., 61. 


\section{Challenges, Risks and Rewards}

While speculative negotiation has essential attributes for radically re-imagining of our political world, especially in the way it actively works against bubbles, it is important to acknowledge its difficulty. Speculative negotiation requires a willingness to remain with anxiety and to take risks, both of which require courage and hard work. But embarking on this taxing emotional labour is necessary in order to do the difficult, but rewarding, work of inclusive world-building. First, placing oneself within the broken middle, where one can painfully encounter the 'Other', transforms both one's judgments and one's identity without "know[ing] the outcome in advance."398 Introspection will also make any philosopher feel anxious, in facing one's complicity in exclusion and misrecognition. As Rose puts it, "[t]o have that experience, we would have to discover and confront our own fascism. ${ }^{399}$ But remaining anxious is precisely what it takes to turn out in negotiation and to learn: speculative negotiation "returns... ready to take on the difficulties and injustices of the existing city. The mourner returns to negotiate and challenge the changing inner and the outer boundaries of the soul and the city; she returns to their perennial anxiety." 400 Taking on the uncomfortable and unsettling feeling of unknowing is necessary for negotiation.

Second, Rose also concedes that approaching philosophy from the middle asks the philosopher to take a risk: 'existential terms such as 'leap', 'risk', 'ruin' and 'hovering' brings in Orphic connotations of individual salvation." first, the risk of epistemic openness that has already been discussed - the risk of opening oneself to others in an unpredictable manner. Second, risk occurs at the level of political action. Philosophising from the middle will likely illuminate the messiness and complexity of life and the capacity of humans to make mistakes. But it will also stress the importance of turning out to take political action nonetheless, of trying for a more just world. For Rose, risk:

reopens the way to conceive learning, growth and knowledge as fallible and precarious, but risk-able. The risk refers to the temporarily constitutive positings

\footnotetext{
${ }^{398}$ Rose, Mourning Becomes the Law, 58.

${ }^{399}$ Ibid., 48.

${ }^{400}$ Ibid., 36.

${ }^{401}$ Ibid., 111.
} 
of each other which form and reform both selves. This constant risk of positing and failing and positing again. ${ }^{402}$

Third, speculative negotiation hence involves courage. Life is clumsy; we make mistakes and we need courage in light of not knowing whether our efforts will succeed, to partake in "joyful erring." 403 The work of recognition, of continuously trying to understand oneself and the 'Other,' is a never-ending dance. In inspiring the courage and hard work involved in speculative negotiation, Rose points to Klee's painting of an angel, Angelus Dubious, "who makes mistakes, for whom things go wrong, who constantly discovers its own faults and failings, yet who persists in the pain of staking itself, with the courage to... go on and on, learning from those mistakes and risking new ventures." 404 She encourages us to accept the potential of making mistakes in judgement and in political action in order to learn and move forward, courageously;

If Fascism promises beginnings of the day, representation exposes the interest of the middle of the day; then the owl of Minerva, flying at dusk may reflect on the remains of the day - the ruins of the morning's hope, the actuality of the broken middle. $^{405}$

Rose asks us to continuously return to the site of the broken middle, between being hurt and moving forward, between abstract hope and political work. Philosophy, for Rose, thus "demands a willingness to participate in power and its legitimate violence for the sake of the good."

\footnotetext{
402 Ibid., 13.

${ }^{403}$ Rose, The Broken Middle, 287.

${ }^{404}$ Rose, Judaism and Modernity, 10.

${ }^{405}$ Rose, Mourning Becomes the Law, 42.

${ }^{406}$ Ibid., 100.
} 


\section{Chapter 6 - Speculative Negotiation in the Classroom}

In the previous chapter, I advocated the importance of speculative negotiation to philosophy and to our everyday lives. In this chapter, I explore what speculative negotiation can bring to $\mathrm{PfC}$ and argue that it is one of a number of cross-paradigmatic approaches worthy of greater attention in $\mathrm{PfC} .{ }^{407}$ Critically, introducing speculative negotiation into PfC would enable children to overcome the limits of paradigmatic thinking and to 'think otherwise' without abandoning previous methods developed by PfC theorists. To locate this discussion in the classroom, I begin by evaluating the suitability of speculative negotiation in CPI, before arguing that it holds considerable potential to enrich learners' lives. I then offer a pedagogical example of speculative negotiation in action to illustrate the pedagogical potential of this approach, an approach that warrants testing in classroom contexts. ${ }^{408}$ Rose is a theorist whose provocative work often remains in the abstract realm. Engaging with speculative negotiation in everyday contexts raises difficult questions of practice and implementation. Yet, I argue its suitability to PfC makes this a less daunting task.

\section{Speculative Negotiation for PfC}

Speculative negotiation can benefit children's learning processes for several reasons. First, it could allow children to explore the philosophical approaches that guide our world without encouraging political tunnel-vision. This is because it provides the resources for students to take ownership over PfC itself, and to develop first- and second-generation inquiry methods beyond their core assumptions. These resources allow children to alter the political lenses available to them. This responds to the second-generation concern about the threat of 'instrumentalising' students for political ends, but in a manner that takes children seriously as epistemic engagers, able to transform what they are given if provided the resources. Second, speculative negotiation gives children an awareness of who and what philosophising in a CPI may exclude, providing both a sense of responsibility for classroom exclusions and an opportunity to shift the programme in light of those exclusions.

\footnotetext{
${ }^{407}$ See Murris, The Posthuman Child; Weber, "Childhood, Philosophy and Play."

${ }^{408}$ I owe a special thanks to Andrea Milligan for helping me think through this pedagogical example.
} 
Third, placing introspection at the centre of cross-paradigm engagement is important to PfC because it resists new conceptual dualisms. Rose's speculative side attends to the ways our abstract world develops from what came before. An overemphasis on children's 'new' thinking without negotiating with the ideas that already guide our world threatens to form a new duality between the existing ('adult' ideas) and the utopian (children's ideas). Turning out to negotiate both analytic and continental ideas, as well as existing political realities (that speculative negotiation provides) should hence accompany children's ideas and epistemic openness. Not doing so leaves behind important parts of philosophy, such as useful philosophical resources for 'thinking otherwise' and engaging in philosophical discourses outside the classroom.

But also, Rose's insistence on reshaping our imperfect existing world (rather than seeking a detached utopia), and her focus on mutual adjustment between 'doing' philosophy and an individual's environment, makes PfC a suitable place to practise speculative negotiation. The pragmatic roots of PfC, as outlined in Chapter 2, holds philosophy near to politics, and understands the closeness between the individual and philosophy, and between the individual and politics. PfC sessions practice mutual adjustment: inviting children to call their sense of self into question in engagement with their environment, and bringing about an adjustment of politics through those selflessons. The PfC programme also encourages children to make mistakes in the practice of politics and philosophy, and to continue to take the risk of thinking and acting. This bears a striking resemblance to the practice of speculative negotiation, making PfC a suitable place to introduce philosophy to everyday settings.

\section{Hesitations}

Before demonstrating how speculative negotiation could help students transcend dominant epistemic assumptions, let me note some possible hesitations about introducing speculative negotiation to PfC. First, I worry that speculative negotiation will leave students stuck in a meta-epistemic circularity. Speculative negotiation, like any philosophical approach, holds a bias. We can witness this in the way that dualisms are held in tension. This almost holds sacred ongoing tension - between anxiety and certainty, epistemic openness and seeking certainty, risk and stability - over the middle or the edges. If negotiation is introduced into the classroom as a higher-order evaluative method, it threatens to uncritically pass that bias on, forming a higher-order circularity. 
It would, after all, be difficult to question the validity and value of negotiation using negotiation itself. The encouragement of turning 'in' and 'out' rests on the same epistemic assumptions and biases of negotiation that privileges an epistemic position that pushes and pulls. Furthermore, Rose's speculative approach is intended to be deeply embedded in one's life, so if followed seriously, it would be difficult to step out and question its value.

Nonetheless, I am reassured by the fact that through engaging with first- and secondgeneration pedagogies students will retain the capacity to question speculative negotiation and its biases from alternative philosophical perspectives. For instance, a student could critique speculative negotiation from an analytic or poststructuralist standpoint, and reshape negotiation accordingly. Because philosophical biases are inevitable, it is primarily important to provide students with resources to overturn the bias. Speculative negotiation presents this opportunity because although it is an ongoing and all-encompassing approach, Rose would argue that speculative negotiation is all-encompassing insofar as it remains a consistent possibility, and that residing in the broken middle does not mean relentless disruption, but the possibility of relentless disruption.

My second reservation is that speculative negotiation seems to necessarily maintain philosophical (and other) dualities, which may create the potential for a dualistic kind of philosophy and politics. However, speculative negotiation, in a truly Hegelian manner, derives philosophy and politics from 'what is' (as opposed to trying to build a utopian world from scratch) and dualisms are a fact of our social, political and philosophical worlds. In a speculative tone, it is vital not to abandon existing philosophy in the face of discovering its limitations. This is because the alternative, that is, not teaching existing methods, threatens to form a new (-old) binary, as already established. Socialising children into politics and philosophy involves teaching them about the political realities that guide social life, and much of philosophy and politics are divided into dualities. Nonetheless, binaries can be worked through and unsettled by negotiation.

Barad, defending this point from a different angle, presents a case for beginning philosophy from the current philosophical dualisms rather than beginning afresh because, she argues, starting philosophy from dichotomies constructively enables us to 
examine why they exist and how they arose in the first place. It provides us a chance to "experiment with different differences, trying to get a feel for how differences are produced and how they matter." ${ }^{409}$ In addition, Vanderbeeken argues that unification, or 'no approach', within philosophy should be avoided because it "can restrain the creative power of disagreement and the (occasional) critical disclosure while facing odds." ${ }^{410}$ I agree with Vanderbeeken that holding more than one philosophical approach in tension holds creative potential to engage with difference in a productive manner: "[s]ince unification coincides with a loss of authenticity, blurring the critical potential of both traditions, we are better off endorsing agonistic pluralism between analytic philosophy and contemporary continental philosophy. In order to do so, a discussion of the split is needed." which can be achieved through a multi-epistemic approach that can then be unsettled.

My final concern is that speculative negotiation may not be open to the philosophical 'non-expert'. Although speculative negotiation makes room for a philosopher whose thinking does not fit smoothly in either paradigm (through unsettling traditional approaches), one first has to engage with, and understand, existing philosophical approaches and the practice of speculative negotiation. Some may claim that this difficulty would exclude children from participating in the philosophical process. However, I am encouraged by the work of constructivist theorists such as Jerome Bruner, who argued that any idea can be made accessible to children, and by Lipman himself, who ably demonstrated that logic can be re-crafted to be accessible to children. ${ }^{412}$ The ideas that follow undoubtedly require refinement. From a Rosean perspective, we should take the risk of mistakes to try for a better outcome and more inclusive path for 'thinking otherwise' - to acknowledge limitations when they arise but nonetheless to take a leap and try again when exclusions arise.

\footnotetext{
${ }^{409}$ Barad and Kleinman, "Intra-Actions," 77.

${ }^{410}$ Vanderbeeken, “A Plea for Agonism Between Analytic and Continental Philosophy,” 18.

411 Ibid., 16.

${ }^{412}$ Bruner, The Process of Education; Lipman, “(USA) Philosophy for Children."
} 


\section{A Colourful CPI: A Pedagogical Example}

As a thought experiment, the rest of this chapter presents an example of speculative negotiation in PfC. Centrally, it involves inviting children into the space between differing philosophical approaches, in ways that allow them to negotiate - or toy with - the borders of each. It is important to restate that this thesis aims to make a conceptual contribution to PfC - I do not suggest that the example that follows is ready for implementation. This offering of speculative negotiation to the classroom is indicative of an untested approach which, in turn, requires greater pedagogical scaffolding that goes beyond the scope of this thesis. It presents a starting-point for further research and may need to be adjusted in light of practice and empirical research.

Although there are a number of different ways that speculative negotiation could play out, my suggestion begins with teaching both generations in PfC sessions. Children will often be engaging with philosophical methods for the first time, or if they have already had some experience with PfC, with a first- or second-generation approach. To engage in speculative negotiation, it is important students are first taught existing PfC philosophical methods so that they can experiment with each approach and familiarise themselves with the steps of the CPI. Speculative negotiation should only be introduced when the teacher considers students adequately familiar with both first- and secondgeneration approaches, and could be introduced as a supplementary class (for example, once every two months if the school is having weekly PfC classes). As outlined in Table 2 below, only steps 1 and 2 of a traditional CPI remain the same, after which the CPI divides into three steps: (3) entering the broken middle, (4) introspection, (5) outward negotiation. Steps 1 and 2 can be found in the discussion on Lipman's CPI in Chapter 2, and I will proceed to outline steps 3-5 in turn. 


\begin{tabular}{|c|c|c|}
\hline & The steps & What happens \\
\hline 1 & The offering of the text & Students read or enact a philosophical story together \\
\hline 2 & The construction of the agenda & $\begin{array}{l}\text { Students raise questions prompted by the text and } \\
\text { organize them into a discussion agenda }\end{array}$ \\
\hline 3 & Entering the broken middle & $\begin{array}{l}\text { Students discuss their questions in a dialogue, drawing } \\
\text { on criteria from first- and second-generation pedagogies }\end{array}$ \\
\hline 4 & Introspection & $\begin{array}{l}\text { Students write a list of who and what the discussion } \\
\text { excluded }\end{array}$ \\
\hline 5 & $\begin{array}{l}\text { Evaluation and negotiation of the } \\
\text { programme }\end{array}$ & $\begin{array}{l}\text { This includes an evaluation of both analytic and } \\
\text { poststructuralist pedagogies and a discussion of } \\
\text { student's experiences throughout the discussion }\end{array}$ \\
\hline
\end{tabular}

Table 2: Describes the recommended steps for a negotiating CPI

\section{Entering the broken middle (Step 3)}

I propose that a CPI discussion can become a broken middle by situating children in the conceptual space between both generational programmes. Let's look at how this could play out in a CPI. Often, turn-taking in a CPI is encouraged by using a ball or object - the student with the ball/object is the one able to speak. When the next person wants to offer input, the ball or object is passed to them. To stage a broken middle I suggest placing three different coloured balls in the middle of the CPI circle. Two colours each represent the existing 'types' of CPIs. A red ball, for instance, could stand for the dialogical and analytic approach while a yellow ball could stand for the relational approach. The third colour, in this case green, could represent an additional philosophical approach that the children invent, for example, if they collectively decide that they want to approach inquiry by pretending they were animals, or through actions rather than words.

During the session the teacher could display a list of criteria for the characteristics of each approach/ball, for children to refer to in inquiry. The characteristics of student's own method (the green ball) can be chosen in the start of the first speculative negotiation class, and reformed for the following class, as we shall soon see. When a student wants to speak, s/he chooses a coloured ball and speaks in the language of that approach, much like De Bono's Six Thinking Hats. ${ }^{413}$ If a student, for instance, wants classmates to engage in ethical listening, they can choose the yellow ball. The yellow

${ }^{413}$ Bono, Six Thinking Hats. 
ball would continue to be passed around until someone decides to approach inquiry through a different line. This CPI can allow students to play around with the different approaches and witness them side-by-side. Engaging different philosophical approaches situates students in between different epistemic worldviews, in a space where they can start a process of negotiation. Table 3 pictured below identifies the kind of characteristics that children can refer to in the broken middle, with the red ball representing criteria for rational dialogue, the yellow ball representing criteria for ethical exposure, and the green ball representing an example of the children's own approach.

\begin{tabular}{|c|c|c|}
\hline $\begin{array}{l}\text { First-generation approach: } \\
\text { Rational dialogue }\end{array}$ & $\begin{array}{c}\text { Second-generation approach: } \\
\text { Ethical exposure }\end{array}$ & Our approach \\
\hline $\begin{array}{l}\text { - Give reasons for what } \\
\text { you are saying } \\
\text { - Use logical tools to } \\
\text { clarify ideas } \\
\text { - } \quad \begin{array}{l}\text { Build on each other's } \\
\text { arguments }\end{array} \\
\text { - Be inclusive, respectful } \\
\text { and responsive } \\
\text { - } \begin{array}{l}\text { Make corrections to } \\
\text { one's argument } \\
\text { - Keep consistent } \\
\text { - Think critically }\end{array}\end{array}$ & $\begin{array}{l}\text { - Listen carefully } \\
\text { Try to understand where } \\
\text { the other person is } \\
\text { coming from } \\
\text { - Be open to different } \\
\text { conclusions } \\
\text { - Leave some time to think } \\
\text { before the next person } \\
\text { speaks } \\
\text { - Think about who you are } \\
\text { as a person } \\
\text { - Notice your feelings } \\
\text { - Share personal } \\
\text { - } \begin{array}{l}\text { experiences } \\
\text { - }\end{array} \\
\text { opene to interpretation }{ }^{415}\end{array}$ & $\begin{array}{l}\text { - Think through actions } \\
\text { alone } \\
\text { - Try to communicate with } \\
\text { hands }\end{array}$ \\
\hline
\end{tabular}

Table 3: Possible characteristics for each approach/coloured ball

\footnotetext{
${ }^{414}$ Lipman, “(USA) Philosophy for Children"; IAPC, "Institute for the Advancement of Philosophy for Children (IAPC)."

${ }^{415}$ Vansieleghem, "Listening to Dialogue"; Biesta, "Philosophy, Exposure, and Children"; Kohan, Childhood, Education and Philosophy. Some of these criteria apply across both generations, such as listening to others.
} 
Introspection (Step 4)

As negotiation starts with an introspective turning inwards, encouraging negotiation in PfC involves evaluating the programme through introspection. Before students can turn outwards in negotiation, speculative negotiation asks students to, in light of more than one philosophical perspective, to turn inwards in introspection to look at and unsettle the epistemic foundations of each view. While it is unlikely children have formed philosophical commitments to one side of the philosophical dualism in the same manner as adults, engaging in the two philosophical approaches at the same time, as in the coloured balls example, may prompt an introspective look inwards by highlighting incompatibilities and biases. A broken middle CPI could make it more apparent for students that holding one philosophical approach excludes another kind of thinking, for example, thinking like an animal excludes thinking like a person, thinking through listening forecloses thinking through speaking, and so on.

At the end of each negotiating CPI session, children could be asked - by themselves, in pairs or in small groups - to write a list of how each philosophical approach they used in that CPI session excluded other ways of thinking, other ideas and even other classmates. This process of introspection could help children develop an epistemic awareness and accountability that understands the closeness of biases and exclusions to philosophical perspectives, and to perhaps eventually understand how each philosophical perspective holds political implications. And, importantly, it gives them a chance to gather their thoughts for the third, evaluative step of speculative negotiation. The process of introspection in the class is vital to negotiation because students have a chance to observe the potential implications of forming unfaltering epistemic commitments. In other words, it allows children to engage with philosophical approaches while maintaining epistemic awareness. 
- Did you feel your ideas were included during the discussion?

- Do you feel like you could express yourself equally with each ball?

- Which coloured ball did you find the easiest to express yourself with?

- Did the balls affect the way you thought about the topic?

- Are there any ideas you were not able to explore properly with one of the coloured balls?

Table 4: Examples of introspective questions

\section{Evaluation/Outward negotiation (Step 5)}

Coming to face misrecognitions within the CPI involves examining the programme's structures that facilitated misrecognition. This last step invites students to witness the relationship between the PfC programme and their philosophical inquiry, and the way that following the programme's 'rules' may marginalise some ways of thinking and other students. This places an epistemic responsibility on them to turn outwards to negotiate reflective ideas with the existing programme. As Schick iterates, speculative negotiation "works against ignorance: it leads us to encounter others and ourselves and to go deeper, re-cognizing again (and again) that which is initially known."416 Rather than practising combining parts of the two methods, students continually rework the nature of each philosophical approach (each of the coloured balls for instance). This works against forming new dualisms because it always incorporates ideas into existing structures.

Outward negotiation begins with students sharing their personal introspective experiences of the broken middle step with the class. Then, students can discuss whether and how they think each of the coloured balls should shift. For example, if a student, through introspection, saw that ethical listening excluded collective endings, the class would discuss whether they should address this limit and how they could remedy it. Or, for another example, if a student felt they could not express themselves properly through actions, they could suggest changing the green ball to represent expression through drawing. Table 5 below presents some examples of the sorts of evaluative questions that could be discussed in outward negotiation. Students can use

${ }^{416}$ Schick, "Re-Cognizing Recognition,” 88. 
their introspective lists as a reference to guide how they feel in adjusting the criteria. The process of turning out in the CPI encourages a negotiation between the self (one's introspective lessons) and the collective, in that the children have to work together through their experiences of exclusion and expression to collectively decide (or negotiate) whether and how to change one or more criteria.

Questions for introspection

- Who felt they could not express themselves using one of the coloured balls?

- Can you point out what part of the criteria made it difficult for you to express yourself?

- Can anyone identify what parts of the three balls contradict each other (for example, we cannot express ourselves through both talking (with the red ball) and not talking (the green ball))?

- Should we change any part of the criteria for the next negotiating class?

- Why do you think it should be changed?

- What should we replace it with?

Table 5: Examples of evaluative questions to guide negotiation

During this discussion, guided by the facilitator, students can compile a list of exclusions and limits they think needs to be addressed, and corresponding remedies. Here the class can decide which criteria need alteration, and how they should be changed for the next speculative session. Some hypothetical examples are presented in Table 6. The collective decision-making process of reworking the approach/method of each ball involves students risking and giving up parts of their experiences in light of each other's experiences. Students will have to risk their introspective lessons in negotiation with analytic and continental approaches, as well as their classmates, their political hopes and structural realities. The evaluative process therefore includes a chance for students to incorporate their ideas into the structure of the programme - to slowly, and with difficulty, renegotiate and disrupt the first and second generation approaches so the curriculum shifts in light of children's inventive thinking and in light of their introspective sessions. 


\begin{tabular}{|l|l|l|}
\hline Exclusions and limitations & Remedy \\
\hline $\begin{array}{l}\text { "I felt like I could not express myself } \\
\text { through actions" }\end{array}$ & $\begin{array}{l}\text { Change 'think through actions alone' in the } \\
\text { green ball to 'thinking through drawing' }\end{array}$ \\
\hline $\begin{array}{l}\text { "Ifelt like it was difficult to remain } \\
\text { experient and share personal }\end{array}$ & $\begin{array}{l}\text { Remove the 'consistency' criteria from the } \\
\text { red ball }\end{array}$ \\
\hline $\begin{array}{l}\text { "I thought it was counter-productive to } \\
\text { leave the discussion without a conclusion" }\end{array}$ & $\begin{array}{l}\text { Change 'leave the discussion open to } \\
\text { interpretation' in the yellow ball to 'reach a } \\
\text { conclusion' }\end{array}$ \\
\hline
\end{tabular}

Table 6: Examples of how identified limitations can be negotiated

\section{Opportunities Ahead}

This section outlines several reasons why classroom engagement with speculative negotiation would better equip children to overcome the limits of epistemic isolation. Speculative negotiation disrupts epistemic circularity through exposing children to alternative and sometimes contradictory viewpoints simultaneously, allowing them to become aware of and question the assumptions that confine thought within paradigms. Through speculative negotiation, children can assume each philosophical stance, turning inwards in introspection to identify biases, and outwards to transform the programme's methods. Students will become aware, for instance, of the stark contrast between a dialogue based on rational debate and one based on ethical listening, or of how basing a CPI on one precludes the other.

Exposing epistemic biases could allow students to develop philosophical methods beyond their initial assumptions, countering the difficulty of evaluating a philosophical approach from its own standpoint. Taking children seriously as meaning-makers trusts them to engage in "adult" dialogues without fear of indoctrination. This enables them to encounter different kinds of philosophising, like rational thinking, while understanding that these need not be moribund - that their borders can shift with the difficult work of negotiation. Speculative negotiation helps overcome the inclination towards invulnerability that hardens paradigm edges, but does so in a way that encourages children not to fear aligning with paradigms - it does not discourage emphasising a single philosophical approach, but works against overly comfortable alignment. 
A negotiating PfC does not carry on knowledge and knowledge processes as-is, but does not abandon these either. It provides space for children to construct their own epistemic and philosophical realities out of existing ones, and embeds the process of questioning established assumptions into the process of 'thinking otherwise'. As Barad puts it, a philosophy that unsettles epistemic foundations understands that epistemic methods are interactive affairs: "a doing" that is "morphologically active, responsive, generative, and articulate." ${ }^{417}$ This active epistemic stance (re)invites embodied experience into philosophy, both by means of the child and by means of speculative negotiation. It allows students to look past the epistemically-intelligible to alternate epistemic worlds that employ unconventional assumptions about knowledge and about what is possible. For children to engage in such deep questioning is to engage them in dominant forms of philosophical conversation without binding them to these. It presses upon those who engage in philosophy to refuse political and epistemic 'givenness'

Furthermore, introspection encourages children to develop accountability when developing their philosophical ideas, making them more aware of the political consequences of strict philosophical adherence - something that other cross-paradigm approaches may not do - because it emphasises looking at the philosophical and political limitations and implications of each inquiry, for example, through the introspective process of writing a list of exclusions. Introspection works against desiring epistemic invulnerability, while turning out unnerves coherence. This is important for 'thinking otherwise' because it works against getting stuck in one way of thinking about politics.

The messier kinds of turning outwards and activism involved in speculative negotiation will again better enable children to understand the political implications of differing philosophies, and the incompatibilities between philosophical perspectives and some actualities. Speculative negotiation discourages strictly universalist, institutional, democratic change - engaging with both the particular and the universal blurs their borders and encourages a politics that also draws on embodied experiences and fluidity. Negotiating between the two pedagogical approaches for 'thinking otherwise' sets up a more responsive philosophy that would further challenge children's ideas. Coming

${ }^{417}$ Barad and Kleinman, "Intra-Actions," 80. 
up against political realities, again, imparts political accountability and awareness of the limits of 'thinking otherwise' through philosophy.

Negotiating the incompatibilities between oneself and one's classmates, between different philosophical approaches, between the self and the programme, and between the philosophical and the political will be laced with mistakes and exclusionary potential. But those borders can again be shaped and reshaped, and the programme adjusted, enabling children to acquire autonomy over philosophy in the process. Supporting epistemic openness in the classroom opens one's ideas and oneself to transformation in uncontrollable ways, opening philosophy to a wider array of resources, varieties of people, and forms of input. These mistakes and unpredictable collaborations would give the programme itself a continuous nature.

Encouraging students to feel comfortable with epistemic openness holds potential to expose an innovative, forgotten side of philosophy. This throws into question the circularity of paradigms that privilege particular ideas and discourages situating political action in simple stories. Introducing speculative negotiation to PfC therefore opens to Rose's pragmatic hopefulness (hopeful and full of mistakes): an imaginative hope that engages with the ordinary and the universal in an ever-renewing manner. The result would be an earthly, embodied and regenerative pragmatism that encourages a continuous negotiation of the political imagination and of what is perceived as possible. 


\section{Conclusion}

I conclude that resisting the threat of political bubble-think requires equipping citizens to be philosophically accountable in envisioning different worlds. I have presented a case for everyday engagement with speculative negotiation to encourage people to respond radically and accountably to challenges in other parts of society.

I began by illustrating how the two dominant contemporary philosophical paradigms present different paths towards 'thinking otherwise'. Influenced by different assumptions about philosophy and the world, each approach provides distinct methods for imagining past existing societies and these methods are likely to influence how we envision different worlds. Post-structuralism practises disruption and engages with difference in order to redefine our relations along fluid and actively non-hierarchical lines, while analytic philosophy inspires rational and deliberative imagining to develop universal blueprints and autonomous imaginers. These influences are present in PfC, where first-generation PfC theorists encourage children to redefine our world through reason, and second-generation PfC theorists encourage disruption. While the influence of philosophical methods over political visions is not problematic in general (it is unavoidable), it becomes a problem when people cannot adequately look beyond a paradigm's core assumptions, which occurs when only one paradigm is integrated into everyday life.

As I have argued, lack of cross-paradigm engagement in philosophy leads to myopic approaches which lack the accountability and self-awareness needed to challenge their own assumptions and exclusions. Hence in Part 2, I argued that isolated paradigmatic thinking restricts our ability to expansively 'think otherwise' by inhibiting our ability to transform inquiry methods beyond the parameters of each paradigm's epistemic world. The stagnation of a paradigm solidifies its political influence, creating the possibility of political tunnel vision that limits the ability of future generations to form new worlds. The epistemically self-sufficient nature of epistemic isolation has presented us with the limits of circular and protected thinking, limits that we should actively address when bringing philosophy to a wider range of settings for 'thinking otherwise'. 
Yet children can change the face of philosophy and politics if given the appropriate resources. In Part 3 I also explained how introducing speculative negotiation to PfC would enable children to transform philosophy, and with it their opportunities for creative political imagining. I showed how introspection in the face of the philosophical 'Other' is an important part of realising how our philosophical methods implicitly shape our political thinking. Introspection invites us to realise our deep involvement in the nature of philosophy - the way our own philosophising shapes philosophy overall - and the ways we are shaped through philosophising. When we shift inquiry methods, we alter how we interact with the world and the kinds of conclusions we draw. In PfC this expands children's ability to progress the world beyond existing arrangements. Resisting political tunnel vision involves an active epistemic stance - actively resisting the need to feel epistemically certain. Instead of unrealistically trying to avoid philosophy's political influence, I argue it should be worked with, which in PfC involves the opportunity to draw on both first- and second-generation pedagogical practices, alongside speculative negotiation, to continuously unsettle existing pedagogical methods.

The speculative pedagogy I advocate for PfC invites children to work across paradigms to both rework them and to pay attention to their involvement in philosophy's character and use. In Part 3 I argue that facing the philosophical 'Other' in the broken middle enables overcoming the limits of epistemic isolation, by exposing epistemic foundations for examination - it encourages people to collaboratively unsettle each paradigm's epistemic foundations and to incorporate lessons from cross-paradigm engagement into each paradigm. Speculative negotiation does not extinguish or harmonise either first- or second-generation PfC sessions but holds their contradictions together in a continuous push-and-pull. In this way it shakes up what has been taken for granted in PfC, but does not gesture towards a detached, utopian future. It engages messy utopian dreaming, which partakes in the difficult process of pragmatically weaving dreams developed in first- and second-generation pedagogies into existing political structures. This asks the child-philosopher to embark on the hard journey of radically reshaping existing society through responding to a wider range of political challenges, difficulties that continuously prompt philosophical self-examination and 'acting otherwise'. 
I argue that public engagement with speculative negotiation will inspire citizens to 'think otherwise' in a manner that actively resists arbitrary exclusions - to 'imagine accountably'. Speculative negotiation promotes an accountable epistemology where people are conscious of who and what they name, lending to a self-aware politics that is conscious of who and what one excludes in pursuing political change. By reworking philosophy accountably, actively, and continuously, speculative negotiation would encourage people to think about politics in a manner that is not confined to our existing political lenses; a political visualising where people have own their tools for 'thinking otherwise'. Engaging with speculative negotiation in the PfC classroom could therefore have widespread implications for children's engagement with philosophy, where ownership over philosophical methods will expand children's ownership over political change, to more radically define their future.

Speculative negotiation continuously unsettles the way both analytic and continental philosophies inspire political envisioning, yet always works towards their ungraspable unity. Therefore the kind of politics invited by 'thinking otherwise' through speculative negotiation is one that works hard towards a hopeful future but takes account of realities; one that works towards a collective universal but is attentive to the particular; and one that works towards a completely unknown politics, but in a manner that does not leave behind what exists. It invites a politics that draws on and unsettles dualities that mark both politics and philosophy and works towards political conclusions that draw simultaneously on the particular and universal, the institutional and the noninstitutional at the same time as receiving a new politics. From Rose we can shape a new politics in a way that is responsible for the complexities of life. Acknowledgement of complexity, Rose tells us, "does not fall into the opposition of mastery/passivity: it acknowledges the negative as it moves beyond eternal loss to eternal confirmation." In this way, engagement with speculative negotiation in everyday life lends towards an achievable utopia - not an abstract dreaming but a slow and pragmatic building from what exists. I am hopeful that this would result in a society more able to respond politically to societal challenges.

${ }^{418}$ Rose, Mourning Becomes the Law, 146. 


\section{Bibliography}

Alston, William. "Epistemic Circularity." Philosophy and Phenomenological Research 47: 1 (1986), 1-30.

Anderson, Elizabeth. "Epistemic Bubbles and Authoritarian Politics." Lecture presented at Massachusetts Institute of Technology, 2017.

Arendt, Hannah. On Revolution. (New York: Penguin Classics, 1963).

Arendt, Hannah. The Human Condition. (Chicago: The University of Chicago Press, 1958).

Barad, Karen. "Interview with Karen Barad." In New Materialism: Interviews and Cartographies, edited by Rick Dolphijn and Iris van der Tuin. (Michigan: Open Humanities Press, 2013), 48-71.

Barad, Karen. Meeting the Universe Halfway: Quantum Physics and the Entanglement of Matter and Meaning. (Durham: Duke University Press Books, 2007).

Barad, Karen, and Adam Kleinman. "Intra-Actions." Mousse 34 (2012), 76-81.

Bell, David, and Neil Cooper. The Analytic Tradition: Meaning, Thought, and Knowledge. (Oxford: Blackwell Publishing, 1990).

Berardi, Francesco. Futurability: The Age of Impotence and the Horizon of Possibility. (Brooklyn: Verso, 2017).

Berardi, Franco, David Hugill, and Elise Thorburn. "Interview with Bifo: Reactivating the Social Body in Insurrectionary Times." Critical Legal Thinking. September 26, 2012. http://criticallegalthinking.com/2012/09/26/interview-with-bifo-reactivatingthe-social-body-in-insurrectionary-times/.

Berlant, Lauren. Cruel Optimism. (Durham: Duke University Press Books, 2011).

Berlant, Lauren. The Anatomy of National Fantasy: Hawthorne, Utopia, and Everyday Life. (Chicago: University of Chicago Press, 1991).

Berlant, Lauren, and David Seitz. "On Citizenship and Optimism." Society and Space. March 22, 2013. http://societyandspace.org/2013/03/22/on-citizenship-andoptimism/.

Biesta, Gert. "Philosophy, Exposure, and Children: How to Resist the Instrumentalisation of Philosophy in Education." Journal of Philosophy of Education 45: 2 (2011), 305-319.

Boghossian, Paul. "Knowledge of Logic." In New Essays on the A Priori, edited by Paul Boghossian and Christopher Peacocke. (Oxford; New York: Clarendon Press, 2001), 29- 55.

Bono, Edward de. Six Thinking Hats. (Boston: Back Bay Books, 1999).

Bozalek, Vivienne, and Michalinos Zembylas. "Diffraction or Reflection? Sketching the Contours of Two Methodologies in Educational Research." International Journal of Qualitative Studies in Education 30: 2 (2017), 111-127.

Braver, Lee. A Thing of This World: A History of Continental Anti-Realism. (Evanston: Northwestern University Press, 2007).

Briggle, Robert, and Adam Frodeman. "When Philosophy Lost Its Way." New York Times. January 11, 2016. https://opinionator.blogs.nytimes.com/2016/01/11/whenphilosophy-lost-its-way/.

Brown, Wendy. Undoing the Demos: Neoliberalism's Stealth Revolution. (New York: Zone Books, 2015).

Bruner, Jerome. The Process of Education. (Cambridge: Harvard University Press, 1977). 
Bryant, Levi. "Rupture/Events: Normal and Revolutionary Politics." Larval Subjects. March 9, 2016. https://larvalsubjects.wordpress.com/2016/03/09/ruptureeventsnormal-and-revolutionary-politics/.

Bryant, Levi. The Democracy of Objects. (Michigan: Open Humanities Press, 2011). Bryant, Levi. "The Ontic Principle: Outline of an Object-Orientated Ontology." In The Speculative Turn: Continental Materialism and Realism, edited by Levi R. Bryant, Nick Srnicek, and Graham Harman. (Melbourne, Re.Press, 2011), 261-279.

Bryant, Levi, Nick Srnicek, and Graham Harman, eds. The Speculative Turn: Continental Materialism and Realism. (Melbourne: Re.Press, 2011).

Buckle, Stephen. "Analytic Philosophy and Continental Philosophy: The Campbell Thesis Revised." British Journal for the History of Philosophy 12: 1 (2004), 111150 .

Burke, Edmund. Reflections on the Revolution in France. (New York: Dover Publications, 2006).

Butler, Judith. Bodies That Matter: On the Discursive Limits of Sex. (New York: Routledge, 1993).

Butler, Judith. Frames of War: When Is Life Grievable?. (New York: Verso, 2009).

Butler, Judith. Gender Trouble. (New York: Routledge, 1990).

Butler, Judith. Undoing Gender. (London: Routledge, 2004).

Butler, Judith. "What Is Critique? An Essay on Foucault's Virtue.” In The Political: Readings in Continental Philosophy, edited by David Ingram. (Massachusetts: Blackwell Publishers, 2002), 212-229.

Cam, Philip. 20 Thinking Tools: Collaborative Inquiry for the Classroom. (Melbourne: ACER Press, 2006).

Cam, Philip. "Dewey, Lipman \& the Tradition of Reflective Education." In Pragmatism, Education, and Children: International Philosophical Perspectives, edited by Michael Taylor, Helmut Schreier and Paulo Ghiraldelli. (Amsterdam: Editions Rodopi, 2006), 163-185.

Campbell, Richard. "The Covert Metaphysics of the Clash Between 'Analytic' and 'Continental' Philosophy." British Journal for the History of Philosophy 9: 2 (2001), 341-359.

Chetty, Darren, and Judith Suissa. "No Go Areas': Racism and Discomfort in the Community of Inquiry." In The Routledge International Handbook of Philosophy for Children, edited by Maughn Rollins Gregory, Joanna Haynes, and Karin Murris. (London; New York: Routledge, 2016), 11-19.

Chisholm, Roderick. The Problem of the Criterion. (Milwaukee: Marquette University Press, 1973).

Critchley, Simon. "What Is Continental Philosophy?" International Journal of Philosophical Studies 5: 3 (1997), 347-363.

Daniel, Marie-France, Michael Schleifer, and Pierre Lebouis. "Philosophy for Children: The Continuation of Dewey's Democratic Project.” Analytic Teaching 13: 1 (1992), 3-13.

Dean, Jodi. Democracy and Other Neoliberal Fantasies: Communicative Capitalism and Left Politics. (Durham: Duke University Press, 2009).

Deleuze, Gilles. Desert Islands: And Other Texts, 1953-1974. Edited by David Lapoujade. (Los Angeles: Semiotext(e), 2004).

Derrida, Jacques. Positions. Translated by Alan Bass. (Chicago: University of Chicago Press, 1982).

Derrida, Jacques. The Ear of the Other: Otobiography, Transference, Translation. (Lincoln: University of Nebraska Press, 1988).

Dewey, John. Democracy and Education. (New York: Free Press, 1916; 1997). 
Dolphijn, Rick, and Iris van der Tuin. New Materialism: Interviews \& Cartographies. (Michigan: Open Humanites Press, 2013).

Dummett, Michael. "The Justification of Deduction." In Truth and Other Enigmas, edited by Michael Dummett. (Oxford: Oxford University Press, 1974).

D'Entreves, Maurizio Passerin. "Hannah Arendt." The Stanford Encyclopedia of Philosophy. 2016. https://plato.stanford.edu/archives/win2016/entries/arendt/.

Edkins, Jenny. Trauma and the Memory of Politics. (Cambridge: Cambridge University Press, 2003).

Ellerton, Peter. "Pragmatist Epistemology, Inquiry Values and Education for Thinking." In The Routledge International Handbook of Philosophy for Children, edited by Maughn Rollins Gregory, Joanna Haynes, and Karin Murris. (London; New York: Routledge, 2016), 111-119.

Fisher, Robert. Teaching Thinking: Philosophical Enquiry in the Classroom. (London: Bloomsbury Academic, 2003).

Fitzsimons, Peter. "School and the Limits of Philosophy." Educational Philosophy and Theory 46: 11 (2014), 1276-1289.

Fletcher, Natalie, and Joseph Oyler. "Curating an Asthetic Space for Inquiry." In The Routledge International Handbook of Philosophy for Children, edited by Maughn Rollins Gregory, Joanna Haynes, and Karin Murris. (London; New York: Routledge, 2016), 153-161

Foucault, Michel. Discipline and Punish. Translated by Alan Sheridan. (New York: Vintage Books, 1995).

Foucault, Michel. Power/Knowledge: Selected Interviews and Other Writings, 19721977. Edited by Colin Gordon. (New York: Vintage, 1980).

Foucault, Michel, and Sylvere Lotringer. Foucault Live: Interviews, 1961-84. (South Pasadena: Semiotext(e), 1996).

Gilson, Erinn. "Vulnerability, Ignorance, and Oppression.” Hypatia 26: 2 (2011), 308332.

Glaser, Jen. "Dialogue and Difference: Philosophical Inquiry in a Complex World." Lecture presented at the FAPSA Conference, Wellington, New Zealand, April 19, 2016.

Glaser, Jen. "Educating for Citizenship and Social Justice." In Children Philosophize Worldwide: Theoretical and Practical Concepts, edited by Eva Marsal, Takara Dobashi, and Barbara Weber. (Frankfurt: Peter Lang, 2009), 103-111

Glendinning, Simon. On Being With Others: Heidegger, Wittgenstein, Derrida. (London; New York: Routledge, 1998).

Glendinning, Simon. The Idea of Continental Philosophy. (Edinburgh: Edinburgh University Press, 2006).

Glock, Hans-Johann. Rise of Analytic Philosophy. (Oxford: Wiley-Blackwell, 1999).

Gray, John. The Silence of Animals: On Progress and Other Modern Myths. (New York: Farrar, Straus and Giroux, 2014).

Green, Karen. "A Plague on Both Your Houses.” The Monist 82: 2 (1999), 278-303.

Gregory, Maughn. "Philosophy for Children and Its Critics: A Mendham Dialogue." Journal of Philosophy of Education 45: 2 (2011), 199-219.

Gregory, Maughn. "Practicing Democracy: Social Intelligence and Philosophical Practice." International Journal of Applied Philosophy 18: 2 (2004), 163-176.

Gregory, Maughn Rollins, Joanna Haynes, and Karin Murris, eds. The Routledge International Handbook of Philosophy for Children. (London; New York: Routledge, 2016).

Guattari, Fèlix. Soft Subversions: Texts and Interviews 1977-1985. Edited by Sylvère Lotringer. (Los Angeles: Semiotext(e), 2009). 
Gutting, Gary. "Bridging the Analytic-Continental Divide." New York Times. February 19, 2012. https://opinionator.blogs.nytimes.com/2012/02/19/bridging-the-analyticcontinental-divide/.

Haack, Susan. "The Justification of Deduction.” Mind 85: 337 (1976), 112-119.

Hand, Michael. "Can Children Be Taught Philosophy?" In Philosophy in Schools, edited by Carrie Winstanley and Michael Hand. (London; New York: Bloomsbury Academic, 2009), 5-17.

Haslanger, Sally. "A Social Construction Analysis of Race.” In Arguing About Human Nature: Contemporary Debates, edited by Stephen Downes and Edouard Machery. (New York: Routledge, 2013), 377-384.

Haynes, Joanna. "Listening as a Critical Practice: Learning from Philosophy with Children." PhD. University of Exeter. (2007).

Haynes, Joanna, and Karin Murris. "The Realm of Meaning: Imagination, Narrative and Playfulness in Philosophical Exploration with Young Children." Early Child Development and Care 183: 8 (2013), 1084-1100.

Hegel, Georg. Science of Logic. (New York: Humanity Books, 1969).

Hutchings, Kimberly. "A Place of Greater Safety? Securing Judgment in International Ethics." In The Vulnerable Subject, edited by Amanda Russell Beatie and Kate Schick. (Hampshire: Palgrave Macmillan, 2012), 25-42.

IAPC. "Institute for the Advancement of Philosophy for Children." IAPC. (n.d.) https://www.montclair.edu/cehs/academics/centers-and-institutes/iapc/.

Kennedy, David. "Rhizomatic Curriculum Development in Community of Philosophical Inquiry." Paper Presented at the 14 Third Annual Meeting of the International Council for Philosophical Inquiry with Children, July 2, 2009, 1-8.

Kennedy, Nadia, and David Kennedy. "Community of Philosophical Inquiry as a Discursive Structure, and Its Role in School Curriculum Design." Journal of Philosophy of Education 45: 2 (2011), 265-283.

Kennedy, Nadia. "Lipman, Dewey, and Philosophical Inquiry in the Mathematics Classroom." Education and Culture 28: 2 (2012), 81-94.

Kochi, Tarik. "Being, Nothing, Becoming: Hegel and the Legal Order." In New Critical Legal Thinking: Law and the Political, edited by Matthew Stone, Illan rua Wall, and Costas Douzinas. (Oxton: Routledge, 2012).

Kohan, Walter. Childhood, Education and Philosophy: New Ideas for an Old Relationship. (London; New York: Routledge, 2014).

Kohan, Walter. "What Can Philosophy and Children Offer Each Other?" Thinking: The Journal of Philosophy for Children 14: 4 (1999), 2-8.

Kohan, Walter. "Childhood, Education and Philosophy: Notes on Deterritorialisation." Journal of Philosophy of Education 45: 2 (2011), 339-357.

Kohan, Walter. The Inventive Schoolmaster. (Rotterdam: Sense Publishers, 2015).

Kolozova, Katerina. Cut of the Real: Subjectivity in Poststructuralist Philosophy. (New York: Columbia University Press, 2014).

Kolozova, Katerina. Toward a Radical Metaphysics of Socialism: Marx and Laruelle. (New York: Punctum Books, 2015).

Kristeva, Julia. Revolution in Poetic Language. (New York: Columbia University Press, 1984).

Laclau, Ernesto, and Chantal Mouffe. Hegemony and Socialist Strategy: Towards a Radical Democratic Politics. (London; New York: Verso, 2001).

Laruelle, François. Philosophy and Non-Philosophy. (Minneapolis: Univocal, 1989).

Laruelle, François. "What Can Non-Philosophy Do?” Angelaki 8: 2 (2003), 169-189. 
Lather, Patti. "Paradigm Proliferation as a Good Thing to Think with: Teaching Research in Education as a Wild Profusion." International Journal of Qualitative Studies in Education 19: 1 (2006), 35-57.

Latz, Andrew. "Gillian Rose and Social Theory." Telos 173 (2015), 37-54.

Laverty, Megan. "The Bonds of Learning Dialogue and the Question of Human Solidarity." Philosophy of Education Philosophy of Education (2009), 120-128.

Legg, Catherine. "Charles Peirce's Limit Concept of Truth." Philosophy Compass 9: 3 (2014), 204-213.

Levinas, Emmanuel. Alterity and Transcendence. (New York: Columbia University Press, 2000).

Lipman, Matthew. Elfie. (Montclair: IAPC, 1987).

Lipman, Matthew. Natasha: Vygotskian Dialogues. (New York: Teachers College Press, 1996).

Lipman, Matthew. "Philosophical Practice and Educational Reform." Journal of Thought 20: 4 (1985), 20-36.

Lipman, Matthew. Philosophy Goes To School. (Philadelphia: Temple University Press, 1988).

Lipman, Matthew. Pixie. (Montclair: IAPC, 1981).

Lipman, Matthew. "Teaching Students to Think Reasonably: Some Findings of the Philosophy for Children Program." The Clearing House 71 : 5 (1998), 277-280.

Lipman, Matthew. Thinking in Education. (Cambridge: Cambridge University Press, 2003).

Lipman, Matthew. "(USA) Philosophy for Children: Some Assumptions and Implications." In Children Philosophize Worldwide: Theoretical and Practical Concepts, edited by Eva Marsal, Takara Dobashi, and Barbara Weber. (Frankfurt: Peter Lang, 2009), 23-47.

Lipman, Matthew, Ann Sharp, and Frederick Oscanyan. Philosophy in the Classroom. (Philadelphia: Temple University Press, 1980).

Lloyd, Vincent. “Gillian Rose, Race, and Identity.” Telos 173 (2015), 107-24.

Lloyd, Vincent. The Problem with Grace: Reconfiguring Political Theology. (Stanford: Stanford University Press, 2011).

Long, Fiachra. "Thomas Reid and Philosophy with Children." Journal of Philosophy of Education 39: 4 (2005), 599-614.

Lyotard, Jean-François. Driftworks. (New York: Semiotext(e), 1984).

Macdonald, Matthew. "Epistemic Circularity." Thesis. Victoria University of Wellington. (2015).

MacKinnon, Rebecca. Consent of the Networked: The Worldwide Struggle For Internet Freedom. (New York: Basic Books, 2013).

Matthews, Gareth. Dialogues with Children. (Cambridge: Harvard University Press, 1984).

Milbank, John. "On the Paraethical: Gillian Rose and Political Nihilism." Telos 173 (2015), 69-86.

Moore, Jason. Anthropocene or Capitalocene?: Nature, History, and the Crisis of Capitalism. (Oakland: PM Press, 2016).

Morton, Timothy. Dark Ecology: For a Logic of Future Coexistence. (New York: Columbia University Press, 2016).

Morton, Timothy. "Ecology without the Present." The Oxford Literary Review 34: 2 (2012), 229-238.

Mouffe, Chantal. Agonistics: Thinking The World Politically. (London; New York: Verso, 2013). 
Murris, Karin. "The Philosophy for Children Curriculum: Resisting 'Teacher Proof'

Texts and the Formation of the Ideal Philosopher Child." Studies in Philosophy and Education 35: 1 (2016), 63-78.

Murris, Karin. The Posthuman Child. (London: Routledge, 2016).

Nissen, Sylvia. "“We Don't Do Protest': Understanding the Attitudes of Contemporary

University Students towards Political Action in Aotearoa New Zealand." Thesis.

Victoria University of Wellington. (2016).

Nozick, Robert. Anarchy, State, and Utopia. (New York: Basic Books, 1974).

Ombler, Jennifer. "Emancipating Space from the Conditions of Violence: The Broken Middle and Inaugurated Mourning in Israel and Palestine." Victoria University of Wellington. (2016).

Osborne, Peter. "Gillian Rose and Marxism." Telos 173 (2015), 55-67.

Paxton, Joseph, Tommaso Bruni, and Joshua Greene. "Are 'Counter-Intuitive' Deontological Judgments Really Counter-Intuitive? An Empirical Reply to.” Social Cognitive and Affective Neuroscience 9: 9 (2014), 1368-1371.

Paxton, Joseph, Leo Ungar, and Joshua Greene. "Reflection and Reasoning in Moral Judgment." Cognitive Science 36: 1 (2012), 163-177.

Peck, Jamie. Constructions of Neoliberal Reason. (Oxford: Oxford University Press, 2010).

Peck, Jamie. "Zombie Neoliberalism and the Ambidextrous State." Theoretical Criminology 14: 1 (2010), 104-110.

Peirce, Charles. Philosophical Writings of Peirce. Edited by Justus Buchler. (New York: Dover Publications, 1955).

Peters, Michael. "Education, Neoliberalism, and Human Capital: Homo Economicus as 'entrepreneur of Himself."' In The Handbook of Neoliberalism, edited by Simon Springer, Kean Birch, and Julie MacLeavy. (New York: Routledge, 2016), 297308.

Pogge, Thomas. "World Poverty and Human Rights." In Ethics and International Affairs, edited by Joel Rosenthal and Christian Barry. (Washington: Georgetown University Press, 2009), 307-317.

Rawls, John. A Theory of Justice. (Cambridge: Belknap Press, 1971).

Reed, Ann, and Tony Johnson. Friendship and Moral Education: Twin Pillars of Philosophy for Children. (New York: Peter Lang, 1999).

Reynolds, Jack. "Sadism and Masochism: A Symptomatology of Analytic and Continental Philosophy." Parrhesia 1: 1 (2006), 88-111.

Reynolds, Jack, James Chase, Ed Mares, and James Williams, eds. Postanalytic and Metacontinental: Crossing Philosophical Divides. (London: Bloomsbury Academic, 2011).

Rorty, Richard. Contingency, Irony, and Solidarity. (Cambridge: Cambridge University Press, 1989).

Rorty, Richard. Truth and Progress: Philosophical Papers. (Cambridge: Cambridge University Press, 1998).

Rose, Gillian. Judaism and Modernity. (Oxford: Blackwell, 1993).

Rose, Gillian. Mourning Becomes the Law: Philosophy and Representation. (Cambridge: Cambridge University Press, 1996).

Rose, Gillian. The Broken Middle: Out of Our Ancient Society. (Oxford; Cambridge: Wiley-Blackwell, 1992).

Rowlands, Anna. “'Angry Angels' as Guides to Ethics and Faith: Reflections on Simone Weil and Gillian Rose." Theology 112: 865 (2009), 14-23.

Roy, Eleanor Ainge. "New Zealand Housing Crisis Forces Hundreds to Live in Tents and Garages." The Guardian. May 17, 2016. 
https://www.theguardian.com/world/2016/may/17/new-zealand-housing-crisisforces-hundreds-to-live-in-garages-tents-and-cars.

Russell, Bertrand. Mysticism and Logic: And Other Essays. (London: George Allen \& Unwin Ltd, 1910).

Sassen, Saskia. Losing Control? Sovereignty in an Age of Globalization. (New York: Columbia University Press, 1996).

Schick, Kate. Gillian Rose: A Good Enough Justice. (Edinburgh: Edinburgh University Press, 2012).

Schick, Kate. 'Re-Cognizing Recognition: Gillian Rose's 'Radical Hegel' and Vulnerable Recognition.” Telos 173 (2015), 87-105.

Schmid, Anne-Françoise, and Armand Hatchuel. "On Generic Epistemology." Angelaki 19: 2 (2014), 131-144.

Sharp, Ann Margaret. "Community of Inquiry as Ritual Participation." In Children Philosophize Worldwide: Theoretical and Practical Concepts, edited by Eva Marsal, Takara Dobashi, and Barbara Weber. (Frankfurt: Peter Lang, 2009), 301306.

Sharp, Ann Margaret. "The Child as Critic." In Children Philosophize Worldwide: Theoretical and Practical Concepts, edited by Eva Marsal, Takara Dobashi, and Barbara Weber. (Frankfurt: Peter Lang, 2009), 201-210.

Sharp, Ann Margaret. "And the Children Shall Lead Them." International Journal of Applied Philosophy 18: 2 (2004), 177-187.

Sharp, Ann Margaret. "The Community of Inquiry: Education for Democracy." Thinking: The Journal of Philosophy for Children 9: 2 (1991), 31-37.

Sharp, Ann Margaret. "What Is a 'Community of Inquiry?" Journal of Moral Education 16: 1 (1987), 37-45.

Singer, Peter. Animal Liberation: The Definitive Classic of the Animal Movement. (New York: Harper Perennial Modern Classics, 2009).

Spivak, Gayatri Chakravorty. A Critique of Postcolonial Reason: Toward a History of the Vanishing Present. (Cambridge: Harvard University Press, 1999).

Splitter, Laurance, and Ann Margaret Sharp. Teaching for Better Thinking. (Melbourne: Australian Council for Educational, 1995).

Springer, Simon. "Fuck Neoliberalism." An International Journal for Critical Geographies 15: 2 (2016), 285-292.

Springer, Simon. "The Violence of Neoliberalism." In The Handbook of Neoliberalism, edited by Simon Springer, Kean Birch, and Julie MacLeavy. (New York: Routledge, 2016), 153-163.

Srnicek, Nick. "Capitalism and the Non-Philosophical Subject." In The Speculative Turn, edited by Levi Bryant, Nick Srnicek, and Graham Harman. (Melbourne: Re.Press, 2011), 164-182.

Srnicek, Nick, and Alex Williams. Inventing the Future: Postcapitalism and a World Without Work. (New York: Verso, 2015).

Steup, Matthias. "Epistemology.” The Stanford Encyclopedia of Philosophy. 2016. https://plato.stanford.edu/archives/fall2016/entries/epistemology/.

Tuana, Nancy. "The Speculum of Ignorance: The Women's Health Movement and Epistemologies of Ignorance." Hypatia 21: 3 (2006), 1-19.

Vanderbeeken, Robrecht. "A Plea for Agonism Between Analytic and Continental Philosophy." Open Journal of Philosophy 1: 1 (2011), 16-21.

Vansieleghem, Nancy. "Listening to Dialogue." Studies in Philosophy and Education 25: 1-2 (2006), 175-190. 
Vansieleghem, Nancy. "Philosophy with Children as an Exercise in Parrhesia: An Account of a Philosophical Experiment with Children in Cambodia." Journal of Philosophy of Education 45: 2 (2011), 321-337.

Vansieleghem, Nancy. "Philosophy for Children as the Wind of Thinking." Journal of Philosophy of Education 39: 1 (2005), 19-35.

Vansieleghem, Nancy, and David Kennedy. "What Is Philosophy with Children-After Matthew Lipman?” Journal of Philosophy of Education 45: 2 (2011), 171-182.

Virilio, Paul. Negative Horizon: An Essay in Dromoscopy. (London; New York: Bloomsbury Academic, 2008).

Wartenberg, Thomas. Big Ideas for Little Kids: Teaching Philosophy through Children's Literature. (Lanham: R\&L Education, 2009).

Wartenberg, Thomas. "Teaching Children Philosophy: Book Modules." Teaching Children Philosophy. n.d. https://www.teachingchildrenphilosophy.org/BookModule.

Weber, Barbara. "Childhood, Philosophy and Play: Friedrich Schiller and the Interface between Reason, Passion and Sensation." Journal of Philosophy of Education 45: 2 (2011), 235-250.

Weber, Barbara. "Embarking into the Future: How to Dream Our Visions into Reality." In Narrative, Dreams, Imagination: Israeli and German Youth Imagine Their Futures, edited by Karlfriedrich Herb, Jen Glaser, Barbara Weber, Eva Marsal, and Takara Dobashi (Zürich; Münster: LIT Verlag, 2013), 15-33.

Wenar, Leif. Blood Oil: Tyrants, Violence, and the Rules That Run the World. (Oxford: Oxford University Press, 2015).

Wilson, Japhy. "Neoliberal Gothic." In The Handbook of Neoliberalism, edited by Simon Springer, Kean Birch, and Julie MacLeavy. (New York: Routledge, 2016), 592 603. 